University of Louisville ThinkIR: The University of Louisville's Institutional Repository

Electronic Theses and Dissertations

$5-2019$

\title{
Innovate within product lines or outside of them? An ethnographic study of corporate innovation in a corporate venture makerspace.
}

Cole Joseph Crider

University of Louisville

Follow this and additional works at: https://ir.library.louisville.edu/etd

Part of the Entrepreneurial and Small Business Operations Commons

\section{Recommended Citation}

Crider, Cole Joseph, "Innovate within product lines or outside of them? An ethnographic study of corporate innovation in a corporate venture makerspace." (2019). Electronic Theses and Dissertations. Paper 3214.

https://doi.org/10.18297/etd/3214

This Doctoral Dissertation is brought to you for free and open access by ThinkIR: The University of Louisville's Institutional Repository. It has been accepted for inclusion in Electronic Theses and Dissertations by an authorized administrator of ThinkIR: The University of Louisville's Institutional Repository. This title appears here courtesy of the author, who has retained all other copyrights. For more information, please contact

thinkir@louisville.edu. 
INNOVATE WITHIN PRODUCT LINES OR OUTSIDE OF THEM? AN ETHNOGRAPHIC STUDY OF CORPORATE INNOVATION IN A CORPORATE VENTURE MAKERSPACE

\author{
By \\ Cole Joseph Crider
}

\begin{abstract}
A Dissertation
Submitted to the Faculty of the

College of Business of the University of Louisville

in Partial Fulfillment of the Requirements

for the Degree of
\end{abstract}

\author{
Doctor of Philosophy \\ in Entrepreneurship \\ Department of Entrepreneurship \\ College of Business \\ University of Louisville, \\ Louisville, Kentucky
}

May, 2019 

INNOVATE WITHIN PRODUCT LINES OR OUTSIDE OF THEM? AN ETHNOGRAPHIC STUDY OF CORPORATE INNOVATION IN A CORPORATE VENTURE MAKERSPACE

By
Cole Joseph Crider

A Dissertation Approved on

April 9 ${ }^{\text {th }}, 2019$

by the following Dissertation Committee:

Dr. Ryan W. Quinn

Dr. Kristen Lucas

Dr. Robert P. Garrett

Dr. Howard Aldrich 


\section{ACKNOWLEDGEMENTS}

Throughout my Ph.D., I received support and encouragement from many. Although only a few are mentioned here by name, I am sincerely grateful for each. I would like to thank Dr. Ryan Quinn, my chair. I learned more from you than I can possibly articulate. Thank you for your patience, encouragement, time, and willingness to see me through this process. Dr. Kristen Lucas, thank you for introducing me to and instructing me in qualitative research, giving me the opportunity to engage in research as an MBA student, and for encouraging me in so many ways. Dr. Robert Garrett, thank you for always being available to answer questions, provide advice, and reassure. And Dr. Howard Aldrich, thank you for your encouragement to conduct a dissertation on this topic, invaluable insights, and for exposing me to institutional theory.

I am grateful to Dr. Jim Fiet who has invested so much in me and in the doctoral program. I would also like to thank the School of Graduate and Interdisciplinary Studies, the College of Business, and the Forcht Center for Entrepreneurship. To all the staff and faculty who have made this journey achievable, thank you!

This dissertation would not have been possible without the cooperation, kindness, and time of all those at MakerHub. I would like to thank the management team for allowing me to conduct my dissertation there in the first place. Also, I would like to thank those who were always willing to answer questions, offer information, and provide context around actions and behaviors, particularly Bob, Ray, and Jean. 
This Ph.D. would not have happened without the encouragement of my family, particularly my mom and dad as well as the support of my in-laws, Tim and Judy Grogan. Lastly, I am grateful for the love of my wife, Claire, and our children, Jack and Ann. 


\begin{abstract}
INNOVATE WITHIN PRODUCT LINES OR OUTSIDE OF THEM?

AN ETHNOGRAPHIC STUDY OF CORPORATE INNOVATION IN A CORPORATE

VENTURE MAKERSPACE

Cole Joseph Crider

April 9 ${ }^{\text {th }}, 2019$

Organizational forms that firms use for innovating include traditional R\&D
\end{abstract} departments, corporate venturing, and open innovation. This dissertation examines a new form for corporate innovation-the corporate venture makerspace. Makerspaces are "shared production facilities," and scholars suggest they are environments in which to create; yet few firms have adopted them as a means to innovate.

This dissertation is an ethnographic study in which I examine why a large corporation with active $\mathrm{R} \& \mathrm{D}$ centers and limited resources also has a corporate venture makerspace as a secondary innovation mechanism when both organizations serve the same overarching function: explorative learning activities intended to generate innovative products that will increase the parent company's profitability. Specifically, I ask in what ways does this organization implement its institutional logics into its organizational design, and what benefits or drawbacks, if any, result from its design.

The reason why the organization ended up with a traditional R\&D department and a corporate venture makerspace is because the makerspace was supposed to be a means to achieve more breakthrough innovations, but a historical process unfolded when product 
successes required increased capabilities and resource spreading, generating increased pressures to adopt a different logic. Further, when products underperformed, additional logics, further increasing similarity, were incorporated to avoid future failure.

The study contributes to the discussion of new product development within a corporate venture, demonstrating both intentional and unintentional ways innovation is enabled and constrained. The results suggest important practical implications for corporate venture managers, particularly ways in which initial innovation goals can be replaced when products succeed or fail. 


\section{TABLE OF CONTENTS}

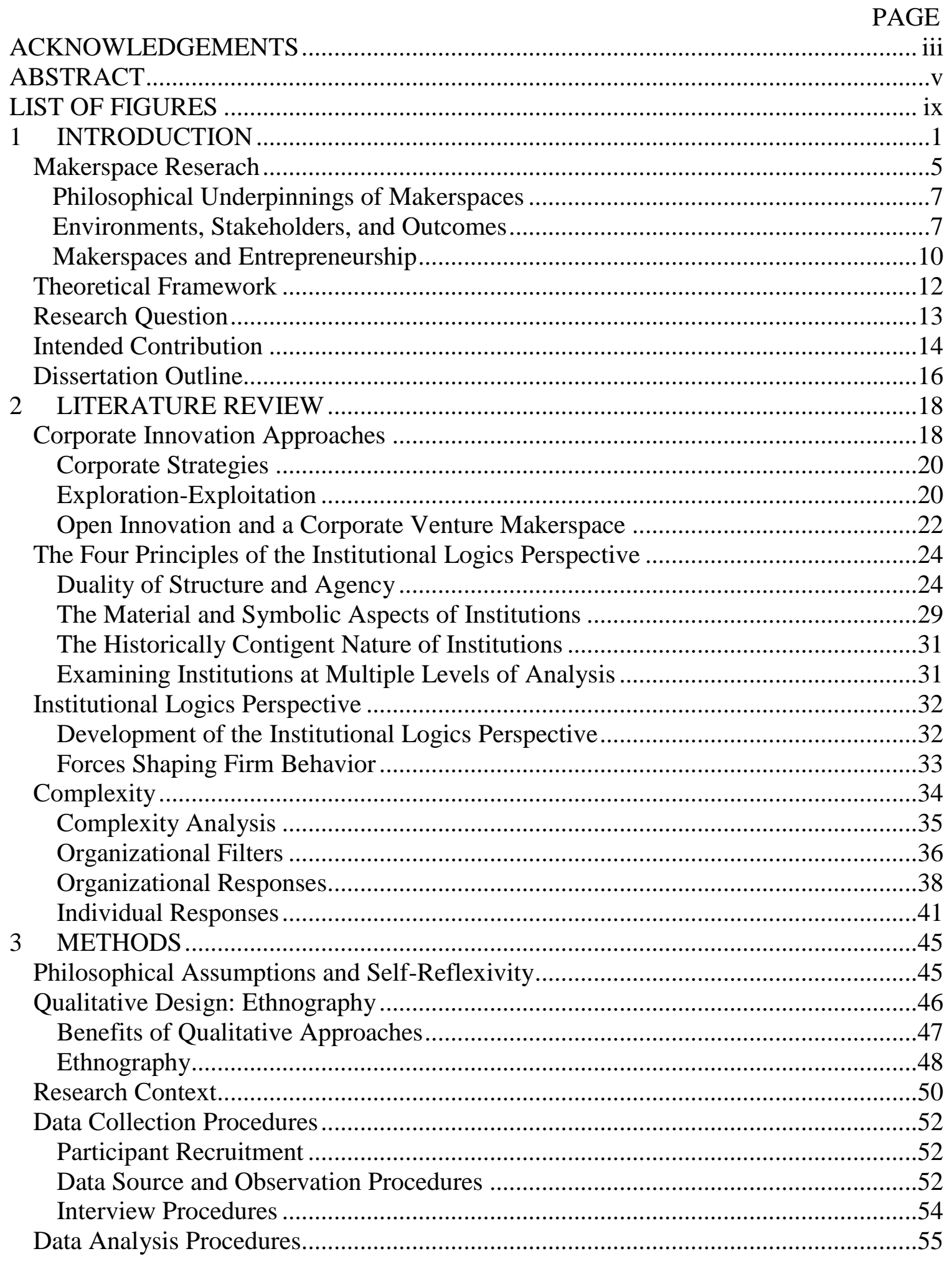




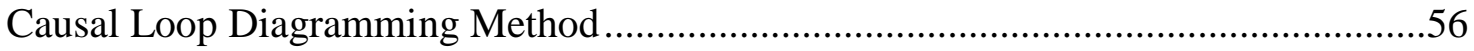

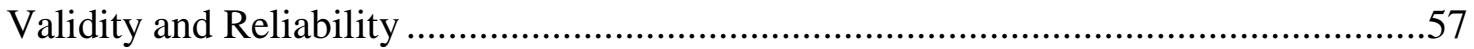

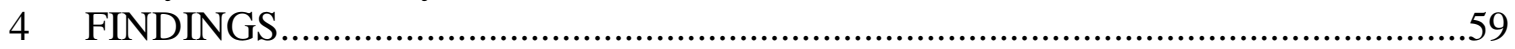

Two Product Development Organizations ..............................................................59

Phase 1: Environmental Forces and MakerHub's Founding .......................................64

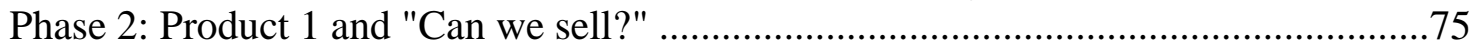

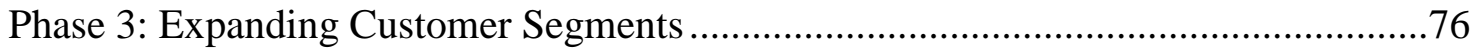

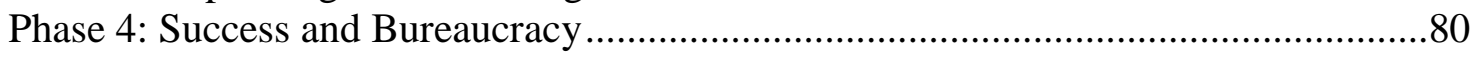

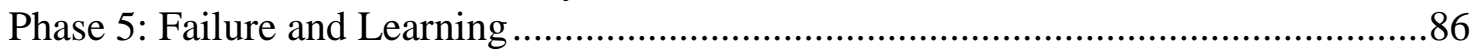

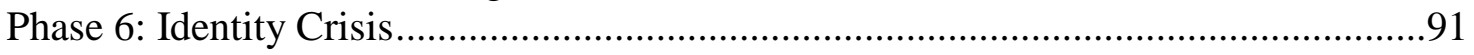

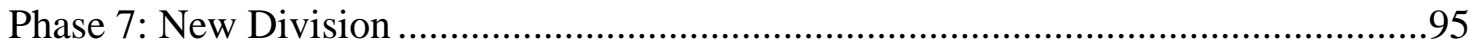

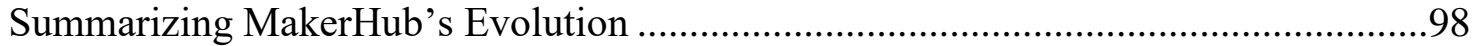

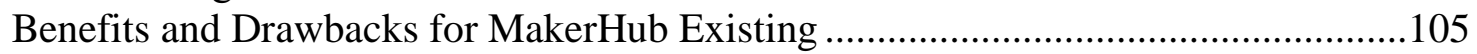

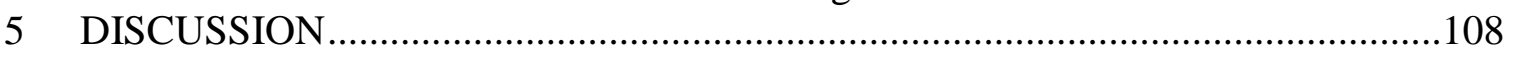

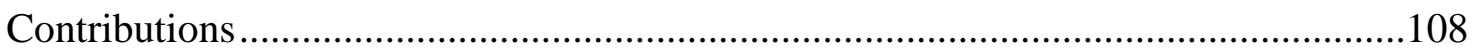

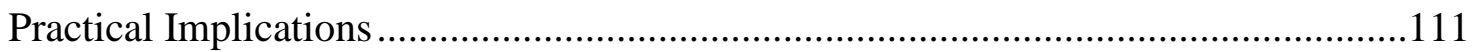

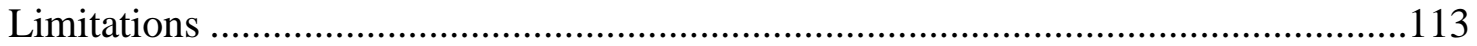

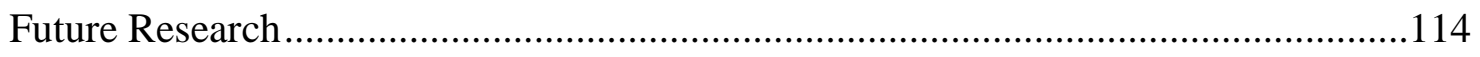

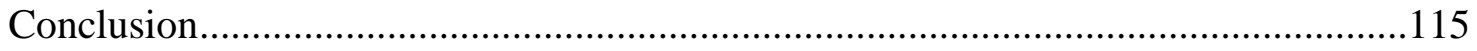

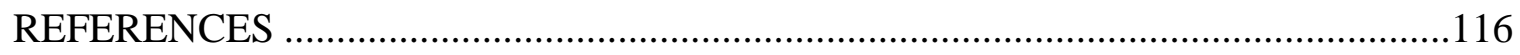

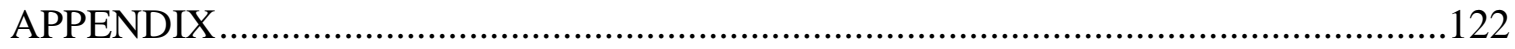

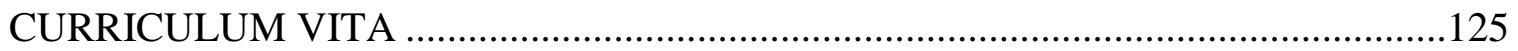




\section{LIST OF FIGURES}

Figure 1: The Build-and-Validate Reinforcing Loop (R1) .........................................72

Figure 2: Expanding its Target Market Reinforcing Loop (R2) ....................................75

Figure 3: Delivery Problems and Bureaucracy ............................................................ 79

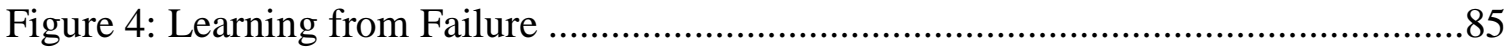

Figure 5: Exogenous Shock and Stakeholder Closeness ............................................93 


\section{INTRODUCTION}

During the latter half of the 20th century, many U.S. manufacturing firms experienced newfound pressure from globalization, particularly in consumer products such as electronics, clothing, and appliances. Asian manufacturers were able to dramatically reduce the timeline from idea to product, forcing U.S. firms to rethink manufacturing practices. Whereas U.S. corporations can stifle innovative ideas, sometimes for years, South Korean companies like Samsung and LG whittle years into months, enabling quick idea-product cycles. U.S. behemoths respond differently. Some stay their course, lose market share, and fade into irrelevancy. Others innovate by investing in R\&D centers, buying agile start-ups, or outsourcing innovation through licensing.

Past research emphasizes the importance of innovation (Damanpour \& Wischnevsky, 2006, p. 2) and, more specifically, new product development (NPD) for firm performance (Karakaya \& Kobu, 1994; Robinson, 1990). Corporate innovation is "the development and use of new ideas or behaviors in organizations. A new idea could be a new product, service or method of production (technical innovation) or a new market, organizational structure or administrative system (administrative or organizational innovation)" (Damanpour \& Wischnevsky, 2006, p. 271). As a key component of corporate innovation, scholars contend, "product development is among the essential processes for success, survival, and renewal of organizations, particularly for firms in either fast-paced or competitive markets" (S. L. Brown \& Eisenhardt, 1995, p. 344). 
Central to NPD is effective learning - what is learned, how it is learned, and how the knowledge learned is utilized (Kiss \& Barr, 2017); companies construct processes and routines to manage the acquisition and dissemination of learned knowledge (Kiss \& Barr, 2017). For firms that need to innovate quickly, effective learning is especially critical. In their research, Kiss and Barr (2017) demonstrate that within turbulent industries, faster NPD implementation strategies were associated with higher firm performance; firms in less turbulent industries benefited from slower NPD strategy implementation speed.

In an attempt to become more innovative, one U.S. manufacturing giant, crafted an unorthodox, entrepreneurial approach to innovation, NPD, and knowledge acquisitionfounding a corporate venture makerspace. The term "makerspace" can refer to everything from a single 3D printer in a repurposed food truck driving around to different city high schools to Microsoft's The Garage, a space with 3D printers, CNC machines, soldering irons, and Arduino boards. Makerspaces are the most recent iteration of the Do-It-Yourself (DIY) culture (Anderson, 2012) generated by greater availability and access to advanced technologies. Barrett and colleagues note, "As the price of the technology associated with 'making,' such as the cost of 3D printers, declined (Canessa, Fonda, Zennaro, \& Deadline, 2013), it allowed for greater development of maker spaces, and the spaces began to spread into more locations" (Barrett et al., 2015, p. 2). Although the DIY movement may engender thoughts of improving existing products, "makers" include a much broader array of activities: "The term 'maker' is a more inclusive concept, referring not only to people who alter the work of others but also those who produce original work, conceptualizing and executing a project of their own design" (Aldrich, 2014, p. 2). For the purposes of this paper, Anderson's (2012, p. 18) broad definition of makerspaces - "shared production 
facilities"-is adopted. A corporate venture makerspace exists when a firm creates a makerspace as a distinct new venture subsidiary.

I will call this U.S. manufacturing company, "Products Inc.” Products Inc. employs more than 10,000 people, generating over $\$ 5$ billion of annual revenue. Although the company operates multiple $R \& D$ centers, executive leadership created a corporate venture makerspace, which I give the pseudonym MakerHub. MakerHub's founding purpose was to shorten the idea-product cycle by acting as a consumer-facing entity designed to enable a quicker feedback loop between engineers and consumers. Moreover, founding leadership envisioned new products being generated through community involvement-in other words, creating an open makerspace design where anyone might walk in and work on their own projects or co-create on a MakerHub product. Hence, MakerHub's mission was to design, prototype, and sell innovative products by co-creating with the community.

Makerspaces are environments in which to learn and create (Litts, 2015). However, as a corporate venture makerspace—Product Inc.'s creative attempt to increase its agility and decrease time from idea to product-MakerHub's combination of corporate venture and makerspace faces singular challenges. First, at the time of MakerHub's founding, Products Inc. was a public company. Thus, for Products Inc. to fulfill its fiduciary responsibility to shareholders, it must adequately justify founding a subsidiary whose primary function is to create and prototype innovative products, products which may or may not ever be profitable or even sold. Like many corporate ventures, MakerHub is tasked with being innovative, yet creativity is inherently messy and inefficient (O'Reilly \& Tushman, 2013), opening the door for shareholders to exert pressure on both Products Inc. and MakerHub to convert MakerHub into something more immediately profitable than a 
creative space for tinkering and uninhibited creativity. Thus, MakerHub is faced with the daunting challenge of justifying its existence to both parent and shareholders while still fulfilling its mission of community innovation.

MakerHub's best strategy for surmounting this task of justifying its existence is through producing sellable products, thereby alleviating pressure from Products Inc.'s shareholders. In addition to producing sellable products, MakerHub also justifies its existence by using its community as a test group for Products Inc., helping determine which products may be more likely to succeed, subsequently reducing Products Inc.'s overall risk of launching an innovative product that later fails. And indeed, one of MakerHub's stated goals is generating over ten new functional products every year to be sold either through Products Inc.'s commercial channels or through MakerHub's own go-to-market strategies.

In addition to the challenge of justifying its existence, MakerHub faces a related challenge - its combination of three stakeholders: stakeholders associated with Products Inc. (the parent company), stakeholders associated with MakerHub products (the venture), and stakeholders associated with MakerHub's makerspace community (the makerspace). Research suggests makerspaces are environments where learning and creativity flourish (Litts, 2015) - thereby satisfying makerspace stakeholders. However, little research examines makerspaces as an effective means of innovating or increasing shareholder value. How corporate venture makerspaces are able to meet the needs of venture stakeholders (i.e. identify and develop novel products and capture market share), corporate parent stakeholders (i.e. generate profit and innovation), and community stakeholders (i.e. space to learn and create) is yet unknown. 
A third challenge for MakerHub's leadership is how best to allocate firm resources and employees' time to satisfy each set of stakeholders. As both their consumer community and "maker" community grow, MakerHub is torn between competing demands, each with resource requirements. Employees are challenged with deciding which stakeholder groups to prioritize to. Further complications may arise from split loyalties among MakerHub's employees. Although many came from Products Inc., several were hired outside of the parent company. Consequently, employees' past experiences and backgrounds could influence how they interact with each stakeholder community.

MakerHub is unique as I could find no other firms founded as a corporate venture makerspace and used as a means for new product development. Given the importance of firms continuously innovating, MakerHub offers an interesting context in which to understand how MakerHub differentiates itself from Products Inc.'s own R\&D Centers, and consequently, what benefits, if any, MakerHub generates for Products Inc. One aspect of MakerHub's intended uniqueness is its makerspace.

\section{Makerspace Research}

As noted above, makerspaces are the most recent iteration of the Do-It-Yourself (DIY) culture (Anderson, 2012), arising from heightened access to more advanced technologies. Makerspace definitions differ, with primary variation around how inclusive the term is. For instance, whereas some argue for a focus on engagement with physical artifacts, others state "makerspaces" encompass hackerspaces, fab labs, and co-working spaces (Colegrove, 2013). Although "hacking" may conjure notions of illegal activity, hackerspaces harken back to the label's initial meaning - the idea of taking something apart, understanding how it works, and improving on it. Fab labs-short for fabrication 
laboratories - were popularized by the MIT media labs and are environments in which physical artifacts can be quickly prototyped using machines such as laser cutters and 3D printers. Co-working spaces are utilized as places for professionals to work and for entrepreneurs serious about moving their hobby to an actual business (Colegrove, 2013; van Holm, 2014): "Coworking space is seen as an extension for individuals in hackerspaces that desire to move from a hobbyist to professional production of an item" (van Holm, 2014, p. 6). Of hackerspaces, fab labs, and co-working spaces, Colegrove (2013) notes, "the common thread running through each is a focus on making rather than merely consuming" (p. 3).

Makerspaces are generating substantial interest and attention. The White House hosted its first Maker Faire in 2014. The International Symposium on Academic Makerspaces held its first meeting at MIT in 2016. And many books are being published on makerspaces, emphasizing makerspaces as culturally transformative (Anderson, 2012; Hatch, 2013), makerspaces as learning environments (Peppler, Halverson, \& Kafai, 2016ab), and makerspace how-to books on building and running makerspaces in schools (Fleming, 2015; Provenzano, 2016). Much of the scholarly makerspace research similarly emphasizes learning and community within a number of environments, including libraries (Bowler, 2014), museums (Cavalcanti, 2013), K-12 schools (Oliver, 2016), and universities (Barrett et al., 2015). However, scholarly research is still relatively scant. Even among scholarly outlets, many articles heavily rely on popular press books for key insights (e.g., Hatch, 2013). Burgeoning research, however, helpfully articulates the philosophical underpinnings of makerspaces, including who interested stakeholders are and the 
subsequent outcomes of makerspaces caused by the combination of environments, stakeholders, and participants.

In the following articulation of makerspaces, I first discuss the philosophical underpinnings behind makerspaces, which, in addition to the popular press books, have driven much excitement among education professionals as a possible means of increasing learning outcomes and among community leaders as a means of improving science, technology, engineering, and math (STEM) fluency in informal learning environments. Second, I attempt to create a coherent framework of past research, emphasizing how the combination of environments, stakeholders, and participants create unique outcomes.

\section{Philosophical Underpinnings of Makerspaces}

For the past half century, government funds directed toward education-K-12 and higher education - escalated, yet educational results remain underwhelming (Hanushek, 1996). Although disagreement exists over effectiveness of total spending (Hedges \& Greenwald, 1996), administrators, educators, and voters agree monies should be spent intentionally toward programs with measurable outcomes (Lips, Watkins, \& Fleming, 2008). Scholars began questioning teaching effectiveness and classroom outcomes, and during the 1980s, scholars argued for alternative learning approaches. Learning theories such as experiential learning theory (Kolb, 2014) and constructionism (Harel \& Papert, 1991) helped popularize interactive forms of teaching and learning. Rather than the widespread lecture-style model of teacher imparting information to passive students, experiential learning promotes student action — a model where students learn through trial and error, creativity, and acquiring information as they need it. This form of learning has 
garnered positive results from both students and educators, generating increased interest in other forms of active student learning (Ito \& Howe, 2016).

\section{Environments, Stakeholders, and Outcomes}

In many ways, the maker movement is antithetical to the structured, routine memorization of current K-12 curriculum, seeking instead to enable learners to engage with both technology and material, allowing the resources at hand to dictate what artifacts emerge. This process-centric approach emphasizes the individual rather than a specific learning outcome, causing a learner to "create their own goals and constraints and these evolve as their understanding and materials develop, and because the learners' activities are based on their own goals and interests, they are more committed to their activity and find it to be fun and playful (Petrich, Wilkinson, \& Bevan, 2013)" (Lacy, 2016, p. 16). Individuals within makerspaces can thus design and create according to their own interests. Consequently, informal learning environments such as museums (Cavalcanti, 2013) and libraries (Bowler, 2014) have blossomed. Notable examples of museums with makerspaces include the Exploratorium in San Francisco, New York Hall of Science, and the Children's Museum in Pittsburgh. Further, one study found 17\% of 162 public libraries sampled host maker events (Bertot, Real, Lee, McDermott, \& Jaeger, 2015).

Government stakeholders at both local and national levels are keenly interested in the long-term outcomes makerspaces may generate among children. One scholar notes many hope heightened interaction with makerspaces will lead to increased interest in STEM fields (Colegrove, 2013). For instance, one study examined how students' familial backgrounds and past experiences with technology inform their activities within a makerspace (D. G. Davis, 2017). Another study examined what middle school students 
from low socio-economic backgrounds created when charged with creating something targeting social issues (Lahana, 2016).

Although less abundant, research has also examined makerspaces within schools (Cross, 2017; DeRosa, 2016; Lacy, 2016). Makerspaces within schools face a number of challenges, including resistance from colleagues unfamiliar with makerspace outcomes: "Educators outside of the Makerspace have the most trouble understanding the underlying purpose and pedagogy that supports the Makerspace" (Cross, 2017, p. 139) and trouble engaging both minority and female students (Lacy, 2016; Lahana, 2016). However, DeRosa's (2016) study demonstrates makerspaces can be useful in formal learning environments. Students' creativity confidence increased and all other learning outcomes met or succeeded "traditional objectives, except for expository writing" (DeRosa, 2016, p. 149).

Universities are a second formal environment in which makerspaces are becoming more prevalent in both the United States (Barrett et al., 2015) and Great Britain (Curry, 2017), particularly within engineering schools. In a recent paper, Barrett and colleagues (2015) articulate how makerspaces potentially solve a growing problem within engineering schools. They bemoan many engineers leave universities possessing little experience working with tangible materials as much of their coursework is digitized (Barrett et al., 2015). However, makerspaces enable hands-on learning, improving job readiness. In emphasizing the importance of makerspaces, Barrett et al. $(2015$, p. 3$)$ write that connecting theory and practice through physical interaction with materials improves learning effectiveness: "Physical modeling and prototyping have been shown to increase the effectiveness and quality of the final design, and both play a key role in the development 
of students by linking the material covered in the classroom to the real world." Schools are realizing the benefits of makerspaces. Over 35 of the top 125 U.S. universities have makerspaces already (Barrett et al., 2015) further supporting the idea that makerspaces generate useful outcomes for adults as well as children.

Past research demonstrates ways in which makerspaces enable learning (Barrett et al., 2015; DeRosa, 2016; Lacy, 2016) and creativity (Petrich et al., 2013), while also recognizing potential constraints (Lacy, 2016; Lahana, 2016), such as stakeholder resistance (Cross, 2017). Learning and creativity are integral to innovation (Sawyer, 2011), and the next section discusses how several corporations attempt to foster innovation by incorporating makerspaces into their firms. I also consider makerspaces as a unique environment in which to respond to past calls for research that investigate opportunity development as it unfolds.

\section{Makerspaces and Entrepreneurship}

Although makerspaces are received with much enthusiasm in learning motivated contexts, corporations have been slow to use makerspaces given their inherent inefficiencies. ${ }^{1}$ As socially-oriented, creative learning environments, makerspaces are by nature inefficient, decreasing inherent attractiveness for cost-focused corporations. In his book, The Innovator's Dilemma, Christensen contends large, successful corporations feel pressure to develop low risk products in order to maintain their current success; whereas, start-ups have little to lose, resulting in higher risk, innovative products. Because of the unattractiveness of makerspaces to many corporate giants, few corporate makerspaces

\footnotetext{
${ }^{1}$ There are several exceptions; tech firms such as Google, Microsoft, Autodesk, and Northrop Grumman have developed internal makerspaces in efforts to keep employees engaged and creative.
} 
exist; therefore, perhaps unsurprisingly, little empirical research examines corporate makerspaces.

On the other hand, entrepreneurship scholars have made recent calls for makerspace research suggesting they may be environments brimming with interesting insights given their emphasis on creativity and prototyping (Browder, Aldrich, \& Bradley, 2019). Their enthusiasm surrounds studying pre-firm activities during the idea-to-product process; generally, entrepreneurs navigating the pre-firm activities are difficult to find and subsequently difficult to study (Browder et al., 2019; Yang \& Aldrich, 2017). Past research examines the entrepreneurial process through several lenses, including cognition (R. K. Mitchell et al., 2002; Shepherd \& DeTienne, 2005) and informational economics (Fiet, 1996, 2007); however, how new venture ideas are fostered and developed is a confounding problem as most empirical studies rely on entrepreneurs' memories of past events.

A critical part of the entrepreneurial process is how opportunities are developed. Although entrepreneurship scholars disagree over the ontological nature of business opportunities (i.e. discovered, created, or imagined), scholars agree on the importance of studying the entrepreneurial process - the antecedents of opportunities, the process itself, and the sociological factors in which those occur (Davidsson, 2016). Opportunity development is the "process of shaping, discussion, and interpretation, whereby initial ideas are elaborated, refined, changed, or even discarded...this term represents both a dynamic, iterative, and a socially embedded view of how entrepreneurial opportunities reach their final form" (Dimov, 2007, p. 714). Dimov (2007) articulates the importance of examining opportunity development in light of time, environment, and competing forces:

In order to systematically and rigorously study opportunity development, one needs to (1) capture its ephemeral beginning and fragile sustenance in order to avoid 
survival bias, (2) reconcile the positivist and constructivist accounts of the nature of opportunities, and (3) incorporate the involvement of stakeholders beyond the individual entrepreneur (Davidsson, 2003; Dutta \& Crossan, 2005; Gartner, Carter, \& Hills, 2003). (Dimov, 2007, p. 714)

This study is not of a pre-firm entrepreneur engaging in pre-firm activities; rather, it is of an entrepreneurial firm engaging in new product innovation - a related activity.

MakerHub's existence suggests the inefficiencies of a makerspace can be effectively managed with the demands of corporate shareholders. Thus, partly motivating the present study is the contention that MakerHub is a viable context in which to study new product innovations as they come to life while also incorporating a rich understanding of MakerHub's three stakeholders: stakeholders associated with Products Inc., stakeholders associated with MakerHub as a start-up, and stakeholders associated with MakerHub as a makerspace. Each stakeholder group both enables and constrains how innovation occurs and manifests. Broadly, the study's purpose is to understand how MakerHub differentiates itself from Products Inc.'s R\&D Centers and how competing pressures impact its NPD processes.

\section{Theoretical Framework}

Products Inc.'s launching of a corporate venture makerspace is unusual, not only because most corporations appear to find the project unfeasible, but because Products Inc. is a giant, and giants think and act like other giants. When an organization participates in a single institutional logic or combines logics with complementary elements, it tends to look like other organizations because organizations mimic practices that are perceived to be legitimate (DiMaggio \& Powell, 1983). However, if an organization draws on multiple logics with competing prescriptions, the form that organization takes becomes more complex. 
The institutional logics perspective is a meta-theory derived from and critical of neo-institutional theory. Broadly, neo-institutional theory argues firms tend to act and think like other firms they perceive as more successful or legitimate, imitating both structure and practices (DiMaggio \& Powell, 1983). Friedland and Alford (1991), fathers of the institutional logics perspective, contested that neo-institutionalism discounted individual and firm agency, arguing firms and the individuals within enact change-firms within corporations and industries, and individuals within firms. To explain this enation and evolution, Friedland and Alford (1991) articulated how structure and agency interact, both impacting and being impacted by the other. Environmental factors shape firms' and actors' decisions (Martin, Currie, Weaver, Finn, \& McDonald, 2017; Zhao \& Lounsbury, 2016). Actors and firms shape environments (Delbridge \& Edwards, 2013; Thornton, Ocasio, \& Lounsbury, 2012). Thornton and Ocasio (1999) define institutional logics as

Socially constructed, historical patterns of material practices, assumptions, values, beliefs, and rules by which individuals produce and reproduce their material subsistence, organize time and space, and provide meaning to their social reality (p.804).

Understanding how Products Inc. and MakerHub interact with the environment, with each other, and with stakeholders to generate innovative products is a difficult task because each is embedded in layers of historical patterns, which influence each entity's self-perception, their perception of each other, and their perception of stakeholders' needs. The institutional logics perspective is battle tested (Lounsbury \& Beckman, 2015; Thornton, Ocasio, Greenwood, Oliver, \& Suddaby, 2008; Thornton et al., 2012), generating much enlightening research. The present research seeks to add to past literature by studying MakerHub - a unique organizational that, on the surface, appears to challenge traditional assumptions about how corporations can innovate. The grand challenge of 
explaining how and why organizations behave the way they do is at the heart of the institutional logics' perspective. Through examining the existing contradiction that is MakerHub, this dissertation seeks to further understand how MakerHub innovates in a way that differentiates itself from Products Inc.'s R\&D Centers by attending to the sets of logics driving both. Therefore, I explore the following two-part research question: In what ways does MakerHub implement its institutional logics into its organizational design? And what benefits, if any, is derived from its design?

\section{Intended Contribution}

This study contributes to institutional logics, entrepreneurship, and makerspace literatures in several ways. First, by observing how one corporate giant diverges from industry norms and pressures, fostering an agile start-up in the form of a corporate venture makerspace, I respond to recent calls for a bottom-up, micro-level perspective of how individuals and firms respond to competing institutional logics at multiple levels of analysis (Greenwood, Raynard, Kodeih, Micelotta, \& Lounsbury, 2011). More specifically, I contribute to the logics literature by articulating how individuals experience and enact the competing institutional logics inherent within their organization as they navigate through the NPD process.

Although a few studies examine the micro-processes demonstrating firms' and individuals' responses to competing logics (Smets, Morris, \& Greenwood, 2012), little is known about how individuals respond within new ventures. New ventures can experience rapid change as products succeed or fail, are adapted to consumer feedback, market forces, or environmental factors. This study provides additional data to the broader conversation 
of how corporate ventures intentionally and unintentionally navigate competing pressures fostered by product outcomes and diverse stakeholders.

MakerHub's story contributes to our understanding (of the phenomenon) by demonstrating how success, necessity, failure, and an exogenous shock may interact to produce a new ordering of logics that differs from that at founding and more similar to what is familiar (e.g. Products Inc.'s R\&D Centers). In this study, four logics are apparent within MakerHub and their competing prescriptions are demonstrated through the negotiations between and actions by employees and management. As MakerHub evolved, developed capabilities, and increased its bureaucracy, competing prescriptions generated a reordering of logics. However, all four logics remained as MakerHub continued to satisfy each of its distinct stakeholder groups.

Second, by studying a corporate venture makerspace intended for creating and fast prototyping products, I contribute to the entrepreneurship literature on factors impacting innovation and NPD, thereby responding to scholars' recent assertion that more ethnography research is needed in new venture processes. In the fall of 2017, entrepreneurship scholars assembled at Princeton University to discuss the need for research of nascent ventures. When I began observing in 2017, MakerHub was a four-yearold enterprise and fit the "nascent venture" label. Moreover, as part of the innovation arm to a major appliance manufacturer, MakerHub is constantly developing new productsspecifically home appliances_-generating new processes, and exploring new go-to-market strategies, enabling me to observe each of these in real-time. This study provides additional data to the conversation regarding what types of innovations corporate venture makerspaces actually generate and the impact open innovation has on their NPD processes. 
Moreover, this study assists in fulfilling the need for more entrepreneurship ethnography by examining how stakeholders' actions manifest themselves in both constraining and enabling ways in product ideation and realization processes.

Third, past makerspace literature demonstrates the importance of intention on makerspace outcomes, whether that be access to a makerspace for children and the subsequent learning outcomes (Bowler, 2014; Cavalcanti, 2013; Litts, 2015) or the importance of interacting with tangible machines, tools, and materials for engineering students and subsequent job readiness (Barrett et al., 2015). Moreover, recent scholarship suggests corporate makerspaces may be a means of corporate innovation and entrepreneurship (Browder et al., 2019). By watching making occur in a corporate venture, I contribute to these relationships by discovering specific ways in which the makerspace enables innovation, particularly through "hacking" existing products and providing an environment conducive to developing new product ideas. Although this study's makerspace is on the edges of a large university's campus in the southern U.S., MakerHub is neither owned nor operated by the university. To my knowledge, this is the first empirical study of a wholly-owned subsidiary, corporate venture makerspace. Thus, this study contributes to current makerspace literature by also examining a new makerspace environment, subsequently creating a different mix of stakeholders engaged in MakerHub's outcomes.

\section{Dissertation Outline}

This dissertation is divided into five chapters and appendices. In the present chapter (chapter 1), I tell the tale of MakerHub, relating the environmental factors which shaped its founding and the uniqueness of Products Inc.'s strategy in diverging from industry 
norms in spawning MakerHub. Moreover, by highlighting current makerspace literature, I illustrate MakerHub's distinctiveness as a rare combination of organizational types-a corporate venture makerspace. I also articulate the fitness of institutional logics as my theoretical lens through which I analyze MakerHub, its relationship with Products Inc., and each of their stakeholders. Further, I feature several of my study's intended contributions.

In chapter two, I discuss corporate venturing strategies to demonstrate the singularity of MakerHub as a means of corporate innovation. Moreover, I relate relevant institutional logics literature, attending specifically to how organizations and individuals make sense of and respond to complexity. In chapter three, I discuss my research method, data collection, and justifications for it, including past calls by both entrepreneurship and institutional logics scholars. Additionally, I express positionality.

In chapter four, I highlight the study's findings, relating how MakerHub evolved from its unique founding to functioning similarly to Products Inc.'s R\&D Centers as it launched products (successful and unsuccessful), developed processes and practices, and encountered unexpected challenges. Moreover, I examine the benefits and drawbacks MakerHub offers to Products Inc. And in chapter five, I articulate the study's contributions, practical implications, areas for future research, and limitations. 


\section{LITERATURE REVIEW}

In this chapter, I discuss innovation and how institutional logics is a useful lens by which to study innovation. I begin in the first section by defining innovation and then highlighting past corporate innovation strategies. I attempt to demonstrate the various innovation problems firms experience, attending to innovation adoption versus generation, balancing exploitation and exploration, and open versus closed innovation strategies. Corporations navigate these tensions both intentionally and unintentionally, subsequently impacting innovation outcomes.

In the second section, I introduce the institutional logics perspective, highlighting the four principles outlined by Thornton and colleagues (2012). Following Thornton et al. (2012), I ground this discussion in seminal institution theory papers. In the third section, I describe the evolution of the institutional logics perspective from Friedland and Alford's (1991) influential chapter to more recent scholarship and further justify its use as the guiding lens behind this study. In the fourth section, I discuss institutional complexity, which has emerged as a major theme within the institutional logics perspective and functions as the phenomenological centerpiece of my dissertation.

\section{Corporate innovation approaches}

Of the 500 companies on Fortune Magazine's maiden publication in 1955, only $12 \%$ remain on the list. Once strongly held beliefs that innovation firmly resides in the test bed of large companies has been put to rest. Firms must innovate. Scholars warn, "Organizations operating under the present conditions of global competition, rapid technological advances, and resource scarcity must innovate in order to grow, to be 
effective, and even to survive. Thus, fostering innovation remains a major challenge for business executives" (Damanpour \& Wischnevsky, 2006, p. 270).

Innovation is an ambiguous term applied in many contexts in diverse ways. As defined earlier, corporate innovation is "the development and use of new ideas or behaviors in organizations. A new idea could be a new product, service or method of production (technical innovation) or a new market, organizational structure or administrative system (administrative or organizational innovation)" (Damanpour \& Wischnevsky, 2006, p. 271). How organizations approach the necessity of innovating differs, and some firms are better suited to acquire innovation rather than develop it internally.

Damanpour and Wischnevsky's (2006) typology of corporate innovation is a useful framework. Their typology is a two-by-two matrix, examining high and low levels of a firm's innovation adoption and innovation generation (Damanpour \& Wischnevsky, 2006). A firm high in both adoption and generation is labeled an "Innovative Organization." A firm high in innovation adoption but low in innovation generation is labeled an "Innovation-adopting Organization." A firm low in innovation adoption but high in innovation generation is labeled an "Innovation-generating Organization." And a firm low in both categories is labeled "Non-innovative Organization" (p. 271).

A further point important to delineate is the relationship between the level of innovation and what type of firm is likely to foster it. For example, in comparing innovation within large firms with entrepreneurial firms, Damanpour and Wischnevsky (2006) theorize whereas entrepreneurial firms or corporate ventures will more likely generate radical innovation, large corporations who will tend to foster incremental innovation (Damanpour \& Wischnevsky, 2006). 


\section{Corporate Strategies}

Whereas corporate innovation is the artifact itself-the innovative product or process - corporate strategy is the specific mechanism by which that artifact comes about. Specifically, corporate strategy "refers to types of corporate innovation that represent different strategic opportunities for firms" (Hoskisson, Hitt, Johnson, \& Grossman, 2002, p. 697). Corporate strategies include internal activities such as R\&D spending, and new

product development; and external activities include "acquisition of businesses that provide new products, processes, or markets" (Hoskisson et al., 2002, p. 697). Many factors may form firms' corporate innovation strategies, including top management teams (Souitaris \& Maestro, 2010), competition (Porter, 1979), technology (Bettis \& Hitt, 1995), and environment (R. J. Mitchell, Shepherd, \& Sharfman, 2011).

In this section, I discuss different types of corporate innovation strategies. I first utilize March's (1991) exploitation-exploration framework to relate the tensions firms experience as they seek to both exploit current assets and explore innovative opportunities. I also highlight corporate venturing as a form of exploration. Second, I review the recent strategy of engaging consumers in the development and creation of products as a means of capturing creativity developed by the crowd. I examine observed outcomes of open innovation and contend a corporate venture makerspace may be a useful solution to the problem of corporate innovation.

\section{Exploitation-Exploration}

In his fundamental work, March (1991) stated firms must balance between exploration and exploitation. Whereas exploitation concerns bettering a firm's current processes through efficiency and execution, exploration focuses on “...things captured by 
terms such as search, variation, risk taking, experimentation, play, flexibility, discovery, innovation" (March, 1991, p. 71). March contends that firms must do both in order to ensure current and future success (March, 1991; Tushman \& O'Reilly III, 1996). The question is how to manage both forms of firm actions as each require firm resources:

As a result, organizations make explicit and implicit choices between the two ... Processes for allocating resources between them, therefore, embody intertemporal, interinstitutional, and interpersonal comparisons, as well as risk preferences. The difficulties involved in making such comparisons lead to complications in specifying appropriate trade-offs, and in achieving them. (March, 1991, pp. 71-72)

MakerHub was intentionally founded offsite from Products Inc.'s main facility as a means of distinguishing MakerHub's explorative purpose. Moreover, although most MakerHub employees came from Products Inc., external hires were made, attempting to help foster cultural distinctions between parent and venture. An additional form of separation between Products Inc. and MakerHub is that MakerHub is a legal entity—a corporate venture.

One means of explorative learning is corporate venturing (Covin \& Miles, 2007). Covin and Miles (2007) state corporate venturing (CV) "involves entrepreneurial efforts in which established business organizations invest in and/or create new business opportunities" (p. 183). In an empirical study of 15 corporations engaged in some form of corporate venturing, Covin and Miles (2007) find misalignments can occur between firms' corporate venturing approach and their business strategies, resulting in ineffective value generating efforts (Covin \& Miles, 2007). They find,

Many firms employing CV never achieve nor sustain positive overall results through their venturing efforts. ... Moreover, dozens of high-profile technologybased companies ... have demonstrated remarkable proficiency in new product development, yet have poor track records in new business development. Thus, while $\mathrm{CV}$ may be recognized as a potentially attractive management practice, it is not a managerial panacea. (p. 183) 
$\mathrm{CVs}$ are mechanisms through which corporations like Products Inc. use to learn and innovate (Covin \& Miles, 2007). However, corporations are starting to utilize other strategies to innovate. I next turn to a strategy MakerHub was built around: open innovation.

\section{Open Innovation and a Corporate Venture Makerspace}

Open innovation is defined as "the use of purposive inflows and outflows of knowledge to accelerate internal innovation, and expand the markets for external use of innovation, respectively" (Chesbrough, 2006b, p. 1). Open innovation skyrocketed into everyday parlance in the mid-2000s. Piloting its rise was Henry Chesbrough, author of two well cited books (2003, 2006b) and several papers on the topic (Chesbrough, 2006a, 2012). Chesbrough's fundamental claim is that corporations' former means of innovatingprimarily through R\&D spending-may no longer be the best means of innovation (Chesbrough, 2012).

In contrast to open innovation, Chesbrough (2003) states closed innovation revolves around firm control: "Companies must generate their own ideas that they would then develop, manufacture, market, distribute and service themselves" (p. 36). Innovation, the theory posits, resulted from spending the most on R\&D, hiring the best people, and protecting the ideas produced through intellectual property thus garnering profits from a first mover advantage (Chesbrough, 2003). However, Chesbrough (2003) highlights several factors causing firms to rethink closed innovation, stating that among the key contributors are the increased ability for individuals to move and the availability in venture capital, enabling employees to take their ideas to potentially more enthusiastic investors if companies disparaged their inventions. 
In contrast to closed innovation, Chesbrough (2003) describes an open innovation model as one in which

firms commercialize external (as well as internal) ideas by deploying outside (as well as in-house) pathways to the market. Specifically, companies can commercialize internal ideas through channels outside of their current businesses in order to generate value for the organization. Some vehicles for accomplishing this include startup companies (which might be financed and staffed with some of the company's own personnel) and licensing agreements. In addition, ideas can be brought inside for commercialization. In other words, the boundary between a firm and its surrounding environment is more porous, enabling innovation to move easily between the two. (p. 36-37)

An adjacent part of open innovation is the idea of collaboration. Scholars extol the benefits of collaboration: "Collaboration can increase the value of creation by expanding the availability and use of relevant knowledge and other resources. Collaboration has been shown to reduce risk, speed products to market, decrease the cost of product development and process improvement and provide access to new markets and technologies" (Eisenhardt \& Schoonhoven, 1996; Fjeldstad, Snow, Miles, \& Lettl, 2012, pp. 734-735).

However, open innovation is not a silver bullet for companies. Birkinshaw, Bouquet, and Barsoux (2011) warn companies are actually much better at internally generating innovative ideas than they are at selecting, developing, or diffusing those ideas. Moreover, they certify, "online tools, open innovation communities and big collaborative forums all have their limitations. None is always right or always wrong. The best approach involves careful judgment and a deep understanding of the particular challenges a company is facing" (Birkinshaw et al., 2011, p. 8). MakerHub engages in open innovation as a means to create, build, and sell new products; however, finding and engaging with the right kind of individuals - those who have both the technical expertise and the industry wherewithal to suggest a viable product— can be challenging as sorting through large quantities of wellmeaning but poorly thought out ideas is time consuming. 
When discussing innovation, scholars often refer to corporations as the innovating entities, studying innovation at the firm level of analysis. However, it is not the corporation which actually innovates. Rather, innovation occurs through the dynamic interaction between factors at the individual, group, firm, field, and environmental levels of analysis. Entrepreneurship scholars emphasize many individual-level factors such as prior experience, education, and cognitive variables. Yet such studies rarely examine specific actions individuals take in response to pressures generated by professional, community, or corporate logics. To more fully understand how individuals and groups of individuals innovate, a nuanced understanding of their environment and how they interact—-both individually and collectively — is needed. I next articulate the institutional logics perspective as a key lens through which to study innovation within MakerHub, a corporate venture makerspace.

\section{The Four Principles of the Institutional Logics Perspective}

In this section, I argue the institutional logics perspective is a suitable lens through which to study innovation and by which useful insights may be gleaned. I begin by highlighting its four key axioms: (a) the duality of structure and agency, (b) the material and symbolic aspects of institutions, (c) the historically contingent nature of institutions, and (d) the examination of institutions at multiple levels of analysis. Subsequently, I connect the formation of all four principles with how each inform a discussion on innovation and organizational design within a corporate venture makerspace.

\section{\#1: Duality of structure and agency}

A central question institutional theory addresses is why firms behave the way they do. Much literature discussed this question over the past half-century, and indeed, is still 
central within the institutional logics literature. A confounding problem exists, however, in explaining firm behavior: To what extent do firm managers control outcomes and to what extent do environmental or field level factors determine outcomes? Prior to Selznick's (2011) seminal work, a dominant assumption in organization research was that firm managers act rationally and with the primary goal of maximizing shareholder value. If true, managerial agency would be driven by that singular motivation, and firm structures and processes would be solely focused on the same goal. However, Selznick (2011) disputes these assumptions, saying they lack explanatory power and misjudge human behavior. His empirical work demonstrates organizations have structures and processes which do not maximize shareholder value (Selznick, 1949, 2011).

To adequately explain firm behavior, and subsequently how firms innovate, an understanding of diverse motivations and misaligned structures is needed. Selznick argues a dynamic relationship exists between agency, structure, and the environment, which causes firm institutionalization. He contends misaligned structures are a combination of institutionalization and mismanagement which occur over time (Selznick, 1996). As managerial motives inform firm decisions, structures constrain and enable the buffet of options available. In Selznick's work, both arguments for structure and agency are clearly seen. However, precise mechanisms by which they interact or change are lacking. He does, however, maintain that managers should actively monitor and shape the relationship between institutions and firms and that if conflicts arise between those, they should be resolved (Thornton et al., 2012).

Whereas Selznick gave agency to managers, Meyer and Rowan (1977), asking a different question—why do firms look similar?-emphasized structure over agency. 
Meyer and Rowan (1977) highlight institutional rules, legitimacy, and isomorphism as means of explaining organizations' similarities. They contend organizations conform to institutional rules as a means of gaining legitimacy, an essential necessary for firm survival (Meyer \& Rowan, 1977). Institutional rules, they argue, are established primarily by the state and professions and are made known through myths and symbols. Their arguments emphasize structure and cultural conformity rather than rational decision making by managers. Zucker (1977) further solidified Meyer and Rowan's (1977) arguments by stating that institutional rules—all socially constructed—generate organizational conformity because they are recognized as facts (Thornton et al., 2012), demonstrating that "institutionalization as driven by cognitive processes that lead to taken-for-granted understandings and behaviors" (Thornton et al., 2012, p. 24).

Zucker's (1977) findings are important for two reasons. First, Zucker (1977) confirmed that the transmission of culture — a structural element—shapes behavior because perception of cultural can become rule-like. This argument substantiates a structural perspective of both managers' decision making and firm behavior. Second, managers use cognitive processes—-what Zucker sees as an agentic element—in rationalizing why they adhere to the cultural rules. Rationalization is defined as "theoretical assumptions about how actors make choices and take social action" (Thornton et al., 2012, p. 29). The idea of rationalization is particularly relevant to the institutional logics perspective and will be unpacked in greater detail.

Similar to Meyer and Rowan (1977), DiMaggio and Powell's (1983) neoinstitutional theory also emphasizes structure over agency. However, they contend a different mechanism causes firm similarity. They assert isomorphism is driven by an 
organization's field structure rather than an adherence to culturally driven institutional rules. DiMaggio and Powell (1983) also assume both the state and professions shape organizational fields and are thus integral in explaining isomorphism. They argue isomorphism tends to increase under many circumstances, including, but not limited to, heightened environmental uncertainty, strategic ambiguity, and the number and strength of ties between firms and professional organizations or governmental agencies (DiMaggio \& Powell, 1983; Thornton et al., 2012). They highlight three types of isomorphism: mimetic, normative, and coercive. Whereas the first two concern adherence to structural forces, coercive isomorphism nods to agentive power (Thornton et al., 2012). However, this agency manifests itself primarily through strong-arm regulation, offering little explanatory richness to "agentive behavior" (Barley \& Tolbert, 1997; Hirsch \& Lounsbury, 1997; Thornton et al., 2012).

The outcome of DiMaggio and Powell's (1983) article was the beginning of neoinstitutional theory. In distinguishing neo-institutional theory from "old" institutional theory, Selznick (1996) considers the importance of legitimacy: "Legitimacy is seen as an organizational 'imperative' that is both a source of inertia and a summons to justify particular forms and practices. The justifications encourage institutional mimicry or mimesis, meaning that the organization is highly sensitive to the cultural environment within which it lives" (Selznick, 1996, p. 273). However, DiMaggio's (1988) paper highlights a fundamental problem within neo-institutional theory: it lacked explanatory mechanisms showing how institutions are created, reproduced, and dissolved (DiMaggio, 1988; Thornton et al., 2012). 
Attempting to address this problem and building on coercive isomorphism, DiMaggio (1988) theorizes institutions can be created and changed by institutional entrepreneurs, individuals who seek to better their own position by changing the "rules of the game." They do so by shaping narratives and manipulating cultural symbols (Hardy \& Maguire, 2008; Thornton et al., 2012). DiMaggio (1988) also theorizes that institutions are reproduced through "socializing new participants," and delegitimized through hybridization (Thornton et al., 2012, p. 29).

Although DiMaggio's (1988) work helps expand institutional explanations, critiques suggest explanatory power is limited due to the reduced agency granted individuals and the lack of a deeper articulation of individual motives (Thornton et al., 2012). Moreover, although institutional entrepreneurship is a mechanism by which individuals can alter institutions, scholars warn generalizing isolated instances may be detrimental to constructive theory building (Hardy \& Maguire, 2008). Further, institutional entrepreneurship is inadequate to explain the relationship between an idea and the environment in which that idea emerges (Leca \& Naccache, 2006; Thornton et al., 2012).

Expanding on Simon's (2013) notion of bounded rationality to explain how actors make choices, March and Olsen's (2010) work returns to a focus on agency. They articulate two forms of rationality: logic of instrumentalism and logic of appropriateness. The former asks, "What are my interests in this situation?" and the latter asks, "What is expected of me in this situation?" (Thornton et al., 2012, p. 30). March and Olsen's (2010) conception of rationality is important because it generates further dialog about what external factors cause and legitimize behavior (Thornton et al., 2012). DiMaggio (1991) expounds on this 
idea: "the meaning of rationality changes with changes in the context of institutional orders" (Thornton et al., 2012, p. 31).

To understand MakerHub's unique organizational design as well as how, when, why, and what types of innovations occur within a corporate venture makerspace, both structure and agency considerations are critical. Without considering structure, an analysis of innovation processes would be merely regulated to a subset of cognitive variableswhile perhaps enlightening, certainly shallow. Conversely, an analysis solely of structure characteristics and their subsequent impact on innovation lacks explanatory power. Thus, the consideration of structure and agency broadens both the scope of activities and potential interpretations of individual, group, and firm actions.

Understanding the tensions between structure and agency is particularly relevant to studying corporate venture makerspaces, because established corporations like Products Inc. tend to experience heightened pressure to conform to industry norms (Greenwood et al., 2011). On the other hand, as a nimble start-up on the fringes of an industry, theory would suggest MakerHub may be more immune to structural pressures, enabling increased agency in its decision-making ability. Such autonomy, however, may be diminished if Products Inc. artificially imposes institutional conformity on MakerHub. The existence and extent of such influences within this specific parent-venture relationship will be discussed.

\section{\#2: The Material and Symbolic Aspects of Institutions}

The second principle of institutional logics understands institutions as both material and symbolic (Thornton et al., 2012). Thornton et al. (2012) clarify, "by material aspects of institutions, we refer to structures and practice; by symbolic aspects, we refer to ideation and meaning, recognizing that the symbolic and the material are intertwined and 
constitutive of one another" (p. 10). An important distinction in the institutional logics perspective is the idea that material and symbolic elements inform artifacts dependent on which institutional order(s) drive rationalization (Thornton et al., 2012). Thornton (2004, p. 12) emphasizes six primary institutional orders: "the market, the corporation, the professions, the family, the religions, and the state." Institutional orders contain “...unique organizing principles, practices, and symbols that influence individual and organizational behavior" (Thornton et al., 2012, p. 2). Understanding institutional order is critical because if the referent institutional order changes, the rationalization of individual actors will change leading to potentially dynamic relationships between actors, symbols, and materials. Moreover, as new individuals come into the firm and others leave, symbols may evolve depending on the ebb and flow of actors within the organization and their respective power. Moreover, cultural norms can generate differences between firms as symbols in one culture represent different meanings than in others.

Neo-institutional theory acknowledges both the material and symbolic. Indeed, Selznick (1996) highlights the role of organizational myths and rituals within neoinstitutionalism stating, "The formal structure is institutionalized from without as well as from within, and it reflects prevailing concepts of how work should be organized. In postindustrial society, formal structures dramatically reflect the myths of their institutional environments instead of the demands of their work activities" (Selznick, 1996, p. 273). Understanding interactions between the material and symbolic is an important differentiator of the institutional logics perspective (Meyer \& Rowan, 1977). And, the institutional logics perspective assumes individuals, groups, firms, and industries 
constantly engage with one or more institutional orders, influencing material and symbolic factors.

Understanding how institutional logics manifest and inform both material and symbolic aspects of firms is important for a study of MakerHub. Innovation does not occur in a vacuum or solely in the mind of an individual. Forces constraining, enabling, and shaping individual, group, and firm actions all have their say on what, when, and how innovation occurs. Moreover, in watching the process of innovation occur, a framework is necessary to categorize related ideas, conversations, actions, artifacts, and processes to make sense of how they came about. At founding, MakerHub embraced both symbolic and material practices reflective of its unique organizational design. However, as MakerHub expanded its NPD activities, competing goals and resource constraints necessitated tradeoffs between practices, resulting in some becoming primarily symbolic.

\section{\#3: The Historically Contingent Nature of Institutions}

The third principle of the institutional logics perspective shows the importance of examining firms within historical contexts. Thornton et al. (2012) elaborate, "Any true picture of social mechanisms must be observed not only across historical time, but also across multiple levels of analysis to capture the cross-level effects" (Thornton et al., 2012, p. 13). A strength of institutional logics is that the focus is on understanding the “...elemental parts of theory — the mechanisms (G. F. Davis \& Marquis, 2005) that mediate between cause and effect and unfold over time" (Gross, 2009; Thornton et al., 2012, p. 13). The internet has transformed how entrepreneurs conduct market research, interact with consumers, and find new go-to-market strategies. While many sociological theories incorporate some aspect of historical contingency, management theories tend to emphasize 
them less. Products Inc. was founded in the early $20^{\text {th }}$ century, and many processes reflect hierarchical management strategies and formal firm-consumer relationships. Although many MakerHub employees were originally with Products Inc., MakerHub was founded with a flatter structure intending to generate innovation and increase external engagement (consumers, makers, etc.).

\section{\#4: Examining Institutions at Multiple Levels of Analysis}

To understand firm behavior, researchers must examine problems at different levels of analysis and the mechanisms connecting and influencing each other across levels. The institutional logics perspective understands action within layers of constraints and pressures - an individual within an organization, an organization within a field, a field within a society. Again Thornton et al. (2012) certify, "The metatheory underlying the institutional logics perspective has grown around the concept of the interinstitutional system as it assumes that institutions operate at multiple levels of analysis with potential for cross-level interaction effects" (Thornton et al., 2012, p. 14).

This principle is relevant to the current study, as any examination of innovation within a corporate venture makerspace requires consideration of individual, group, firm, and field level factors. In the present study, firm, and individual levels are each salient as MakerHub experiences competing pressures externally (i.e. consumers, maker movement) and internally (i.e. Products Inc. and managerial decision making), fostering within its organizational design.

\section{Institutional Logics Perspective}

In this section, I highlight several of the key elements within the institutional logics perspective as it has evolved over the past 27 years. First, I discuss Friedland and Alford's 
(1991) work and the two subsequent articles that generated additional interest in the institutional logics perspective among researchers. Second, I note several of the early institutional logics papers, highlighting key findings and additions to the institutional logics perspective. Third, I conclude by noting the impact of external factors influencing firm performance.

\section{Development of the Institutional Logics Perspective}

Friedland and Alford's (1991) conception of institutional logics gained little following until the late 1990s when two influential articles were published in the American Journal of Sociology: Haveman and Rao's (1997) article on the evolution of the thrift industry from 1865-1928 and Thornton and Ocasio's (1999) article on how the publishing industry evolved from an editorial logic to a market logic. Haveman and Rao's (1997) article, while not explicitly an institutional logics article, was influential as it demonstrated the impact socially constructed forces have on firms at multiple levels of analysis - social, field, and firm — and how firms evolved. Thornton and Ocasio's (1999) article focused on three mechanisms by which logics impact executive power: rules of prevailing logics, attention of logics, and assumptions of logics. The change in logics caused change in the determinants of executive succession (Thornton \& Ocasio, 1999). Moreover, their article also highlights some of the material and symbolic aspects of institutional logics previously discussed.

The early logics literature primarily focused on the antecedents to and consequences of field-level change, such as Thornton's (2002) paper on the publishing industry and Lounsbury's (2002) study of the finance industry. Scholars also began using an institutional perspective to research meso- and micro-level variables such as how 
rhetoric can enact institutional change (Suddaby \& Greenwood, 2005) and how individual identity need not align with an incumbent logic or subsequent logic for change to occur (Lok, 2010). Rao, Monin, and Durand (2003) also examined the relationship between changes in logics on individual identity. In a fascinating article on French cuisine, their narrative describes classic French cooking's displacement by Nuevelle cooking. The authors find logics form behaviors, in part, through systems which reward conforming behavior and punish non-conformity, further demonstrating the usefulness of a logics perspective applied at lower levels of analysis.

\section{Forces Shaping Firm Behavior}

Before examining logics at the firm and individual level, a brief description of past research on macro-level effects is useful. A country's cultural values and norms moderate the interaction between logics and firm behavior. For example, Ozen and Akkemik's (2012) study demonstrates how logics converge with cultural norms at the nation-state level. They discuss the impact of nationalist logics on the perception of corporate behavior as legitimate or illegitimate, arguing legitimacy is gained through aligning corporate goals with nationalist goals (Özen \& Akkemik, 2012, p. 523).

Past research also features the importance of environmental munificence as a potential moderator between logics and firm behavior. Biniari, Simmons, Monsen, and Moreno (2015) examine the impact of resource dependence between parent and corporate venture, and their respective dependence on environmental munificence to predict which dominate corporate venture logic would be chosen. Relatedly, logics moderate network factors to shape firms' ability to innovate and exploit structural holes (Vasudeva, Zaheer, \& Hernandez, 2013). 
This section has concerned general literature within the institutional logics perspective, demonstrating different applications of the perspective to explain phenomena at various levels of analysis and the dynamic links between logics and firms. In the next section, I turn to complexity-how firms engage with contrasting prescriptions between logics. As articulated, firms make tradeoffs in order to generate or adopt innovation. Further explanation as to how firms balance tensions between competing logics is needed.

\section{Complexity}

A critical research theme within the institutional logics literature is complexity. Complexity is "the simultaneous operation of different logics that impose contradictory demands on an organization” (Dalpiaz, Rindova, \& Ravasi, 2016, p. 348). Greenwood and colleagues (2011, p. 317) state, “Organizations face institutional complexity whenever they confront incompatible prescriptions from multiple institutional logics." Institutional complexity is important because of both its prevalence within firms (Schildt \& Perkmann, 2017) and the unique outcomes complexity can cause for organizations and their members. First, I review why complexity is difficult to study and the need to understand the specificity of the logic itself. Second, I discuss organizational filters-organizational elements that impact how they perceive institutional logics and interact with them. Third, I focus on how organizations respond to complexity. Fourth, I discuss research studying the relationships between individuals and complexity.

\section{Complexity Analysis}

Institutional complexity is difficult to quantify yet perceptively understandable, difficult because a logic's prescription may differ depending on the environment (Biniari et al., 2015), firm (Miller, Le Breton-Miller, Amore, Minichilli, \& Corbetta, 2017), or 
interpretation of the decision maker in power (Greenwood et al., 2011). Moreover, logics affect firms in varying degrees. For example, whereas centralized firms within a field network may face greater pressure to conform to logics' prescriptions, firms less centralized in a field face fewer constraining pressures (Greenwood et al., 2011). Furthermore, a firm may experience heterogeneity within a single logic (Sauermann \& Stephan, 2013) as Jain and Sharma's (2013) study of India's telephony sector demonstrates; they identified three distinct market logics.

Attempting to parse prescriptive elements between two competing logics, understand the degree to which they differ, and digest the subsequent impact those disagreements manifest themselves in firm and individual actions is daunting. Indeed, some scholars acknowledge the conception of an "idealistic logic," while helpful in analyzing, lacks descriptive impact (Sauermann \& Stephan, 2013), complicating analysis between logics' distinct theoretical boundaries. Conversely, the existence of competing logics is observable and intuitive in organizations like universities and hospitals. Pressure to conform to professional practices and ethics competes with realizing budgetary needs. To best articulate relevant research, I heavily incorporate Greenwood et al.'s (2011) formulation of complexity, following their outline and marking recent adaptions to their framework.

The manner in which complexity impacts organizations is in part due to the logics' specificity (Goodrick \& Salancik, 1996). Highly specified logics have clear prescriptions for firms, constraining action and quickly punishing non-conforming firms (Battilana \& Dorado, 2010; Greenwood et al., 2011). Moreover, the more specified the logics, the more pressure firms face to dissolve the complexity between logics. For example, two logics 
with highly specific, competing prescriptions of firm behavior must be dissolved for tension within the firm to be alleviated, forcing firms to choose a dominant logic or create a hybrid logic (Greenwood et al., 2011). On the other hand, firms with ambiguous prescriptions have greater ability to innovate practices or structures with less fear of repercussions for nonconformity (Greenwood et al., 2011).

\section{Organizational Filters}

Field Position: Greenwood et al. (2011) discuss the salient factors that filter how organizations experience and respond to complexity. The first factor discussed herein is field position (Greenwood et al., 2011, p. 334). How centralized a firm is within a field alters the level of complexity it may experience (Greenwood et al., 2011). Scholars have argued that those on the edges of a field may experience less pressure to resolve potential complexity due to either an ignorance of expectations (Kraatz, 1998; Westphal, Gulati, \& Shortell, 1997) or a lack of "social nudging and policing that reaffirms existing practices" (Greenwood et al., 2011, p. 341), potentially enabling more innovative behaviors. Conversely, those in the center of a field may face heightened pressure as visibility brings demands from competing factions with potentially competing logics (Greenwood et al., 2011). However, if a firm is big enough, they may be beyond regulatory censure regardless of how central they are within an industry (Greenwood et al., 2011). Moreover, as complexity driven tensions increase, large firms may perceive complexity more clearly, enabling greater agency in how they choose to respond (Greenwood et al., 2011).

Structure: How firms respond to institutionally complex environments is also informed by individual decision makers within a firm. Similar to Hambrick and Mason's (1984) Upper Echelon's Theory, firms respond to external environments through the 
interpretive lens of those in positions to make decisions. Greenwood et al. (2011, p. 342) pen, "Institutional pressures do not just enter an organization - they are interpreted, given meaning and 'represented' by occupants of structural positions. It follows that the more differentiated and thus complex the organization, the greater the likelihood that it will experience institutional complexity." In some ways, this concept harkens back to Selznick's (2011) emphasis on a manager's monitoring the institutionalization of a firm.

Ownership and Governance: The third organizational filter moderating firms' experience of complexity is ownership and governance. "Those in power most likely to determine organizational responses to multiple institutional logics—and, in a way that reflects their interests. In other words, appreciation and recognition of logics, and the choice of which logic to prioritize and how to do so, will be dictated by those with power" (Greenwood et al., 2011, p. 344). The corporate innovation literature discussed earlier, although not explicitly articulating complexity, substantiates the importance of ownership and governance. Owners inside the firm desired different innovation strategies than those owners outside the firm (Hoskisson et al., 2002). Shifts in logics due to changes in ownership is also seen in Bernstein's article on innovation shifts within firms as they go through an IPO. Further, research on family firms' experience with complexity also finds ownership and governance as critical (Miller et al., 2017).

Identity: Lastly, identity shapes how organizations perceive and respond to institutional logics at two levels: the institutional level and the organizational level (Greenwood et al., 2011). The institutional level concerns the socially generated labels which grant legitimacy to firms who claim them and conform to their prescribe norms. Organizations tend to respond to complexity in ways consistent with the institutional labels 
with which they have self-identified, necessarily enabling some actions while constraining others. Identity at the organizational level:

is concerned with attributes that define the organization as different from other organizations - especially those sharing the same institutional category. At this level, identity has been shown to influence how expectations and pressures are prioritized; and, perhaps more so, it has been shown to shape which repertoires of possible responses are assessed and selected. (Greenwood et al., 2011, p. 347)

Discussing both institutional and organizational identities is important as they form a more holistic and nuanced understanding of how a firm perceives itself in relation to other firms, both as a part of and distinct from other firms (Kraatz \& Block, 2008); those perceptions may be positive or negative, subsequently influencing behaviors differently (Greenwood et al., 2011; Kraatz \& Block, 2008). Firms may adhere to different identities to various degrees: "The strength of an organizational identity is the extent to which it is deeply shared, and the stronger the identity the more it will condition an organization's approach to institutional demands" (Greenwood et al., 2011, p. 348).

\section{Organizational Responses}

Research suggests organizations respond to institutional complexity through two means: strategies and structures (Greenwood et al., 2011). Within strategic responses, scholars contend firms generally respond in one of two ways. The first way is championed by Pache and Santos (2010), who examine the extent to which firms accept field-level norms and prescriptions, and study how "... logics are given voice within the organization" (Greenwood et al., 2011, p. 348). This approach contends firms respond to complexity by receiving logics into the firm and giving leverage to those logics best suited with firm goals.

The second strategic response is highlighted by Kraatz and Block (2008), who assume more agency by firms and individuals within firms, stating organizations utilize 
identity as a mechanism to respond in four different ways. First, firms may choose a dominant logic identity, reducing the emphasis of the competing logic identity. Mair, Mayer, and Lutz (2015) label this strategy as a conforming hybrid. For example, social enterprises, they argue, are inherently hybrids. Those that emphasize a social identity over a profit identity—or vice versa—are conforming to a specific hybrid (Mair et al., 2015). Second, firms may attempt to create shared meaning between identities in an effort to satisfy both (Binder, 2007). For example, in Mair and colleagues' (2015) study of over seventy social enterprises, they found some firms innovate new governance structures and mechanisms, thereby conforming to neither logic. Third, firms may retain both identities and instead actively seek to minimize external conforming pressures (Smets et al., 2012). Fourth, firms may compartmentalize identities through "symbolic commitment to certain logics while preserving a core identity" (Greenwood et al., 2011, p. 350). This strategy Mair et al. (2015) label "selective decoupling" disclosing it enables firms to choose the best of both practices (See also Hamilton \& Gioia, 2009).

Firms can also strategically use the same institutional logic in multiple combinations. For example, Dalpiaz et al. (2016) examined Alessi, an Italian manufacturing firm, who combined the conflicting logics industrial manufacturing with cultural production. Over the course of three decades, Alessi used three distinct hybrid strategies, "imbu[ing] its products with new cultural meanings" (Dalpiaz et al., 2016, p. 377).

Organizations also respond to institutional complexity through structures of two types: blended and structurally differentiated. Blended structures seek to "combine and layer practices from different logics" with the intent of "achieving field legitimacy and the 
positive benefits of both logics" (Greenwood et al., 2011, p. 352). Blending depends on both micro and macro level factors (Lo \& Kennedy, 2014) and is particularly difficult as Battilana and Dorado (2010) demonstrate. In a study of two banks in South America, Battilana and Dorado (2010) contend there are two primary approaches to hybridization: apprenticeship and integration. Battilana and Dorado (2010) studied the hiring practices of both banks in order to better understand how management engaged with developmental and banking logics. One bank utilized the apprenticeship approach by hiring new employees with backgrounds in banking, causing friction between current employees with development backgrounds. Subsequently, the friction between the incumbent employees with a development logic and the incoming employees with banking logic caused operational problems. Executives were fired and growth substantially slowed. Conversely, the second bank employed an integration strategy. They hired recent graduates with allegiances to neither logic, enabling the bank to incorporate new employees into the hybrid logic itself.

Structural differentiation is the other type of structural response. Greenwood et al. (2011, p. 354) report firms responding with structural differentiation seek to separate logics into different subunits, "essentially partitioning and compartmentalizing an organization into different mindsets, normative orders, practices and processes." A recent study (Miller et al., 2017) demonstrates the importance of structure in how family firms can capitalize on the strengths of market logic and family logic through a family firms' governance structure. They argue the ability for firms to effectively capture the strengths of both depends on the level of family values within the community. The stronger the community's family values the more likely a family firm will have a family governance structure. In an 
environment with family dominant governance structures, they contend, family firms who increase market logic elements would create synergistic combinations of both the market and family logic (Miller et al., 2017).

As a corporate venture makerspace, MakerHub provides a unique research domain because it creatively synthesizes in its design an institutionally complex blend of goals, needs, and logics. From Product Inc.'s corporate perspective, MakerHub must justify its existence. The two primary metrics established at MakerHub's founding were to breakeven and to develop 12 never-seen-before products a year. Practically, then, MakerHub must both balance the demand to be innovative with the ability to generate profitable products. From a start-up perspective, MakerHub was also founded to be agile, ready to pivot to consumer demands, necessitating employees be comfortable in ambiguous roles. Lastly, from a makerspace perspective, the environment was founded to be conducive to creating, experimenting, and learning.

\section{Individual Responses}

Past research demonstrates the constraining and enabling influence of investors' logics on young-firm innovation. One study found that among types of investors-VCs, corporations, and state funding agencies—state funding agency state logics constrained young firm innovation; whereas, $\mathrm{VCs}$ ' professional logics enabled innovation, and corporation logics fell between constraining and enabling (Pahnke, Katila, \& Eisenhardt, 2015). However, parental logics may also be influential through individuals who were with the parent company but then transitioned to the new venture. In this section, I discuss the relationship between complexity and individuals, attending specifically to how individuals perceive, interact with, transform, and carry logics. 
Individuals transport logics via four mechanisms: artifacts, routines, symbolic systems, and relational systems (Pallas, Fredriksson, \& Wedlin, 2016). Delbridge and Edwards (2013) apply Kraatz and Block's (2008) emphasis on agency to the individual level: "Logics do not determine action precisely because the institutional sources of action are a relational feature of the actor position of individuals and their reflexive ability to recognize opportunities" (p. 7). In other words, the logics-individual relationship is a cyclical one where each constantly informs the other. While some argue individuals can only choose from the logics available to them (Martin et al., 2017), the buffet of options is dynamic rather than static.

At both the individual and firm level, identity is also crucial. Among available logics, individuals can embrace multiple logics and their identities as long as those identities do not simultaneously become salient. Brandl and Bullinger (2017) demonstrate how the relationship between salience and identity impact individuals' decisions to engage one logic over the other. Past literature tends to divide into two broad perspectives of logics' impact on individual behavior, each based on distinct assumptions. The socialization perspective understands logics as external forces which in large part drive the thoughts and behaviors of the individual. Actors will choose specific logics based on their knowledge of a logic, the accessibility of a logic, and the practice or experience with a logic (Brandl \& Bullinger, 2017). Conversely, the strategic perspective assumes actors have greater agency in disembedding themselves from the environment and strategically choosing what logics are most relevant to the situation. Brandl and Bullinger (2017) contend individual behavior is based on salient identities that are hierarchically ordered and chosen based on their importance to the individual. Utilizing identity control theory 
(ICT), they maintain that if no conflict exists between logics, individuals can maintain association with both; however, when conflict occurs, individuals choose which is more important to them and may even actively dissociate themselves from the other logic.

Understanding complexity at the individual level is challenging as complexity may occur within the minds of individuals even if not manifested in actual practices. Recent research demonstrates such a discrepancy can occur between firm logics and incoming employees' perception of what the firm's logics ought to be (Smith, Gillespie, Callan, Fitzsimmons, \& Paulsen, 2017). And indeed, Products Inc.'s logics had (and continue to have) a profound impact on MakerHub's processes, practices, and goals - both directly (firm level) and through individuals (individual level).

MakerHub was founded with competing goals: 1) develop innovative products, 2) develop products quickly, and 3) develop products that are potentially profitable. Given the impact parental logics may have on a new venture and the various strategies employees may utilize to respond to those logics, I examine the ways in which MakerHub implemented its institutional logics into its organizational design to navigate these competing goals; the ways in which parental logics drew MakerHub to more closely imitate Products Inc.'s own R\&D Centers; and the benefits, if any, MakerHub provides to Products Inc. 


\section{METHODS}

In this chapter, I discuss my potential biases and the philosophical assumptions of qualitative research. Then, I review my methodology, research context, data collection procedures, and data analysis procedures. Qualitative analysis emphasizes building theory by meaningfully engaging in the research context, providing readers "think descriptions" of both context and phenomena (Geertz, 1973).

\section{Philosophical Assumptions and Self-Reflexivity}

Any observation, interpretation, or synthesis of human action requires a lens through which to see, question, and understand. In this section, I will outline my biases and strategies for reducing potential influences on findings. Biases may arrive from past experiences or educational background, forming paradigms by which the world is perceived (Tracy, 2012). Paradigms are important to consider as they are "a basic set of beliefs that guide action" (Guba, 1990, p. 17). My undergraduate degree is in the Humanities, and both my graduate degrees (MBA and Ph.D.) are in business. My assumptions of the world, therefore, are formed by both, and I view both business and work as a means of human flourishing but not an end in and of themselves. In many ways, I am a post-positivist, but hesitate to fully align with any particular philosophy of science.

Studying MakerHub was a unique experience for me because of my singularly nontechnical background. I did not participate in robotics or engineering-like programs growing up. Therefore, studying innovation in an environment dominated by engineers was both exciting and intimidating. I asked basic material, machine, and process questions of how and why things work the way they do. For example, when an intern made cutting 
boards and deliberated types of wood to use, I asked about the benefits of various woods. He described how some where better for cleaning. On another occasion, I asked one MakerHub employee how extruders are made using a large machine MakerHub owns. He described the process and the different steps he went through to prepare the machine and how the machine worked.

My lack of knowledge concerning all things "Making" was both an advantage and disadvantage. Positively, I asked many questions and did not assume I understood what was going on. The engineers at MakerHub became my teachers, and they seemed to enjoy educating me. This relationship was greatly beneficial as information and insights perhaps otherwise unknown surfaced. The disadvantage of my non-technical background was that I may have missed something. To truly appreciate something, a degree of knowledge about that thing is necessary.

A second potential bias was my familiarity—albeit from a distance — of MakerHub before my research began. I took several tours of MakerHub's facility before I ever considered research there. Moreover, MakerHub is lauded in both the community and university as a place for innovation, entrepreneurship, and community engagement. Therefore, I entered MakerHub's environment expecting to find innovation occurring.

$$
\text { Qualitative Design: Ethnography }
$$

Qualitative methods have been heavily used in makerspace research (Cross, 2017; DeRosa, 2016; Lacy, 2016; Lahana, 2016; Litts, 2015), entrepreneurship research (Baker \& Nelson, 2005; Lucas, Kerrick, Haugen, \& Crider, 2016; Sarasvathy, 2001; Shane, 2000), innovation research (Hargadon \& Douglas, 2001; Hargadon \& Sutton, 1997), and institutional logics research (Battilana \& Dorado, 2010; Currie \& Spyridonidis, 2016; 
Dacin, Munir, \& Tracey, 2010; Dalpiaz et al., 2016; Haveman \& Rao, 1997; Smets et al., 2012; Thornton \& Ocasio, 1999). Indeed, over half of the articles on institutional logics use qualitative data (Reay \& Jones, 2016). Using a qualitative methodology is particularly useful in these research streams because of the ability for researchers to examine contextual elements, examine individuals within their work environments and the interaction between individuals and their environments, and examine both intentional and unintentional actions and how those actions unfold over time.

\section{Benefits of Qualitative Approaches}

Qualitative approaches have a number of benefits. First, qualitative research emphasizes an organization's everyday occurrences. Consequently, researchers' viewpoints are formed through close relationship with the data, enabling descriptive pictures of organizational life (Miles, Huberman, \& Saldana, 2013). MakerHub's employees work individually, work in teams, schedule meetings, engage in informal conversations, and constantly communicate about work and non-work issues. All these actions create meaning individually and collectively that inform how MakerHub innovates. Qualitative research is well suited to capture this type of data.

Second, qualitative approaches also provide "thick descriptions" (Geertz, 1973), which "are vivid, are nested in a real context, and have a ring of truth that has a strong impact on the reader" (Miles et al., 2013, p. 11). Stimuli accost an individual's brain constantly with sights, sounds, smells, tastes, many of which are immediately dismissed and forgotten. Humans tend to remember the abnormal rather than the everyday, "uninteresting" events. However, sometimes the uninteresting is important to how events 
or processes unfold. Qualitative research is useful in catching some of these events that may otherwise be left out of a respondent's recounting.

Third, qualitative approaches are beneficial because studies are generally longitudinal:

We can go far beyond snapshots of "what?" or "how many?" to just how and why things happen as they do - and even assess causation as it actually plays out in a particular setting. And the inherent flexibility of qualitative studies (data collection times and methods can vary as a study proceeds) gives further confidence that we really understand what is going on. (Miles et al., 2013, p. 11)

Longitudinal studies enable researchers to find patterns as some events may decrease in importance or others become central to a study. Moreover, as events unfold, the focus of observations or questions can change, enabling a researcher to potentially shift focus as the data dictates.

Lastly, qualitative approaches enable researchers to gain nuanced understanding of how individuals create and define meaning: "Qualitative data, with their emphasis on people's lived experiences, are fundamentally well-suited for locating the meanings people place on the events, processes, and structures of their lives and for connecting these meanings to the social world around them" (Miles et al., 2013, p. 11). Relationships are a formidable factor in how individuals create meaning (B. Brown, 2015) and in how innovation occurs. In his book Explaining Creativity, Keith Sawyer warns against solely focusing on individuals in the search for understanding how and why innovation occurs (Sawyer, 2011). Rather, he emphasizes examining individuals within groups, teams, and environments to better explain outcomes. 


\section{Ethnography}

In this study, my data collection occurred in two phases: ethnography (via observation and participation) and semi-structured interviews. I begin this section by discussing ethnography. Ethnography is particularly useful for studying the creation, design, and prototyping of new products within a makerspace because the researcher is present as it occurs. Ethnography is an appropriate method to synthesize these multiple data sources: "Ethnographic methods tend toward the descriptive. The analysis task is to reach across multiple data sources and to condense them" (Miles et al., 2013, p. 8). Further, ethnography is particularly useful for understanding the everyday routines of employees (Van Maanen, 1979), how they make sense of the world around them, and their interpersonal relationships with others (Demetry, 2015).

The decision to use ethnography was also formed by recent calls for more ethnographic research in entrepreneurship. In the fall of 2017, entrepreneurship scholars assembled at Princeton University to discuss the need for research of nascent ventures, particularly research using an ethnographic approach. MakerHub is a nascent venture and using ethnography to study how logics were implemented into its design, how innovation occurred, the tensions forming innovation, and the ways in which MakerHub innovates as distinct from Products Inc.'s R\&D Centers contribute theoretically, practically, and methodologically.

In the second phase of my study, I conducted semi-structured interviews of MakerHub employees (See Appendix A). By interviewing MakerHub employees, I gained further insights into specific questions concerning my research focus on how MakerHub incorporates its institutional logics into its organizational design in an effort to innovate 
and contribute to Products Inc., enabling MakerHub employees to expound on what they see as critical to the innovation process, potential barriers to innovation, and how they "fit" within that process.

Institutional logics scholars have also emphasized the need for further research on topics for which qualitative analysis is particularly useful. For example, questions such as those regarding the material aspects of culture (Ashraf, Ahmadsimab, \& Pinkse, 2017), the process organizations use to systematically combine different logics (Dalpiaz et al., 2016), and how individuals internalize logics and the micro conditions under which institutional influences are carried to a greater or lesser degree into the practices of the organization (Almandoz, 2014). All these elements were part of understanding how MakerHub innovates. Given the prevalence of qualitative research within the entrepreneurship, institutional logics, and makerspace literatures as well as the calls for further research from a qualitative approach, I utilized ethnography and semi-structured interviews as a suitable means of studying MakerHub.

\section{Research Context}

As noted, the context in which this study took place is MakerHub-a corporate venture makerspace created in 2013 and owned by Products Inc. MakerHub's founding purpose was to shorten the idea-product cycle by acting as an external-facing entity designed to enable a quicker feedback loop between engineers, makers, and consumers. Moreover, founding leadership envisioned new products being generated through community involvement-in other words, creating an open makerspace design where anyone might walk in and work on their own projects or co-create on a MakerHub product. 
Hence, MakerHub's stated mission (paraphrased) was to create, prototype, and test innovative products by co-creating with the community.

Ideas for products come from MakerHub and Products Inc. employees, local stakeholders (i.e. those who come in and use MakerHub's workplace), and the community. MakerHub employees discuss product ideas and suggest the best ideas to MakerHub's leadership team. If the leadership team perceives the product idea has potential, one or more engineers may be assigned to work the technical feasibility of the product. Once the engineer(s) are confident the product is technically viable, market research is conducted to learn about potential interest among consumers. If there does seem to be a market for the product, additional members may be assigned to the project, including the industrial designer, additional engineers and commercial team members. As MakerHub's engineers work through technical problems, they often file patents for which they are (if accepted) monetarily compensated by Products Inc.

During the stages of idea development, technical problem solving, and customer research, the leadership team also considers the best go-to-market strategy. Past strategies MakerHub has used include selling through the parent (Products Inc.), crowdfunding through Indie-GoGo, or crowdfunding through MakerHub's own website. Additionally, at any point during these activities or stages, a project may be discontinued due to a perceived lack of market interest, technical feasibility, operational feasibility, cost-price threshold, or lack of product consistency with MakerHub's first adopter brand image.

MakerHub has approximately 23 employees and consists of a commercial team (sales, marketing, and social media/brand), product developers (many of whom are mechanical engineers), product development technicians, designers, software engineers, an 
office manager, and a product enthusiast. Approximately half of MakerHub's employees have engineering backgrounds.

MakerHub is located on the edge of a large Southern university in the United States and resides in a mid-sized city. University students benefit by having access to MakerHub, its equipment, and employees. Business, engineering, and design professors occasionally bring students to MakerHub for tours of MakerHub's facilities. Moreover, MakerHub offers part-time work opportunities to students who can gain hands-on experience building first batch products in MakerHub's micro-factory. The university provides benefit to MakerHub through the use of MakerHub's building at a reduced rent.

\section{Data Collection Procedures}

\section{Participant Recruitment}

When I began observations and participation in the fall of 2017, I informed MakerHub employees why I was there and asked if I might occasionally observe their actions and ask questions about them. All employees responded affirmatively and were very willing to accept both my presence in their environment and informal questions. The majority of data collected concerns MakerHub employees; however, I also collected data during a hackathon MakerHub held as well as interviewed non-MakerHub employees. Both hackathon participants and all interviewees I talked to were willing to be part of my data collection.

\section{Data Source and Observation Procedures}

In total, I visited MakerHub more than 160 times and spent over 600 hours there. Most of the hours I spent at MakerHub were between 9 a.m. and 5 p.m. I also went there on Saturdays, as well as before and after the stated hours. My observations began 
September 5, 2017 and continued through March of 2019. For the first several months of observations, I averaged 20 hours a week to saturate myself in the culture, processes and everyday actions of the people at MakerHub.

During this time, I participated in a weekend hackathon at MakerHub; learned how to use the CAD software, Onshape, to make designs for MakerHub's laser cutter that I then cut out; became acquainted with the basics of computer software, using an Arduino microcontroller; and cut foam board using a band-saw. Moreover, MakerHub employees showed me how to weld, make wooden cutting boards, and pan-sear steaks.

While at MakerHub, I attempted to create some value for the company and employees as my presence and questions consumed time from employees' tasks. Therefore, I attempted to engage in projects as a means of gaining deeper insights into MakerHub's processes, creating value for MakerHub, and enabling relationship building with the employees there. I assisted with the creation, development, and analysis of customer surveys that were designed to capture interest in different products MakerHub was working on. I sat in on and participated in meetings which discussed timelines, product features, promotional campaigns, crowdfunding campaigns, and conference details. I accompanied MakerHub employees as they engaged with industry professionals, DIY enthusiasts, and consultants.

At times, my activities at MakerHub were fast-paced and I jotted notes afterward. Other days allowed sufficient time to take notes while there, even clarifying questions about what was said or meant by statements or actions. The research analysis during this period was iterative. I frequently read through my data, writing memos to myself about potential themes that were emerging, and making notes about questions I had. 


\section{Interview Procedures}

I conducted 14 interviews using a semi-structured interview approach (See Appendix A). Of these 14 people, two were employed by MakerHub when I started my observations in the fall of 2017 but no longer work there as both were promoted to other positions within Products Inc. Ten of the interviews were in person and four were over the phone. I interviewed members of the executive team, commercial team (sales, marketing, and social media/brand), product developers (many of whom are mechanical engineers), and design team. I also interviewed the founder of a local non-profit, a maker who collaborated with MakerHub, and a city government official who interacts with MakerHub for various projects and events. In total, I amassed over 380 pages of doublespaced notes and transcripts.

Semi-structured interviews are a conversation between the researcher and the interviewee (Babbie, 2015). The researcher navigates the general direction of the conversations through planned questions, generated to address the study's research questions. However, as the interviewee emphasizes particular points, the conversation may turn to other insightful topics (Haugen, 2015). My semi-structured questions (See Appendix A) revolved around how innovation occurs on day-to-day basis, tensions between types of activities (i.e. community, product development, sales), and the practices and processes which enable and constrain innovation.

Trust and rapport are important components to effective conversations between researchers and interviewees. Through my extensive time spent at MakerHub and the employees' openness to my being there, both trust and rapport were built, which alleviated 
potential timidity, anxiety, or awkwardness during interviews. Lastly, interviews were audio recorded to ensure accuracy.

\section{Data Analysis Procedures}

To analyze the data, I imitated past research using ethnography and causal loop diagramming methodology (Perlow, Okhuysen, \& Repenning, 2002). This approach enabled an in-depth understanding of processes and actions over time and generated "... an explicitly dynamic and feedback-driven model" (Perlow et al., 2002, p. 932), which was important to answer in what ways MakerHub implemented its institutional logics in its organizational design and the benefits derived. The data analysis occurred in several stages. In the first stage, I wrote down observations and notes as I participated in the activities previously mentioned. I transcribed all field notes and observations myself, organizing the data and inputting it into the qualitative software, Atlas.ti. In the second stage, interviews were transcribed with the assistance of an artificial intelligence software. To ensure accuracy, I read through transcriptions while listening to the recordings. I then imported the transcriptions into Atlas.ti.

In the third stage of my analysis, I read through all the material multiple times to saturate myself in the data, "gain(ing) a holistic understanding of the organization" (Milosevic, 2014, p. 45). I also drafted a description of MakerHub, attempting to articulate "what" before engaging in any interpretation of "why" or "how." In the fourth stage, I engaged in descriptive open coding, which consisted of identifying specific occurrences in the data, relating to actions and processes. I then looked for themes around ways in which MakerHub implemented logics into their organizational design, ways in which MakerHub was enabled and constrained in their innovation processes, specific manifestations of logics 
and ways in which logics generated tension, and the mechanisms by which MakerHub engaged with their stakeholders. Thematic analysis involves discerning patterns across data forms, going back and forth between my observation and participation notes, and interviews to create codes as themes emerge.

Coding is critical to discovering themes across participants and data types and has been utilized by institutional logics scholars in past research (Currie \& Spyridonidis, 2016; Thorén, Ågerfalk, \& Rolandsson, 2017; Villani, Greco, \& Phillips, 2017). Following the iterative analysis approach, I used descriptive first-level codes and analytic second-level codes (Tracy, 2012, p. 184). Tracy (2012, p. 184) describes iterative analysis as a "reflexive process in which the researcher visits and revisits the data, connects them to emerging insights, and progressively refines his/her focus and understandings (Srivastava \& Hopwood, 2009).” I generated twenty-two descriptive codes and my end model consisted of nine dimensions derived from the data.

\section{Causal Loop Diagramming Method}

As I coded the data, it became clear that MakerHub's continuous innovation processes were recursive and that MakerHub, designed to be unique, became increasingly similar to Products Inc.'s R\&D Centers. Thus, in the fifth stage of my data analysis, a method enabling a holistic understanding was adopted to explain MakerHub's evolution

and recursive system. To do so, I constructed a dynamic model using the causal loop diagramming methodology (e.g. Sterman, 2000). Causal loop diagramming involves “...follow(ing) an iterative process of identifying links among categories and then returning to the data to confirm or disconfirm the links' existence" (Perlow et al., 2002, p. 934). 
Dynamic models derived from ethnographic data can be useful in studying processes within social systems (Weick, 1979). For example, scholars studied the ways in which role changes within firms can delay benefits from new technology implementation (Black, Carlile, \& Repenning, 2004). Others constructed a dynamic model from ethnographic data to study decision speed in startups (Perlow et al., 2002).

Throughout the analysis process, I referred back to precedent literatures to ensure my findings contribute to scholarship. Further, to check the reliability, relevance, and meaningfulness of my conclusions to practitioners, I discussed findings with various MakerHub employees (Christians \& Carey, 1989; Creswell \& Miller, 2000). This process, generally referred to as member checking, is important to both establish the study's reliability and validity and protect against misinterpretations.

\section{Validity and Reliability}

I followed past research and recommended practices for validating and reliability procedures (Creswell \& Poth, 2017; Milosevic, 2014). These included careful examination of personal biases, member checking, triangulation, and extended immersion in MakerHub's environment.

Extensive participation and observation at MakerHub generated the core of my data collection; however, I also conducted semi-structured interviews intended to triangulate themes, which is critical to reliability: "The triangulation of data sources is critical as it enables

collection of more accurate information and improves the robustness of the resulting findings" (Milosevic, 2014, p. 48). I also engaged in member checking to ensure my interpretations were accurate. These conversations proved invaluable in clarifying and 
nuancing my understanding as well as generating additional insights previously unknown as employees brought up issues relevant to the study. 


\section{FINDINGS}

"I'm concerned we are becoming more and more like Products Inc., which I don't like."

$\sim$ MakerHub

employee

"Why are we wasting so much time and money creating 3D printed prototypes when we could just do renderings?"

former

MakerHub employee

"We don't take big swings anymore. I'm embarrassed we even put that (pointing to a wall listing products) on our wall under current products. That's not innovative!"

$\sim$ MakerHub

employee

\section{Two Product Development Organizations}

At the Products Inc. Corporation, two organizations engage in new product development. The first is a traditional R\&D unit housed within the parent company's walls (Products Inc.). In this traditional R\&D unit, each product line has an internal R\&D team engaged in developing advanced technologies. Product line A has an internal R\&D team A; Product line B has an internal R\&D team B, and so on. Products Inc. executives then determine what technologies are potentially viable and assign New Product Introductions (NPIs) to project managers. The NPI process primarily consists of testing and design and follows a checklist of steps which must occur before the product can launch (e.g. be sold through various sales channels) (2017-10-4_O $)^{2}$. NPIs may discontinue before launch due

${ }^{2}$ (Year-Month-Day: O-Observation, I-Interview) 
to changes in executives' priorities, project managers, design issues, or other testing problems (2017-10-12_O).

The second organization engaged in innovation activities is Product Inc.'s corporate venture makerspace-MakerHub, housed in a separate location less than ten miles from Product Inc.'s headquarters. MakerHub's purpose is to develop innovative technologies, ideate new product ideas, and validate those new products through diverse stakeholder engagement, small batch production, and sales. Although differences exist in both the precise mechanisms of innovating and the scope of stakeholders involved, the overarching function of both organizations is similar: explorative learning activities intended to generate innovative products to increase Products Inc.'s overall profitability. Consequently, each are evaluated based on their success enacting that function, which generate similar centralized decision making norms (2017-12-14_O).

In the table below (See Table 1), grey rows represent similarities between MakerHub and Products Inc.'s R\&D; white sections represent differences between them. As the table demonstrates, both use technology developed internally (either at Products Inc. or MakerHub), and the source for the most radical and innovative products also come from internal sources (Products Inc. engineers, MakerHub engineers). Moreover, MakerHub employees have articulated frustration over slow, centralized decision making, long product development timelines, lack of efficiency, and unnecessary processes, stating such actions remind them of how product development activities are conducted at Products Inc. (2017-10-19_O). At MakerHub, the end goals (explorative innovation) are accomplished primarily by internal knowledge capital (Products Inc. and MakerHub engineers). Thus, to adequately answer the research question-In what ways does 
MakerHub implement its institutional logics into its organizational design and what benefits, if any, does MakerHub derive from its design - answering why an organization with limited resources ends up with two R\&D organizations is important.

Therefore, to answer these questions, we must first understand why Products Inc. created MakerHub and how it was intended to be different. I describe this in the first section of the chapter by discussing how MakerHub was intentionally created to be a distinct organizational form. Once it is clear why it was created and how it was supposed to be different, I then explain how it came to be similar to the R\&D unit in Products Inc. in seven stages: 1) Environmental Forces and MakerHub's Founding, 2) Product 1 and "Can we sell?”, 3) Expanding Customer Segments, 4) Success and Bureaucracy, and 5) Failure and Learning, 6) Identity Crisis, and 7) New Division. I describe each of these phases in order. 
Table 1: Current Similarities (grey) and Differences (white) Between Products Inc. R\&D and MakerHub

\begin{tabular}{|c|c|c|}
\hline & MakerHub & Products Inc. R\&D \\
\hline Stated Purpose & $\begin{array}{l}\text { Quickly ideate, build, and validate } \\
\text { innovative product ideas through } \\
\text { engagement with external makers }\end{array}$ & $\begin{array}{l}\text { - Produce innovative technology relevant } \\
\text { to product lines }\end{array}$ \\
\hline Actual Purpose & $\begin{array}{l}\text { Develop innovation technology } \\
\text { - Build, design, and validate new } \\
\text { product ideas }\end{array}$ & $\begin{array}{l}\text { - Develop innovative technology that } \\
\text { could eventually go into new products }\end{array}$ \\
\hline $\begin{array}{l}\text { Product } \\
\text { Development } \\
\text { Timeline } \\
\end{array}$ & $\begin{array}{l}\text { - "We aren't fast enough!" } \\
\text { - "The process is inefficient and too } \\
\text { long" }\end{array}$ & $\begin{array}{l}\text { - "It can take years for a product to see the } \\
\text { light" }\end{array}$ \\
\hline $\begin{array}{l}\text { Source of } \\
\text { Product } \\
\text { Technology }\end{array}$ & - Products Inc., MakerHub & - Products Inc., MakerHub \\
\hline $\begin{array}{l}\text { Primary source } \\
\text { for viable and } \\
\text { innovative } \\
\text { product ideas }\end{array}$ & $\begin{array}{l}\text { - Products Inc. engineers, MakerHub } \\
\text { employees }\end{array}$ & - Products Inc. executives or engineers \\
\hline $\begin{array}{l}\text { Engineering } \\
\text { Technical Scope }\end{array}$ & $\begin{array}{l}\text { Analyze technical feasibility of new } \\
\text { technology, develop/adopt new } \\
\text { technology, stress test new } \\
\text { technology, }\end{array}$ & $\begin{array}{l}\text { Analyze technical feasibility of new } \\
\text { technology, develop new technology, } \\
\text { stress test new technology }\end{array}$ \\
\hline $\begin{array}{l}\text { Decision } \\
\text { Making }\end{array}$ & $\begin{array}{l}\text { - Managers decide what moves forward } \\
\text { - Cost driving product development } \\
\text { decisions } \\
\text { - Before moving the project forward to } \\
\text { market validation, leadership asked } \\
\text { for cost-benefit analysis. } \\
\text { - } \text { MakerHub] is becoming stifled with } \\
\text { "more centralized leadership making } \\
\text { that emphasizes profits" }\end{array}$ & $\begin{array}{l}\text { Project managers decide what moves } \\
\text { forward and what does not. } \\
\text { Engineer related a time he worked for } \\
\text { months on a project that was eventually } \\
\text { discontinued when a new project } \\
\text { manager came in. } \\
\text { - Former CEO concerned project } \\
\text { managers were not developing } \\
\text { innovative enough products }\end{array}$ \\
\hline $\begin{array}{l}\text { Source of } \\
\text { Legitimacy }\end{array}$ & $\begin{array}{l}\text { - Technology's innovativeness } \\
\text { - Organizational profitability }\end{array}$ & $\begin{array}{l}\text { - } \quad \text { Profitability } \\
\text { - Technology's innovativeness }\end{array}$ \\
\hline $\begin{array}{l}\text { Practices/Materi } \\
\text { al/ } \\
\text { Structures }\end{array}$ & $\begin{array}{l}\text { Daily meetings, scheduled work } \\
\text { hours, outcome reports, product } \\
\text { deadlines/Gantt Charts, Products Inc. } \\
\text { training meetings, end-of-year } \\
\text { evaluations, 5S }\end{array}$ & $\begin{array}{l}\text { Daily meetings, scheduled work hours, } \\
\text { outcome reports, product deadlines/Gantt } \\
\text { Charts, Products Inc. training meetings, } \\
\text { end-of-year evaluations }\end{array}$ \\
\hline $\begin{array}{l}\text { Physical } \\
\text { Environment }\end{array}$ & $\begin{array}{l}\text { - Open environment-anyone can walk } \\
\text { in } \\
\text { - Located on edge of college campus } \\
\text { - Makerspace with tools available to } \\
\text { anyone }\end{array}$ & 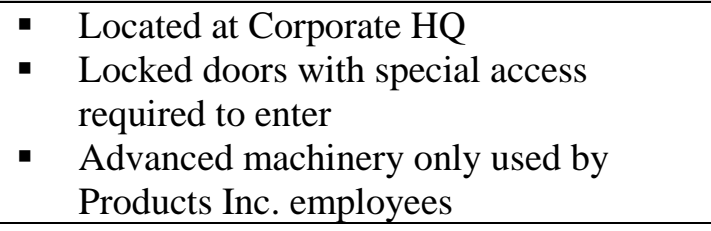 \\
\hline Cognitive Scope & $\begin{array}{l}\text { Employees can explore/ideate } \\
\text { products related to small or large } \\
\text { home appliances }\end{array}$ & $\begin{array}{l}\text { - Explore technology that could potentially } \\
\text { be used in large appliances related to the } \\
\text { specific product line in which they work }\end{array}$ \\
\hline
\end{tabular}




\begin{tabular}{|l|l|l|}
\hline & \multicolumn{1}{|l|}{$\begin{array}{l}\text { Focus on products easily incorporated } \\
\text { into Products Inc. manufacturing lines } \\
\text { OR on products small enough to be } \\
\text { shipped via FedEx directly to } \\
\text { consumers. }\end{array}$} \\
\hline $\begin{array}{l}\text { Stakeholder } \\
\text { Access }\end{array}$ & $\begin{array}{l}\text { Have access to makers, culinary } \\
\text { enthusiasts, first adopters, consumers, } \\
\text { Products Inc., and other interested } \\
\text { parties (local and regional politicians, } \\
\text { non-profits, startups, corporations, } \\
\text { universities) }\end{array}$ & - Products Inc. \\
\hline Level of & - "You never know who will walk in... \\
Formality & - $\begin{array}{l}\text { That's exciting!" } \\
\text { "Coolest place I'll ever work" }\end{array}$ & - Formal working environment \\
\hline
\end{tabular}

*Similarities (shaded grey) and Differences (shaded white) between Products Inc. R\&D and MakerHub 
Phase 1: Environmental Forces and MakerHub's Founding

MakerHub's mission was to ideate, prototype, and validate never-seen-before technologies and products (2017-9-14_O). MakerHub would accomplish its mission through shortening the idea-to-product cycle by soliciting makers, enthusiasts, and potential customers for product ideas, feedback on proposed products, and testing minimum viable products, which would lead to more feedback and further testing (20179-22_O).

When MakerHub was founded, the key parts still different from the R\&D unit today were made to be intentionally different (See Table 1). I describe those key parts below. However, there were also parts which were intended to be different but are no longer different. I will describe each of these as well.

Physical Environment. Product Inc. founded MakerHub with a distinct organizational design (separate from itself) in several ways. First, MakerHub was founded to be unique by being physically distinct from Products Inc. The term physical environment represents the idea of tangible and aesthetic characteristics, which includes 1) geographic location (located on a university campus and geographically separate from Products Inc.'s corporate campus), 2) ease of building access (unlocked, open to anyone), 3) aesthetic distinctness (open layout), and 4) availability of tools, machines, and areas to prototype (makerspace, micro-factory).

MakerHub's physical environment is in stark contrast to Products Inc.'s corporate campus (2017-9-22_O). Whereas MakerHub is on the edge of a college campus, easily accessible with a parking lot mere feet from the door, Products Inc. has gates with a security guard; visitors have to sign in, and all employees walk through turnstiles to access 
the various buildings. MakerHub was intentionally designed to be physically distinct and geographically separate from Products Inc. MakerHub's leadership wanted to foster creativity and thought the environment's openness and accessibility would be welcoming to makers and enthusiasts, generating increased engagement. However, these desires were only partially realized.

The physical layout of MakerHub consists of four primary sections; each serves a specific function. The first section contains two industrial kitchens and a number of workstations primarily used by the commercial team and office manager. This space also contains an area for meals and presentations and is used on a weekly basis for meetings with all MakerHub employees present. Moreover, the space is used for interviews for prospective interns or employees, conversations with interested news organizations, and impromptu meetings between employees. In addition to the practical function, this section also serves a symbolic function as the section contains a number of MakerHub products as well as community developed prototypes, providing visitors tangible evidence of MakerHub's output.

The second section is the makerspace, consisting of two floors. The majority of engineers sit at workbenches in the middle of the lower level while the software engineers, designer, and social media manager sit on the upper level. The makerspace contains several 3D printers, a number of hand tools, a laser cutter, soldering stations, white boards, workbenches, and several computer stations with CAD software. A second meeting place is located off to the side with a large table, chairs, two whiteboards, and a TV to mirror computer screens. Unlike Products Inc.'s locked R\&D centers, the makerspace offers a collaborative environment open to guests. MakerHub constructed the makerspace to 
encourage prototyping and building; however, the space is primarily used by MakerHub employees or university students.

The third section is the workshop where many parts are machined. This section is accessible only by a key card and people must wear protective eyewear to enter. This space houses fifty machines, including band saws, lathes, mills, a water jet, table saw, joiner, planer, sander, belt sander, surface grinder, and other machines and tools. This area also contains shelves stacked with different types of wood. The workshop is a critical part of MakerHub's prototyping process as MakerHub engineers require customized components for product development.

Adjacent to the workshop is the fourth section, the micro-factory, where many of the initial production batches are assembled. Long workstations are designed so that student workers and interns can assemble production units that have been sold. This section also contains a storage area, loading dock, and several testing areas for product testing. Products Inc.'s manufacturing capabilities are designed for large batch production to maximize efficiency and lower per unit costs. For MakerHub to manufacture tens or even hundreds of units at Products Inc. would be an inefficient use of resources. Thus, MakerHub's own manufacturing capabilities are cost-effective.

Cognitive Scope. The second way in which Products Inc. founded MakerHub as unique was by giving its employees expanded mental space concerning product ideas, what I am calling cognitive scope. Whereas Products Inc.'s R\&D teams each have a defined product line focusing and constraining their cognitive scope, MakerHub employees' cognitive scope extends to all product lines, including both large and small appliances. A key distinction between the cognitive scope at Products Inc. and MakerHub is the frequency of 
making, experimenting, and employee autonomy - the ability for employees to work on projects they find intrinsically interesting. When MakerHub was founded, the leadership emphasized the importance of employees working on projects they were passionate about, arguing that focused passion would enable more creative thinking and commitment to a project. Of MakerHub's founding director, one former employee remembered:

[The founding director] was a rare leader in which he wanted everybody to explore the thing they were most passionate about. His theory was we've hired really good people, and if they're on some sort of vein like let him mine it. And you know if there's some way that they can find greatness in the thing you are searching for, then awesome. And I think that was very enabling with [Founding director]. (2018-12-12_I)

The makerspace environment and openness of MakerHub convey a creative space for passionate people and are conducive to having impromptu conversations about product ideas, mechanical explanations of "how things work" between engineers, or in some cases just prototyping an idea (2017-9-14_O). While giving a tour to undergraduate students, a senior member of the commercial team remarked that MakerHub often generates product ideas through normal daily conversations between employees asking, "What about this?" (2019-1-31_O). Products Inc. units also hold meetings, day-long trainings, and events at MakerHub with the primary intent of spurring creative thinking.

Relational Access. Third, MakerHub was unique because its employees were empowered with increased access to diverse stakeholders. The term relational scope represents this idea of diverse stakeholder access. Whereas Products Inc. R\&D engineers primarily interact with executive management, product line project managers, and other engineers in the R\&D field, MakerHub employees interact with makers, culinary enthusiasts, first adopters, consumers, Products Inc. engineers, and other interested parties (local and regional politicians, non-profits, startups, corporations, universities, and news outlets). 
A significant assumption in the founding of MakerHub was that smart and creative people desire to develop innovative products and associate with a place where ideas could be iterated, prototyped, and potentially launched: "when we talked about community we were mostly talking about a group of people that would be like minded individuals who would want to tinker on new appliances ideas with us" (2018-12-17_I). MakerHub was an attempt at capturing some of this brain power while also being a consumer-facing and community-facing mechanism intended to create goodwill. Consequently, creating buy-in from many in the community was critical to MakerHub's ability to accomplish this relational goal.

MakerHub's founding was celebrated by many different stakeholders, enabling potential opportunities for engagement. Excited stakeholders included makers, startups, nonprofits, local and state governments, and a large state university on whose campus MakerHub currently resides. Each stakeholder group viewed MakerHub as a positive factor in their own mission, whether that be developing local entrepreneurial ecosystems, being a resource to pre-stage startups building prototypes, attracting engineering and design students, or claiming to be innovative through the creation of an entrepreneurial environment.

To foster community engagement, corporate leadership determined MakerHub must not only look and act distinct from the large, intimidating, corporate environment of Products Inc. but also provide employees leeway to engage the outside community, including makers, enthusiasts (first adopters, amateur chefs etc.), or potential consumers. Consequently, MakerHub employees were encouraged to engage community members both inside and outside MakerHub's physical building. And the building itself was 
designed to inspire outside community to come into MakerHub. Whereas Products Inc. requires all visitors check in at a security hut before entering through turnstile gates, MakerHub often has individuals walk in unexpectedly, desiring to use machines, tools, or take a tour.

a. Tours: Distinct from Products Inc., MakerHub engages with the community internally in several ways, including tours and hackathons. Tours of MakerHub's facility are a practical way for community to "see what MakerHub is all about." Tours range anywhere from twenty minutes to over an hour, pending on schedule constraints, which employee gives the tour, and for whom the tour is given. In fact, I once gave a tour when MakerHub was short-handed (2018-9-10_O). MakerHub tours consist of three distinct parts: first, an overview and the purpose of MakerHub and its relationship with Products Inc. is discussed; second, the tour guide provides examples of past and current products; and third, he or she showcases the equipment and machines available for both MakerHub employees and anyone from the community.

MakerHub tours were also designed to create a sense of community and do so in a number of ways. First, most full-time MakerHub employees give tours, including all members of the executive team down to more recent hires, providing opportunities for employees to articulate the purpose of MakerHub to diverse groups. Second, tours are a means of showcasing products under development as well as those developed through hackathons (braille stove top), by community members (laundry application for seeing impaired), or failed prototypes (cold brew coffee maker). Tours showcase these various products and are a means of talking about the engagement MakerHub has with its various community members. Third, tours are an easy means of collecting visceral feedback about 
products under development. Often senior management will ask those on tours what they think about various products, wanting to gain ideas or confirmation about what MakerHub is developing. Asking for feedback provides a sense of participation by those taking a tour, further establishing relational connections.

b. Hackathons: Hackathons share a dual purpose as they develop community relationships and new product ideas. Hackathons generate diverse perspectives and engage both potential entrepreneurs with new product ideas as well as validate customer and product segments. Hackathons have grown from dozens to over a couple hundred participants. For example, in 2018, MakerHub hosted a two-day hackathon that included over 200 participants.

In the past, hackathons have also been a means of local non-profits engaging with MakerHub on social-impact projects. For example, MakerHub's first hackathon was in partnership with a local non-profit that focuses on water purification mechanisms for third world countries (2019-1-23_I). The hackathon centered on different purification solutions to turn undrinkable water into drinkable water. More recently, a local government entity and MakerHub's management are discussing a civic hackathon focused on local community problems.

c. External Engagement: Although MakerHub is successful in attracting diverse visitor groups ${ }^{3}$, they also emphasize getting out into the community—both locally and nationally (2018-7-9_0). One way MakerHub accomplishes this is by embracing the maker

\footnotetext{
${ }^{3}$ Interested visitors come to learn about how MakerHub innovates, see the physical space, and ask questions about ways to imitate MakerHub's processes. Visitors include consultants from top national and international firms, local and regional politicians, CEOs and other executives from Fortune 500 companies, professors from Top 20 business schools, and journalists and media from national outlets.
} 
culture. MakerFaire is an organization that celebrates makers and making. The organization helps local communities launch events that attract participants from local makerspaces, companies, non-profits, makers, and regional high school and college students. MakerHub has participated in the local MakerFaire for several years and even hosted the event in 2018. While a hackathon went on inside MakerHub, a MakerFaire was hosted outside its building in the parking lot drawing over 3,000 people (2018-9-16_O). Although events like MakerFaire are successful, MakerHub has been less successful in attracting makers into the building to work on long-term projects. However, MakerHub has been extremely successful engaging culinary enthusiasts such as local chefs (2018-2-14_O).

MakerHub engineers are particularly good at engaging culinary experts. For example, in late 2017, MakerHub engineers were investigating the viability and desirability of a product targeting grilling enthusiasts. A lead engineer on the project reached out to a local butcher to gain advice and suggestions on both the process and expected outcomes such as what the meat should look like, how it should taste, potential problems to avoid, and best practices for storage and cleanliness. I accompanied three other MakerHub employees to the butcher shop and we toured their facilities (2017-11-3_O).

MakerHub successfully generated excitement among many diverse stakeholders within the community (2018-8-29_O). Moreover, MakerHub engineers often interact with culinary experts to gauge product quality or functionality. However, MakerHub's assumptions concerning sustained participation by makers, both locally and digitally, have not been fully realized, which has led to a recent effort to increase the quality of external engagements (e.g. increased interactions) rather than quantity (2018-11-30_I). 
Level of Formality. Fourth, MakerHub was also founded to be unique because of its low level of formality. MakerHub leadership believed a low level of formality would enable greater external input (more outsiders would engage in the ideation, prototyping, design, and selling processes). A low level of formality is demonstrated through MakerHub's emphasis on casual dress (most employees wear jeans and t-shirts), frequent laughter, informal manager-employee relationships, loud music, and coffee shop type atmosphereall much more informal than Products Inc.'s (2018-2-19_O). Processes, rules, and symbolic norms also embody specific logics. In an effort to be different from Products Inc., MakerHub embraced numerous anti-corporate routines and norms to create meaningful separation between itself and Products Inc. Such actions include: 1) open access to the building and makerspace, 2) casually dressed employees intended to enable outsiders to feel comfortable coming into the space, 3) loud, popular music played throughout the facility, giving a non-corporate, coffee shop feel to the environment, 4) using signs made on MakerHub's laser printers and shop bots, articulating the rules that connotes the impression outsiders are not only welcome but wanted, and 5) free use of makerspace tools including 3D printers, laser cutter, hand tools, soldering stations, CAD software, workbenches, and gourmet coffee.

MakerHub's efforts to create an informal culture welcoming to visitors worked. I have observed hundreds of visitors via tours, hackathons, and events. Their reactions often reflect surprise over the makerspace's size and workshop's capabilities; interest over the types of products MakerHub has developed and is developing; and enjoyment of the popular music, gourmet coffee, relaxed environment, and friendly employees (2018-9$\left.15 \_0\right)$. 
MakerHub Founding Logics. In its founding phase, MakerHub exhibited distinctly different logics than the traditional corporate or professional logic used to describe Products Inc., demonstrated by creating a physically distinct, open environment conducive to enabling and encouraging employees to think creativity and in untraditional ways. MakerHub's founding logics were further differentiated by leadership's focus on creating relational access, engaging community both inside and outside MakerHub. Lastly, MakerHub attempted to also separate from Products Inc.'s logics by creating informal social norms, which include loud music, gourmet coffee, open workspace, most employees wear t-shirt and jeans, frequent laughter, impromptu cooking tutorials between employees, and a flat social hierarchy (frequent and casual interaction between senior and junior staff). I contend these practices, norms, and symbols suggest a different type of logic, a startup logic.

\section{MakerHub's Founding Assumptions}

MakerHub was founded with two fundamental assumptions. The first assumption was that MakerHub could engage in a quicker, more creative, new product idea validation process than Products Inc.'s traditional process by being both unique (e.g. physical environment, cognitive scope, relational access, and level of formality) and capable of ideating, building, designing, testing, and small-batch manufacturing new product ideas. MakerHub's second founding assumption was that external inputs (ideas, time, labor, skills) from makers, enthusiasts, and potential consumers, would foster creative product ideas, and assist with the building and designing of prototypes, further increasing the level of product innovativeness. The goal was to develop innovative products quickly in order to validate if there was a market for the product idea (profitable), a market for something 
close to the product idea to which they could pivot (potentially profitable), or no market for the product idea (not profitable).

I examine these assumptions as they emerge through two key innovation processes: 1) Active Builds, and 2) Product Market Validation. An Active Build refers to the ideation, prototyping, and design of a product. Product 1 and any accessory products (accessory products are any products which are developed as part of or in addition to the initial product) represents one active build. Product 2 (and any accessory products) represents a second active build and so on. Product Market Validation refers to the number of customers buying products. MakerHub leadership believed that they would be able to keep introducing new builds as long as there was a general trend of validation of those builds over time, a self-reinforcing, positive feedback loop (R1, See Figure 1). A self-reinforcing loop is an unchecked, positive feedback loop which, left unchecked, can lead to exponential growth. Exponential growth did not occur as loops, which I will introduce later in this chapter, constrained this process. However, Product 1's Build—Product Market Validation process occurred largely as expected.

Figure 1: The Build-and-Validate Reinforcing Loop (R1)

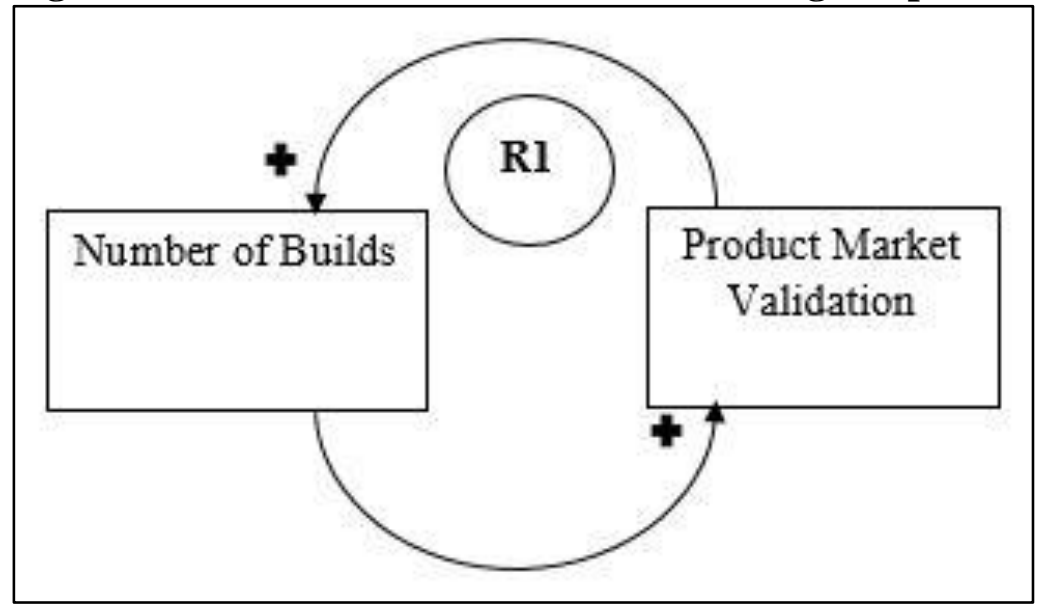


Phase 2: Product 1 and "Can we sell?"

Key Events: As depicted in Figure 1, MakerHub employees believed that product development would occur through a process of building and validating. Therefore, they began by trying to come up with a build that they could use to begin the process. One of the initial engineers knew of a technology within Products Inc. that had not been built yet that would enable "dumb appliances" to be reprogrammed to become "smart appliances." Product 1 was designed as an add-on that required intermediate programming knowledge and was targeted to the DIY community—-particularly makers interested in hacking their home appliances. One employee at the time related,

So a project that we were working on early was [Product 1]. . [MakerHub engineer] had been looking around for ways that we could reach out to community and he found out there was a conference ... hosted by Make Magazine in San Francisco. And so he told me we should sign up for it. So [founding MakerHub director] said, 'you're going to go out and speak at this thing.' And when we did, we said 'we gotta have something to say.' So we had been working on developing [Product 1], and we decided to launch it coincident with that conference. . . . The Maker culture really latched onto the idea that [Products Inc.] was interested in that (hacking). . . And we sold a lot of those things ... I got on stage and talked about the thing, and then we had a little chat with Make Magazine. And we sold like . . . 50 in a day and 100 in a week, which was for us like crazy. (2018-1217_I)

MakerHub's leadership interpreted Product 1's success as evidence makers and enthusiasts were willing to engage with MakerHub and willing to spend time hacking appliances, despite MakerHub's ties to a large corporation. Again, the same employee noted,

If we're being honest, . . . most people who are involved in open source don't think of big corporations as their friends. So that (success of Product 1) was an early indicator that we [...] were doing things different. And the people who are most likely to want to come out and purchase one of those were the exact people that you would want to target for this thing because they're dedicated beyond just being like a weekend warrior and they're like, 
'Oh I'm actually gonna sit down and write some code for my appliances.' So to get 300 people like that on board early on is actually a big deal. (201812-17_I)

Although makers were uninvolved in the ideation or prototyping of Product 1, MakerHub leadership believed Product 1 confirmed MakerHub's ability to engage makers and sell new products, increasing its market validation. The building and validation of Product 1 led to activities that would culminate into the development of Product 2, such that validation motivated more builds and more builds motivated more validation. This selfreinforcing, positive feedback loop occurred with MakerHub as the success of Product 1 quickly led to the continued development of Product 2 (the second build).

\section{Summary: Affirming R1's Process}

MakerHub's initial product targeted the type of people MakerHub wished to develop long-term relationships with—namely, makers. Moreover, Product 1's successful market validation generated a second active build. Thus, the belief that product development would occur through a process of building and validating was further solidified through R1's successful verification.

\section{Phase 3: Expanding Customer Segments}

Having validated the first product and verified the development process, MakerHub employees then began developing Product 2. Product 2 incorporated precision temperature technology in a single stovetop and probe. This system enables liquids to be kept at a constant temperature. The stovetop provided the heat, and the probe measured the liquid's temperature, fostering greater control. For example, Product 2 allowed for individuals to cook steaks via Sues Vide (in a pot of water on a stove), allowing users to cook steaks to the desired internal temperature. 
Figure 2: Expanding its Target Market Reinforcing Loop (R2)

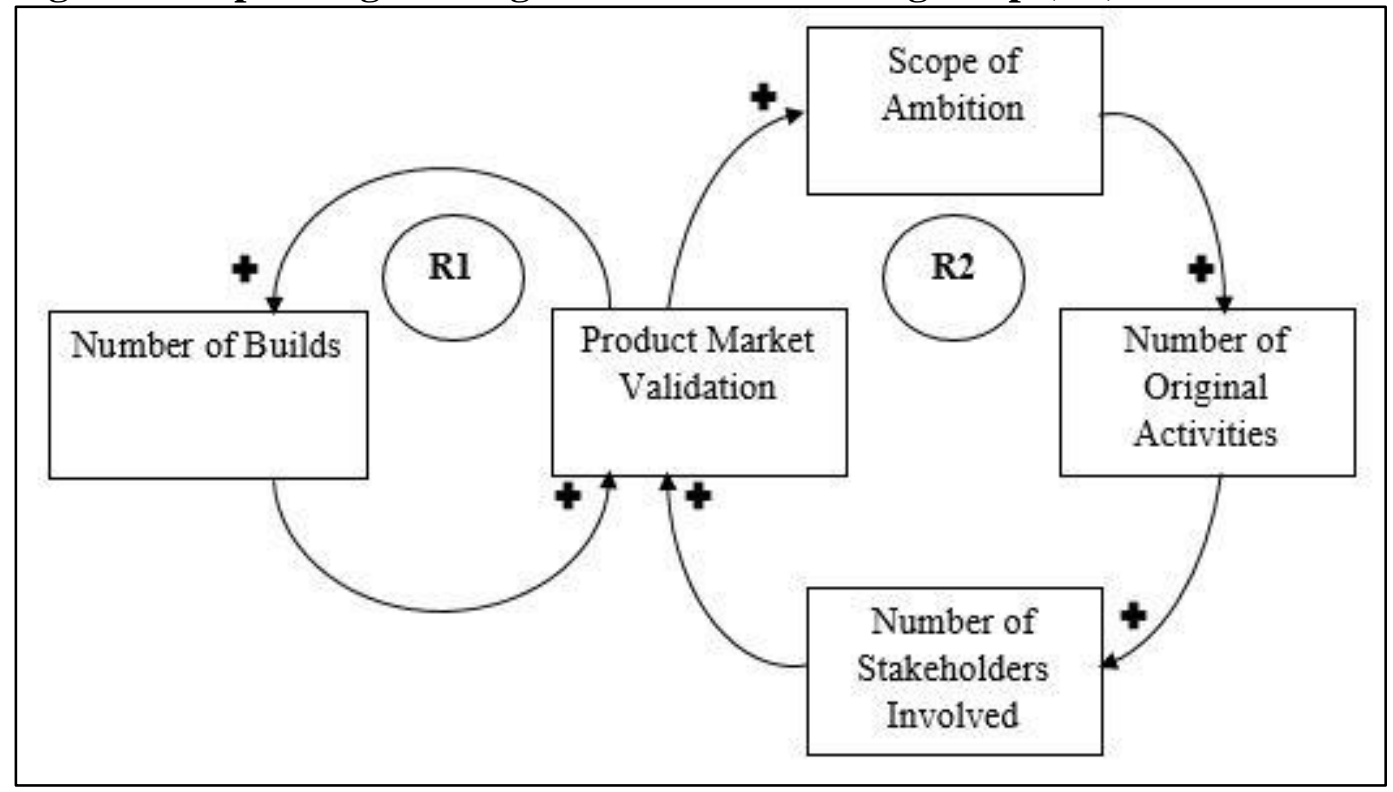

The level of Product 1's success and market validation led to additional builds and further product market validation activities as well as increased the Scope of Ambition for Product 2 (See Figure 2). Scope of Ambition refers to how ambitious the organization is becoming, which can include ambition relating to 1) how uncertain a product's market is, 2) the number of external stakeholders involved in the product's ideation, prototyping, or design, or 3) the size of the market the organization is trying to capture with the product. Product 2 suggested a greater scope for MakerHub's ambition because Product 2 incorporated more market uncertainty (e.g. dissimilar from existing products and more expensive ${ }^{4}$, increased the number of stakeholders involved (e.g. design challenge, YouTube, news outlets), explored a different validation strategy (Indie GoGo), and was targeted toward a larger consumer market (home chefs and culinary enthusiasts) ${ }^{5}$.

4Product 2's MSRP was $\$ 179$, significantly higher than Product 1's price-point of $\$ 20$. ${ }^{5}$ Product 2 required no coding and was targeted primarily to culinary enthusiasts who desired precise control of cooking. 
An increase in MakerHub's scope of ambition for Product 2 is further evidenced by an increase in the number of organizational activities, which refers to the number of activities related to the ideation, prototyping, design, and validation of a product. When the efforts to market and launch Product 1 succeeded, MakerHub management duplicated many of those same strategies for Product 2. However, MakerHub also increased the number of activities, particularly around sales and marketing; they conducted a design challenge, launched and wrote copy for their crowdfunding campaign, produced videos demonstrating how Product 2 worked, and increased overall advertising spending. Launching a crowdfunding campaign through Indie GoGo was an attractive option because manufacturing costs could be covered by pre-orders, rather than generating up front cost through manufacturing units and then trying to sell those units.

The increase in organizational activities subsequently increased the number of stakeholders involved, which refers to the number of stakeholders involved in the ideation, prototyping, design, and validation of a product. Stakeholders included the design challenge participants, news outlets such as the New York Times, and over 2,000 crowdfunding campaign contributors, generating over $\$ 350,000$. In addition to growing consumer awareness, MakerHub attempted to use their community—both local community and online community — through creating a design challenge, in which multiple individuals submit design ideas to MakerHub, and the first, second, and third place finishers received some type of remuneration. MakerHub's design team incorporated aspects of each finalists' designs in Product 2's design.

Reinforcing Loop (R2). MakerHub's crowdfunding campaign was successful in that they reached the required goal to continue on with the manufacturing and producing of Product 
2. MakerHub's leadership interpreted Product 2's success as evidence MakerHub could sell to both makers and culinary enthusiasts. While Product 2 did not sell as many units as hoped, successfully launching a crowdfunding campaign — particularly on their first attempt — was a significant milestone in justifying MakerHub's commitment to small batch, quick product development (2018-12-17_I). Moreover, the successful crowdfunding campaign led to further validating Product 2's potential by meeting the crowdfunding goal via generating actual sales, an important step in the overall validation process (Blank \& Dorf, 2012). This process generates a second self-reinforcing feedback loop (R2, See Figure 2), motivating both MakerHub and benefited stakeholders to additional active builds and further market validation activities.

As noted earlier, MakerHub's positive R1 feedback loop did not grow exponentially. The overall lack of non-employee engagement with Product 2 partially tested MakerHub's assumption about the "tinkering" role non-employees would play in product development. This assumption began to evolve as external inputs for Product 2 were primarily aesthetic and had little impact on ideation or technical development. Although makers and enthusiasts were excited about MakerHub, its mission, and the type of product development occurring, the design challenge was the most significant contribution by anyone outside of MakerHub. One employee described the change in thinking:

In the beginning, we had the hypothesis that community was going to be a group of people that were kind of a jack of all trades. They were people that were enthusiasts that were also makers that would be people that we could collaborate with that would develop product with us. And then eventually we'll make prototype to be something that they purchase. So we found that's not broadly true. Within a large swath of the population there are (only) a few people that are similar to that, people that are so passionate about something that they'll carry it all the way through. (2018-11-30) 
Summary. Product 2's development and launch suggests tension between startup, corporate, and community logics. Launching a design challenged proved an effective and efficient way to engage external aesthetic input (corporate logic) while also maintaining the organizational identity of corporate venture makerspace - an organization intent on cocreating (engaging external input in the development process). However, Product 2 expanded MakerHub's target market from maker to culinary enthusiast, increased advertising spending, and utilized free marketing channels (corporate logic).

Phase 4: Success and Bureaucracy

During phase 4, several negative balancing feedback loops emerged (B1, B2, \& B3). Balancing feedback loops stabilize a system through tension, preventing the system from collapse or exponential growth. These loops arise from the addition of two new dimensions in the model: Awareness of Execution Problems and Bureaucracy. I define awareness of execution problems as the extent to which individuals (both internal and external to MakerHub) are cognizant of issues surrounding a product's development, design, or delivery. I define bureaucracy as the extent to which an organization implements formal rules or protocols (See Figure 3). Below, I discuss Product 3's process through R2. I then highlight the challenges which arose, generating each of the negative balancing feedback loops (B1, B2, \& B3). 


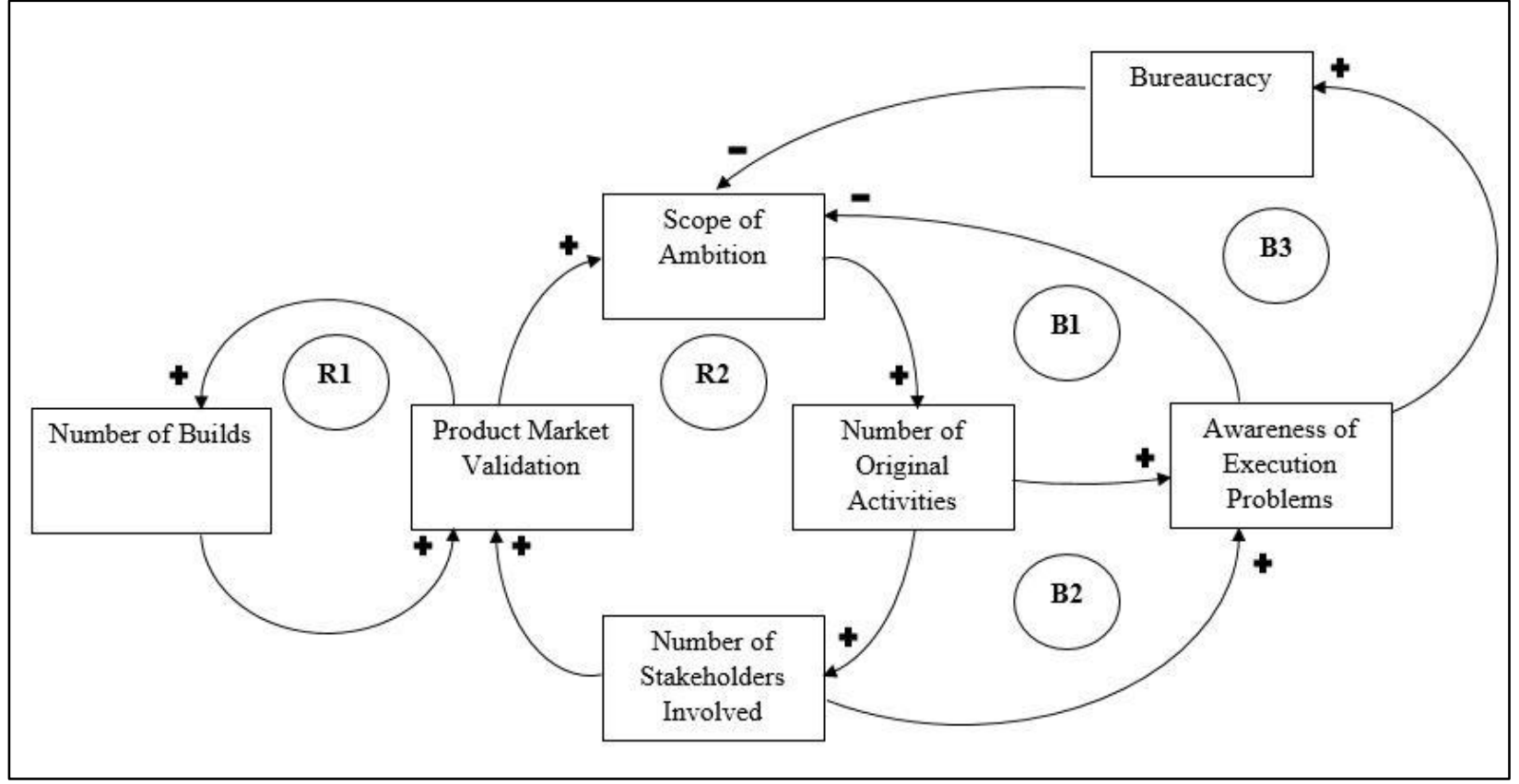

Product 3 revolved around a product idea already available in large units to commercial buyers but unavailable to the residential market. The technology and idea for this product came from Products Inc. engineers who wanted to incorporate the product's function into a kitchen appliance unit; however, the idea received pushback and the initiative stalled. When MakerHub was founded, those engineers saw a potential outlet to make their idea a reality; MakerHub developed the idea into a stand-alone, counter top product (Product 3). (2017-12-15_O)

Product 3 through R2. Similar to Product 2, MakerHub launched an Indie GoGo crowdfunding campaign and utilized past marketing strategies and channels to create excitement among first adopters and technology enthusiasts, including activities such as conferences in which to showcase the product and talk with news outlets. However, Product 2's success also led to an increase in scope of ambition for Product 3. Product 3's MSRP was over $\$ 500$ and was not targeted to makers. With Product 3, MakerHub was testing a different consumer market. 
Product 3 also led to a significant increase in original activities. MakerHub spent money for ads on Facebook, adopted a more effective pricing strategy, traveled to New York City to promote the product and generate excitement among different demographics, launched a website to gage interest, and continued to develop consumer excitement through emails and website promotions. The amount spent on advertising and marketing also dramatically increased for Product 3, which also led to an increase in the number of stakeholders involved. One former executive related the marketing strategy and its impact on Product 3's overall success:

The other thing that's different is we really doubled down on a new channel for generating leads. So all of the leads for [Product 2] were generated through people that we happen to know, people who walked through the doors, channels that we had access to. So, I'll give you one random example. [Products Inc.] had a publication that they put out for investors and other people who are associated with [Products Inc.]. We got interviewed by them and got out in front of them. Any channel that we could access that was free for us. We got in front of [Products Inc.'s] newsletter for Product 3 and media. For [Product 3], we weren't as nervous about putting a little bit of money behind it because now we'd seen that it was a channel that could work for us. So we did all of the free channels plus we turned on the ads. And that was a huge thing for us to overcome because ads tend to be pretty expensive to run. We had run seven thousand dollars worth of ads on the [Product 2] campaign actually on YouTube of all places, and it resulted in like five sales maybe something like that. . We didn't really go very deep into ads on the [Products 2] campaign. . . Seven thousand dollars sounded like just an outrageously high number for us to spend for ads. . . We were hoping to see "oh, seven thousand dollars and you sell another 300 or 400 units," and we sold three or four. But [a newly hired sales member] actually came in and said no we really didn't do ads and so he actually ran the ad campaign for Product 3's campaign. And that really ended up being the thing that made him throw it to (millions of dollars). Without that [...] it wouldn't have been anywhere near as big as it was. I don't think our ad spend was particularly efficient, but it was really important for us to do it because it created a business that otherwise probably wouldn't exist. (2018-12-17_I)

The increase in resources allocated toward marketing was so significant that according to the marketing manager at the time of Product 3's launch, the Products Inc. executive 
overseeing MakerHub called often, "freaking out" over the amount being spent on marketing activities. (2018-12-12_I)

Challenges and Balancing Loops. MakerHub also experienced a number of challenges with Product 3. First, while the engineers figured out the technical side of developing the product as a stand-alone unit that could sit on a countertop, reliability, durability, and size were all problems yet to be solved. Once the engineers felt certain they could solve those problems, management told the commercial team to start the crowdfunding campaign even though the end design and technology were incomplete. When the crowdfunding campaign was wildly successful, the engineers were under significant pressure to not only deliver the product as described but also to deliver on time (2017-11-29_O). One former MakerHub employee remembered, "Whenever [Product 3] was going on, it was $\mathrm{f}^{* * * i n g}$ chaos. . . Everyone was freaking out" (2018-12-12_I). MakerHub's increase in activities increased the awareness of execution problems. Further, an increase in awareness of execution problems combined with the promise to customers of a certain delivery date resulted in a sense of heightened pressure. An employee at the time viscerally remembered the chaos and stress saying, "If we do another crowdfunding campaign, I'm quitting." The increase in awareness of execution problems coupled with the desire not to repeat the same level of chaos which ensued generates a negative balancing feedback loop (B1 in Figure 3)

MakerHub's first challenge also generated a second negative balancing feedback loop (B2 in Figure 4) as an increase in stakeholders exacerbated execution problems. Product 3 ended up being shipped over several months later than promised in the campaign. The delay resulted in upset customers and hundreds of emails from people asking about the delivery date of their purchase. Commercial team members whose jobs were to explore 
sales channels and develop marketing strategies were now responsible for customer questions, which subsequently led to developing standard protocols for how to respond in emails, what could or could not be said, and how refunds were processed. One commercial manager said, "I was responding to over 120 emails a day for weeks" (2017-11-30_O). The increase in organizational activities, particularly the increase in advertising and marketing spending, had the intended effect of raising Product 3's visibility; however, when Product 3 was delayed, the increase in visibility also meant an increased awareness of execution problems by external stakeholders (consumers, suppliers, or those following the crowdfunding campaign). This dynamic generates a second negative balancing feedback loop (B2 in Figure 3).

A second challenge MakerHub experienced with Product 3-generating B3-was that once the product was shipped, MakerHub's commercial team and product engineers were ill prepared for the customer service aspect of selling a highly successful product. These included angry customers who had broken units, confused customers who did not understand how something worked and needed someone to walk them through it, ecstatic customers sending congratulatory emails, and many other emails and phone calls for various reasons. Additional protocols were developed for broken units, repairs, or replacing units. Customers were directed to follow a standard procedure that included taking pictures of the unit and emailing those pictures to a specific email address. The awareness of execution problems prompted MakerHub leadership to develop protocols to better handle reoccurring complaints and issues, which increased MakerHub's overall level of bureaucracy. As defined earlier, bureaucracy represents formal rules and protocols an organization puts into place. As more issues were uncovered, protocols were developed. 
Handling customer complaints, product repairs, or other related issues were not MakerHub's original intent. This dynamic generates a third negative balancing feedback loop (B3 in Figure 3).

A third challenge MakerHub experienced with Product 3 was the impact success had on future products. Given Product 3's success, consumers wanted and suggested addons. One consumer hacked an add-on and sent a picture to the engineering team who thought they could develop and produce the idea relatively easily. Subsequent to the initial product, a number of add-on products were developed and sold. These add-on products were incremental innovations, "not the kind of innovations MakerHub was intended to produce" (2019-2-19_O). To better maximize both Product 3's profitability and accessory product development, MakerHub restructured part of the engineering team, and the lead engineer on Product 3's development became lead on all projects related to Product 3 (2018-1-25_O). Product 3's success generated additional incremental innovation products. I have defined builds as distinct product lines. Accessory products are therefore absorbed and are explained by the current model without further adjustment.

Because of Product 3's success, leadership realized MakerHub could generate significant excitement in broader markets among consumers enthusiastic about specific value propositions. Product 3's success encouraged more emphasis on marketing spending such as promotional campaigns, conference engagements, and social media engagements than past products.

Summary. In order to develop its own set of capabilities around sales and supply chain, MakerHub needed more than a startup logic. A corporate logic was adopted and manifested in a number of ways, including through digital content and marketing efforts. Just prior to 
transitioning between MakerHub and a Products Inc. promotion, one employee remarked, "MakerHub is different now than when [the initial director] ran it. We used to be more focused on makers, staying true to the community and who they are. Now we are more concerned about making a profitable business ... the difference in those approaches necessitated different digital marketing approaches" (2017-10-17_O). When MakerHub adopted a corporate logic to facilitate capabilities development, the startup logic driving much of MakerHub's initial approach was replaced. The emphasis on corporate logics is further demonstrated in MakerHub's focus and the number of projects worked on. One MakerHub executive recently commented, "We haven't had this many projects going on since before [Product 3]" (2019-2-14_O)

Phase 5: Failure and Learning

During phase 5, two additional reinforcing feedback loops emerged (R3 and R4). These loops arose from the addition of one dimension in the model: Process Learning Emphasis. A process learning emphasis includes 1) the number of activities completed in determining when market validation is considered to be done and 2) the rigor of metrics used in determining when market validation is considered to be done (See Figure 4). Below, I describe Product 4 and discuss Product 4's process through R2. I then explain how Product 4's lack of market validation led to two reinforcing feedback loops (R3 \& R4). R3 and R4 are "vicious circles" (Weick, 1979), reinforcing overall decreases in active builds and scope of ambition. 


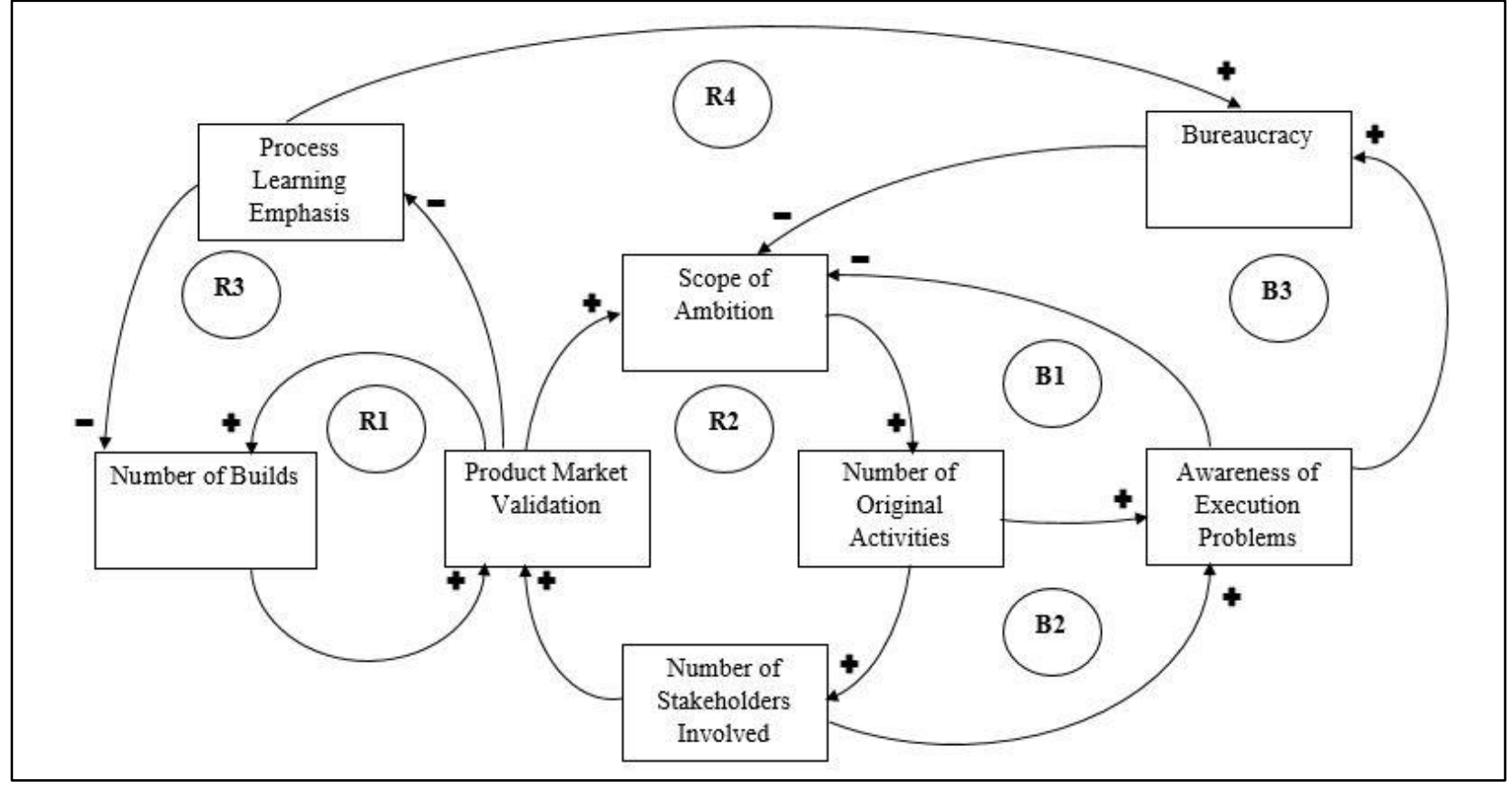

MakerHub's third crowdfunding campaign was a new brewing method for residential coffee drinkers (Product 4). The product was both significantly faster than current market solutions and provided gourmet coffee shop quality. An emphasis in their go-to-market strategy for this product was engagement with experts on the product's taste. Because this was a first of its kind invention that revolved around the consumer's perception of quality, MakerHub management and engineers felt the taste had to be comparable to what the high end coffee shops produced. Consequently, MakerHub engineers spent significant time engaging with coffee experts, particularly with baristas at local high-end coffee shops.

Product 4 through R2. MakerHub's increased ambition with Product 4 is demonstrated in Product 4's novelty (unlike any other product on the market), MakerHub's increased engagement with coffee baristas over taste, and both MakerHub's uncertainty in how big the actual market was and uncertainty over the price point consumers would be willing to pay. Moreover, similar to past actions, MakerHub repeated the activities which made 
Products 2 and 3 successful (e.g. marketing channels, engaging enthusiasts, launching a crowdfunding campaign etc.). MakerHub also held a design challenge, launched a crowdfunding campaign, and utilized past marketing strategies (2017-12-19_O), increasing the number of stakeholders involved.

Lack of Product Market Validation. Past engagements with Indie GoGo liaisons had taught MakerHub that for crowdfunding campaigns to be successful, the campaign's first couple days and final day were critical to the overall outcome as those were the biggest "funding" days. When MakerHub launched their innovative brewing method, the first couple days were underwhelming. Management was concerned the target goal would not be reached and decided to pull all advertising spending on Product 4, contending that if the product truly had value, advertising spending would not be necessary. Others argued that when advertising spending was cut for the product - primary through Facebook and other social media sites - there was little likelihood of Product 4 reaching the goal, and all potential for the product to move forward shut down.

Consequences and Reinforcing Loops. The failure of Product 4 had two primary consequences on MakerHub's subsequent actions. First, management emphasized the importance of learning from the failure in an effort to avoid future similar mistakes. MakerHub is an organization constantly learning, particularly within its engineering functions via prototyping and testing; however, Product 4's lack of market validation led to an emphasis on process learning. Again, a process learning emphasis encapsulates the activities and metrics MakerHub uses to determine when the market validation process is done. 
Although well intentioned, a dramatic increase in a process learning emphasis led to some level of paralysis: "I think the organization got PTSD after that happened [Product 4's unsuccessful launch]. And it shouldn't have happened because our organization was designed to . . . be a culture that would be able to manage failure. And I don't think it managed that very well" (2018-12-17_I). Another executive commented, "We should've just moved on. [Product 4] failing wasn't that bad. . . We held a funeral for that thing. Just move on ... we learned the heck out of that" (2019-2-14).

The second consequence of Product 4's failure was on the number of active builds. Although MakerHub continued to launch products, they were primarily accessory products - already within an existing product line (e.g. within Products 2 and 3). New active builds appeared to slow as a process learning emphasis dictated more activities and more rigorous metrics to ensure similar mistakes were avoided. Management's emphasis on process learning was evident even in lower risk items. For example, management debated for several weeks over one accessory item's price point. Finally, one exasperated executive said emphatically, "just ship it out the door. If it doesn't sell, who cares? Just get it out! It's low risk" (2017-12-4_O). The desire to avoid future failure led to an increase in validation activities (e.g. surveys, consumer interactions) as well as an increased focus on low risk, accessory products. MakerHub's actions suggest a negative reinforcing feedback loop (R3, See Figure 4).

Efforts to learn from Product 4's failure spawned additional processes and practices, increasing overall firm bureaucracy, generating an additional reinforcing negative feedback loop (R4, See Figure 4). Practices include a significant increase in surveys soliciting potential consumer preference around product features and an increased 
emphasis on financial analyses. Although these practices are often couched in terms of learning, employees have voiced frustrated at the apparent decrease in product development speed and increase in overall risk aversion. However, as one employee noted to me that although he thinks MakerHub is slower now (as a result of Product 4's failure), speed is difficult to measure because MakerHub is developing its own technology on several products rather than taking existing technology from Products Inc. This is an important point as part of MakerHub's initial intent was to validate quickly. By developing its own technology, MakerHub is slowed and further imitates practices already conducted in Products Inc.'s R\&D centers.

Summary. After Product 4's unsuccessful crowdfunding campaign, there was a significant shift in logics, which resulted from several coinciding factors. First, MakerHub's founding director left for a personal family reason, and a long-time Products Inc. project manager (and engineer) was instilled as MakerHub's new director. Although a startup logic would rationalize failing as both expected and necessary, the new director had been embedded in a professional-corporate logics hybrid where failure presents a learning opportunity to avoid future failure. Employees who speak fondly of this director also lament, "he [the new director] is very risk averse" (2019-2-14_O).

A second factor impacting a shift in MakerHub's logics was the increasing profitability of Product 3 and the ability to produce even more accessory products. The failure of Product 4 combined with the continued success of Product 3 enabled MakerHub's new director and primary decision maker to rely on his past thinking as a professional manager in a corporate setting. MakerHub could be profitable and reduce risk by launching 
low technology, inexpensive accessory items that required relatively little resources and generated sufficient financial returns.

The success of Products 1 and 2 were justification for MakerHub's initial leadership coalition to increase the scope of ambition, culminating in significant investment of Product 3's development and marketing. However, Product 4's failure pressured the new leadership coalition dominated by a professional and corporate logic to renew efforts to maximize past innovations (Product 3) rather than continuing with a startup logic of quickly attempting new ones. The institutional logics perspective helps explain this shift and why an organization founded to be distinct began making more centralized decisionssimilar to Products Inc.'s R\&D function.

\section{Phase 6: Identity Crisis}

The success of Product 3 and its subsequent add-on products provided a conundrum to MakerHub's management. Was the goal to become profitable or innovative? A number of firm wide meetings ensued where employees argued over the mission and vision of MakerHub. Sales personnel questioned the extent of their role if profitability was a minor goal. Others, particularly those who helped start MakerHub, contended that the fundamental goal of MakerHub was to innovate and validate never-seen-before products, not develop long-term sales strategies. Moreover, they argued, MakerHub was becoming much like Products Inc. in its profit emphasis, centralized decision making, longer product development timelines, and process of identifying problems fostering product solutions (2017-10-13_O). Below, I relate the conflicting factors spawning these identity discussions. I then summarize by relating MakerHub's efforts to maintain aspects of its 
founding identity (driven by startup and community logics) while simultaneously shifting its focus (driven by professional and corporate logics).

Conflicting Factors. Several conflicting factors spawned these discussions over MakerHub's core identity and purpose. First, some argued that if the goal was to be profitable, why have MakerHub be distinct from Products Inc. at all? Although MakerHub is well fitted to prototype single units or "hack" existing products, it was not designed to produce units at scale. Therefore, if MakerHub was to shift its focus to a profit motive, the space constrained rather than enabled. Indeed, Products Inc.'s facilities were much better equipped for large scale production. As one former MakerHub executive commented, "MakerHub ... is a physical space that can make goods. (MakerHub existed) only because Products Inc. wasn't ready to say, 'Hey, we can create a place in our factory where we can make the stuff.' There's nothing that is unique about the equipment back there, so you don't actually, in my opinion, need a physical space” (2018-12-17_I).

A second factor that generated disagreement among employees about MakerHub's identity and purpose was the way in which MakerHub began imitating Products Inc.'s decision making norms and the metrics by which decisions were made. Like Products Inc., MakerHub began operating under a central decision maker. Also similar to Products Inc., product decisions were being primarily driven by financial metrics, such as how many resources will be required to develop the product, and how risky the product is perceived to be. Answers to these decisions further informed the length of product development, potential customer segments, sales channels, and marketing strategies. In regard to the growing similarities between MakerHub and Products Inc., one employee commented how the "budgeting processes is becoming extremely granular" (2019-2-14_O). 
A third factor that generated discussion over MakerHub's identity and purpose was how decision making impacted what product ideas were invested in. Many current and past employees mentioned MakerHub's seeming lack of focus on developing innovative products. As one team member lamented to me: "We don't take big swings anymore. I'm embarrassed we even put that (pointing to a wall listing current products) on our wall under current products. That's not innovative!" (2019-2-14_O).

Summary. As MakerHub grappled with its purpose and identity, leadership utilized a segmented strategy, keeping distinct logics in tension. A corporate logic is apparent through the efforts to maximize Product 3's success and was further demonstrated by an emphasis on developing profitable accessory products. Moreover, professional logics were strongly apparent through the continued emphasis on safety, fully understanding product technologies, and stress testing.

MakerHub continued to be involved in local events such as MakerFaire, host hackathons, give tours, and hold events - all demonstrating at least trappings of a community logic. Further, leadership consistently utilized words, phrases, and symbols representative of a community logic, such as "we are all about community," "we want you to engage with us," "[MakerHub] begins and ends with community." As MakerHub's focus shifted, so did the definition of what "community" meant. I asked one long-time former employee if MakerHub still did "co-creation," which is the idea of engaging with community to ideate, prototype, and design products with non-employees, she said, "No way!" (2017-12-17_O). However, when I asked a different employee, a senior member who had not been at MakerHub as long, he said, "I think we do co-creation now better than ever" (2017-12-19_0). His argument was that consumers were being questioned 
about product features more than previously, which was his definition of co-creation. I found that employee tenure tended to be the primary determiner of how an employee responded to the question: does MakerHub do co-creation well? Whereas new employees felt like MakerHub did co-creation well, thereby embracing a community logic, longer tenured employees felt an emphasis on co-creation (and subsequently a community logics) had decreased.

Lastly, efforts to maintain processes driven by startup logics primarily revolved around low-tech products or products requiring few resources to validate. During this time, MakerHub was approached by various external entities who wanted to engage with MakerHub's engineers on projects related to a specific need. For example, a local religious leader asked MakerHub to develop an appliance add-on enabling easier adherence to religious observances. MakerHub engineers also worked with a local apartment complex to develop a vending machine-like system for laundry applications, enabling users to pay with credit cards rather than coins.

When I discussed MakerHub's current activities to engage external input in the ideation, development, design, and prototyping process with a former community member, he praised the quality of MakerHub's engineers but said he thought they were constrained in their ability to get customer feedback:

[MakerHub engineer] fantastic guy! He has his heart and his head in 100\% the right place. In the three years I was in (city name), I saw him bump his head up against, like a bunch of times I've seen him try to go out and get customer feedback, and he gets his hand slapped every time by management, and I guess he's learned that that's not something we try to do. . . I think that's problematic. . . I think that their commitment to learning anything from the crowd is superficial. (2018-12-19_I) 
Although MakerHub exhibits all four types of logics, disagreement and confusion over MakerHub's identity and purpose impacted the kinds of activities, the amount of resources allocated to those activities, and the ways in which employees were encouraged or discouraged in pursuing diverse activities.

\section{Phase 7: New Division}

During phase 7, a fourth negative balancing feedback loop emerged (B4). An exogenous shock (New Division) generated an overall shift in MakerHub's strategy by decreasing overall activities, leading to a new dimension: Stakeholder Closeness, which I define as the level and frequency of engagement with external stakeholders in the product development process (See Figure 5).

\section{Figure 5: Exogenous Shock and Stakeholder Closeness}

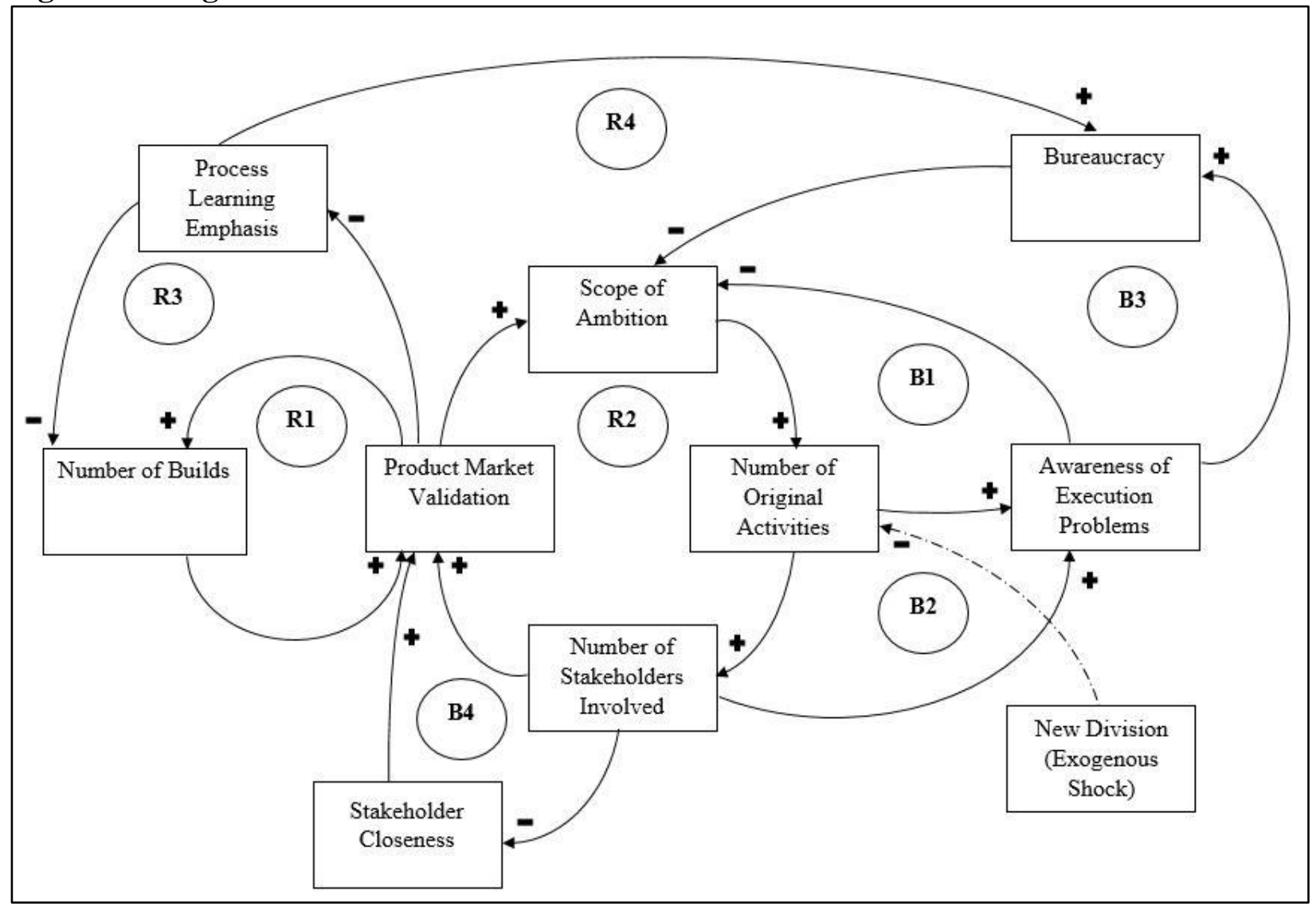


Key Events. In the fall of 2018, Products Inc. launched the small appliances division, and two of MakerHub's senior management team left MakerHub to lead it. Once MakerHub validates the market for a new product, the small appliances division will take over, enabling MakerHub to reduce the overall total number of activities related to sales and marketing new products, decreasing B1's impact on R2. The new division's impact on the overall system is already captured in the model, and new division is not a dimension in the system. The purpose for visually including new division in the model is for conceptual clarity (See Figure 5).

The launch of the small appliances division spawned a refocus on developing product ideas. The new division enabled MakerHub to shift resources away from commercial related activities toward market validation activities, decreasing the number of original activities. One sales member lamented, "we have no interest in being profitable anymore" (2019-2-13_O). Further MakerHub's recent successes in crowdfunding low tech, low cost items through its own website are viewed by management as a means of interacting with different consumer groups around preferences and needs, maintaining its "maker" image, symbolically solidifying R1. MakerHub's primary strategy for selling high-tech riskier products is through Products Inc.'s formal channels rather than through its own sales channels under the MakerHub brand, which further reflects this shift in resource allocation and decrease in commercial related activities, decreasing B2's influence on R2.

Major Actions. The launch of the new product division enabled MakerHub to refocus on ideation and relational engagement with enthusiasts (R1 \& R2). One executive noted, "We haven't worked on this many projects (concurrently) since before [Product 3]" (2019-2- 
14_O). Increased efforts are also underway to attract more makers and enthusiasts into the building. A current employee explains the shift in mindset:

We're trying to be more close to community, more intimate. We're trying to be more physical with community as opposed to having [a] digital divide here because we found that we [...] have a large number of people there internationally and on the digital side that are interested in [MakerHub]. But the amount of feedback that we're getting from them is relatively small in context to the amount of effort we might put into that. So we found that finding that searching for the groups that we want to interact with instead of having them come to us might be a better solution for getting higher fidelity feedback from the people that are going to care. So we've been strategizing on different ways to discover these enthusiast groups here locally or regionally and coming to them and learning from them. (201811-30_I)

Budget spending further reflects the shift in focus (See Phase 5 in Table 4). Recently, MakerHub hired a full-time community relations specialist to oversee, initiate, and develop community relationships both locally and nationally.

MakerHub is currently shifting from an emphasis on broader activities and broader reach to more specific stakeholder engagements (i.e. stakeholder closeness) and a more focused set of activities around product validation. MakerHub's renewed focus on validation is a return to its founding purpose; however, their stakeholder emphasis is subtlety different. MakerHub's founding belief was that by engaging external inputs, MakerHub could quickly generate and prototype innovative product ideas. However, MakerHub realized makers will not be a core mechanism for quick, innovative product ideation or prototyping. Moreover, given its resource constraints and inability to exponentially go through R1's feedback loop, MakerHub is attempting to maximize each engagement rather than maximize the number of engagements-focusing less on the quantity of stakeholders involved and more on those who provided greatest input toward product market validation. This relationship generates a balancing loop as the quantity of 
information and feedback decreases but the quality increases (B4, See Figure 6). This development is potentially critical as through emphasizing stakeholder closeness, MakerHub may fulfill part of its initial purpose by capturing innovative product ideas from external inputs, distinguishing itself from Products Inc.'s R\&D Centers.

Summary. The new small appliances division alleviated many of MakerHub's selling and marketing activities, enabling MakerHub to refocus toward community logics, demonstrated through MakerHub's emphasis on physical engagement and their hiring a relations specialist. Moreover, the shift in activities also lessoned the centrality of corporate logics with MakerHub's daily activities.

\section{Summarizing MakerHub's Evolution}

At the outset of this chapter, I stated the following research question: If the end goals (explorative innovation) are accomplished primarily by internal knowledge capital (Products Inc. and MakerHub engineers), why does an organization with limited resources end up with two R\&D organizations? This section attempts to identify MakerHub's critical loops determining the overall system and to summarize how MakerHub's product development system caused MakerHub, founded as a distinct entity, to more closely reflect Products Inc.'s R\&D capabilities and practices.

Critical Loop. Weick suggests one way to determine a system's outcome is to identify its critical loop (assuming loops are of unequal importance); if the loop is a reinforcing loop (deviation-amplifying), the system will likely collapse, and if the system is a negative balancing loop (deviation-counteracting), the system will likely stabilize (Weick, 1979). One means of identifying the critical loop is by counting the inputs and outputs for each element and then determining which loop includes elements with the most inputs and 
outputs (Weick, 1979). Product Market Validation contains six inputs and outputs. While no dimensions have five, three dimensions have four inputs and outputs: Scope of Ambition, Number of Stakeholders, and Awareness of Execution Problems. This suggests either R2 or B1 is the critical loop as both loops contain three of the four dimensions, but neither contain all four, so using this method of determining the system's fate appears inconclusive.

If loops are assumed to hold equal importance in the system, Weick suggests a second strategy may be useful in determining the system's fate. This method involves counting the number of negative loops: "By a negative loop we mean a closed loop that contains an odd number of negative causal relationships. We would predict that any system will survive as a system only if it contains an odd number of these negative loops" (Weick, 1979, p. 76). According to this strategy, MakerHub has a deviation-amplifying system (even number of negative loops), suggesting its system is unstable. Problematically, though, the data does not support the idea that MakerHub's loops hold equal importance.

In an effort to discern the core of MakerHub's system, I consider two competing goals that have, at one time or another during its history, driven MakerHub's decision making: profit or innovation. Below, I consider how these goals interacted with product market validation - the dimension with most inputs and outputs.

Finite Resources Constrained Innovation. MakerHub was built on the idea R1 represents; build and validate, which leads to additional building and validating. However, MakerHub has a finite number of resources; therefore, as MakerHub proceeds through R1 and R2, generating more builds, available resources to allocate to new active builds decreases. Balancing loop B1 regulates MakerHub's overall scope of ambition as 
MakerHub's awareness of execution problems and actions to solve those problems entail an understanding of what is technically and operationally feasible given the resources available, consequently decreasing the rate at which MakerHub can proceed through R1 and R2. At founding, an important distinction between MakerHub and Products Inc.'s R\&D was the speed at which the build process occurred; however, B1's regulation slowed R1 and R2 processes, decreasing MakerHub's overall distinctness from Products Inc.'s R\&D.

Execution Problems Constrained Innovation. At founding, and in contrast to Products Inc.'s R\&D Centers, MakerHub's cognitive scope was intended to be broad, enabling innovative product ideas across product lines or even appliance size. However, over time, MakerHub's cognitive scope became more constrained. Innovative product ideas generate additional stakeholders and additional execution problems — problems that further decrease speed. Consequently, B2 regulates R1 and R2 as MakerHub's understanding of execution problems coupled with the potential publicity of those problems demotivates higher-risk product ideas.

Developing Commercial Capabilities Constrained Innovation. Balancing loop B3 further regulates MakerHub's overall scope of ambition and the speed at which MakerHub can proceed through R1 and R2, decreasing the number of products validated. After Product 3's successful market validation, MakerHub leadership attempted to hand it off to Products Inc.; however, Products Inc.'s leadership refused. One interviewee recalled,

We'd said this place existed so that we can validate something and then when we validated it, they'd (Products Inc.) take it. And they wouldn't take it. We had the meeting with everyone all the way up to the CEO, and it was decided, "We (Products Inc.) don't know what to do with this. We can't do anything with it. So, you guys (MakerHub) are going to own it." . . . It didn't make sense for the guy who was responsible for sales to take one of 
the salespeople who could generate 100 million dollars in sales and have them spend all their time developing a market for something that may sell another 3 or 4 million dollars next year. (2018-12-12_I).

Consequently, MakerHub developed capabilities it was not initially designed for, specifically extensive sales activities geared toward broader markets and sales channels. To more effectively navigate both sales practices and customer engagement, MakerHub implemented protocols, increasing the firm's bureaucracy. These activities also increased the need for more central decision making as more consequential, far reaching relationships developed. Collectively, balancing loops B1, B2, and B3 regulate MakerHub's ability to quickly build and validate as resources were allocated away from validating products to commercial activities; execution problems further demotivated MakerHub's ambition slowing R1 processes.

Product 3's continued success (including accessory products) required additional resources and capabilities around sales and marketing activities (B1 and B3), decreasing overall resources focused toward generating novel product ideas further decreasing speed through R1 and R2 processes. Product 3's success and profitability forced MakerHub to consider competing realities: 1) there is a limited number of resources, 2) the number of products that can be potentially prototyped is much larger than the number of products that can be potentially sold, 3) Product 3 accessory products (and similar types of products) are faster, cheaper, and lower risk to develop; therefore, 4) is the goal profit or innovation?

Slowing R1 and R2 to Develop Innovation and Maximize Profit. As described earlier, Product 4's unsuccessful crowdfunding campaign coincides with an increase in risk-averse decision making, generating a process learning emphasis. A consequence of limited resources, competing goals (e.g. innovative or profitable), and a desire to avoid future 
mistakes was that MakerHub's scope of ambition became bifurcated toward two types of products: either innovative, technology infused, high-risk products or non-innovative, low technology infused, low-risk products. Low technology products were low cost, faster to prototype, and required fewer resources to validate. Moreover, a number of low risk products (particularly Product 3 accessory products) were "hacks" created by consumers and suggested back to MakerHub. Examples include a product enabling an increase in capacity and a cleaning kit for Product 3. MakerHub validated and continues to validate many of these types of products through crowdfunding campaigns held on its website. They launch small batches, generally ten units, as "tests" to see if consumers purchase them, and MakerHub has launched several low technology products this way.

Conversely, higher risk, innovative products are assigned two or three engineers. The engineers are tasked with developing the technology and building the product in a way Products Inc. could incorporate into its manufacturing capabilities and sell at a high margin. Core value propositions, product feature sets, and price points have all proved challenging in this process. When I once asked the commercial team about their process for identifying answers to these questions, I was told "we are a pretty good representatives of our customer base." However, consensus is rarely quick, and several engineers confided their frustrations over not knowing what features to include and exclude in the product. These challenges slow product development and market validation (R1 and R2). For example, in my notes concerning one product under development, I wrote,

Seems like a merry-go-round between software, hardware and marketing. The software component say they need to know what the [product] will have so they can write the code. The hardware people say they need to know what consumers want before they can fully develop the product. The marketing people say they need to know what wow factors the [product] will have so they can write a compelling story for the crowdfunding campaign. Nobody 
knows what price point will sell best and what features will set the product apart. (2017-11-29_O)

MakerHub attempts to maintain its image of quickly building and validating products by generating low technology products often with external inputs (such as consumers or student groups). Their image of being an innovative company is sustained through longterm, high-risk products that may or may not ever be handed off to Products Inc.

Further slowing down innovative products' validation is an increase in overall bureaucracy, generated by both the success of Product 3 and the failure of Product 4. Also, MakerHub generates much of its own technology for its current, highly innovative products under development rather than its initial practice of utilizing existing technology at Products Inc., further decreasing speed from prototype to validation.

Stakeholders as a Mechanism for Innovation. One of MakerHub's founding assumptions was that by engaging with makers and enthusiasts, they could quickly prototype and validate innovative products, increasing MakerHub's process through R1. This assumption is evident through MakerHub's founding components (physical environment, cognitive scope, relational access, and level of formality), through their initial digital marketing strategy (e.g. maker focused), through the metrics established (e.g. develop twelve new products a year), through Product 1's target market (makers), and through the overwhelming response by diverse stakeholder groups.

Although Product 1 created excitement within the maker community, Product 2 targeted a broader customer segment, demonstrated by the type of product itself (required no coding or "hacking"), the increase in price point, and the product's overall success (sold more units). Product 2's development also challenged one of MakerHub's core assumptions, namely that makers were going to engage in the product development 
process. The design challenge demonstrated interest in aesthetic collaboration, but MakerHub was less successful enticing makers into the physical building. This lack of relational success coupled with MakerHub's increasing profitability led to relationships with external inputs becoming more symbolic rather than substantive.

However, Products Inc.'s new division reduced MakerHub's need for sales and marketing capabilities, causing a decrease in overall activities and a refocus on external inputs. A key difference is the emphasis on stakeholder closeness (e.g. quality of engagement) rather than overall quantity. This shift in focus is significant as previous quotes, actions, and interpretations demonstrate that makers were not prevalent in the ideation or building of products. Designers were the primary source of external input and were utilized through design challenges.

Increased bureaucracy, increased risk aversion, and the lack of external input generated a profit focused organization similar in many ways to Products Inc.'s R\&D centers. However, the recent founding of the new division may enable MakerHub to return to its build-validate emphasis, generating more innovative products. Also, MakerHub's renewed efforts to foster high-quality engagements with key stakeholders in the development process may increase the speed through which MakerHub can build and validate.

Overall Outcomes: Given MakerHub's resource constraints, an innovation focused system would likely only survive if commercial activities were executed elsewhere and different metrics were used to evaluate MakerHub's output. Innovation is messy and unpredictable. Metrics such as developing 12 products a year or financially breaking-even are inherent contradictions to developing innovative products, particularly if products 
require advanced technological development. The new division enables this type of innovation focus. However, an innovation focused system also requires a key change in rationalizing successes and failures, a change from corporate and professional logics back to a startup logic. Otherwise, an organization focused on developing innovative products will be little different than Products Inc.'s current R\&D Centers.

As describe throughout this study, a profit focused system governed much of MakerHub's decisions post-Product 3's development. To satisfy the break-even and 12 products-a-year metrics, MakerHub pursued accessory products that were profitable, quickly produced, and low risk. A combination of corporate and professional logics meant protocols were developed to enable efficiency, safety, and avoidance of future mistakes. However, when MakerHub was driven by a profit motive, concerns were raised over its contribution to Products Inc. Profits were never MakerHub's purpose as the initial goal and logic driving MakerHub's design was to validate innovative product ideas.

\section{Benefits and Drawbacks for MakerHub Existing}

Benefits. In many ways, MakerHub evolved away from its startup logics and initial mission to embrace risk by failing-fast and creating radically innovative products through maker engagement. Product 3's success necessitated bureaucratizing MakerHub. Product 4's failure exacerbated the new leadership coalition's reliance on professional and corporate logics, which consequently led to an increase on learning from failure rather than embracing its founding notion of failing fast and moving on. The increased emphasis on process learning further increased bureaucracy. There are, however, a number of important ways in which MakerHub still helps contribute to Products Inc. 
First, MakerHub is a physical place in which innovative ideas can occur and be prototyped. MakerHub recently hosted a Products Inc. hackathon for Products Inc. engineers (2019-2-21_O). This nuanced type of internal "innovation tournament" is consistent with other recent strategies large corporations are undertaking to maximize employee innovation (Tersiesch \& Ulrich, 2009). Moreover, MakerHub is getting progressively better at identifying the types of individuals who are most useful in developing truly innovative ideas and the means through which to engage those individuals. MakerHub's development of internal (employee hackathons) and external (events or practices targeted to specific groups) mechanisms designed to capture high quality, innovative ideas and expertise is forward looking, particularly within its own industry.

Second, MakerHub small batch manufacturing capabilities are beneficial to Products Inc. Like auto manufacturers, Products Inc.'s facilities are designed for producing thousands of units. MakerHub's small batch manufacturing capabilities enable customization, design changes, and product "hacking" without shutting down large scale operations. Such capabilities are particularly useful when questions are raised about how a product might modified or enhanced with additional features. MakerHub can "slap" something together to quickly "see if it works" and discover what potential problems may arise in larger scale operations.

A third way in which MakerHub benefits Products Inc. is by developing different mechanisms for engaging with consumers and their opinions, particularly around product desirability and product features. Surveys are as easy as "thumbs up or thumbs down" type questions on Facebook. MakerHub is constantly experimenting on how to better engage 
with consumers and reduce the potential barriers (time, access, complexity) for consumers to engage with them. These experiments are important as consumer engagement and feedback are problems many corporations are attempting to figure out.

Finally, MakerHub benefits Products Inc. by serving as a mechanism for good will and external engagement. Whereas Product Inc.'s imposing corporate campus is inaccessible to the community, MakerHub is a friendly environment in which enthusiasts, makers, or consumers can engage. Large corporations' brand image is become increasing known through social media, which has led to digital strategies to appear friendly or innovative. MakerHub generates a wonderful external image for Products Inc., which is further demonstrated by the amount of positive press both locally and nationally.

Drawbacks. Part of MakerHub's founding stipulation with Products Inc. was that it would pay for itself. Product 3's success enabled several years of operating in the black; however, other products have not attained the same level of success. Highly innovative products are inherently risky; therefore, how will MakerHub financially sustain itself, particularly if its most successful products are sold through Products Inc. new division? If MakerHub is not able to demonstrate that increased closeness with stakeholders generates innovative product ideas and increases speed through the product validation process, then MakerHub may merely become an expensive $\mathrm{R} \& \mathrm{D}$ center, providing intangible benefits to the community (open makerspace symbolic of community's innovation) and a physical environment for Products Inc.'s employees to quickly "hack" an idea. 


\section{DISCUSSION}

In this chapter, I articulate the theoretical contributions of this study, practical implications, areas for future research, limitations, and offer a conclusion.

\section{Theoretical Contributions}

This study makes several contributions. First, Products Inc.'s attempt to respond to market pressures by launching MakerHub provides insights into how ventures founded to be dissimilar from the parent form and evolve. Past research demonstrates firms can evolve for many reasons, including external pressures and managerial changes among others (Greenwood et al., 2011). Less research examines the impact product outcomes have on the formation, development, and evolution of firm logics. MakerHub's story contributes to our understanding (of the phenomenon) by demonstrating how success (Product 3), necessity (production capabilities for Product 3), failure (Product 4), and an exogenous shock (new division) may interact to produce a new ordering of logics that differs from that at founding and more similar to what is familiar (e.g. Products Inc.'s R\&D Centers). These findings suggest both firms' need for additional logics and rationalization of incumbent logics may evolve in both intended and unintended ways.

Related to the first, this study's second contribution suggests a cluster of competing logics may act as both structural constraints and agency enablers as outputs or needs vary, causing logics' salience to ebb and flow. Although a few studies examine the microprocesses demonstrating firms' and individuals' responses to competing logics (Smets et 
al., 2012), little is known about how individuals respond within new ventures. MakerHub's story highlights the constraining role of certain logics vis-a-vis the enabling function of still other logics within a new venture. Product 3's unexpected success combined with Products Inc.'s lack of ability to take on Product 3 "forced" MakerHub to adopt a logic which could enable maximum performance (corporate logic). Adopting a corporate logic subsequently focused MakerHub's resources, constraining its ability to maintain startup logics. When Products Inc. launched a new division, the need for a corporate logic decreased. Although MakerHub retains aspects of a corporate logic, maximizing product exposure (e.g. marketing spending) is no longer emphasized. In this study, four logics are apparent within MakerHub and their competing prescriptions are demonstrated through the negotiations between and actions by employees and management. As MakerHub evolved, developed capabilities, and increased its bureaucracy, competing prescriptions generated a reordering of logics. However, all four logics remained as MakerHub continued to satisfy each of its distinct stakeholder groups.

MakerHub retained all four logics by utilizing key phrases broadly thereby compartmentalizing certain logics through "symbolic commitment" (Greenwood et al., 2011, p. 30). For example, over time "co-create" and "community" became allencompassing words that could mean any engagement at any stage in the product development process. Therefore, MakerHub could emphasize both its community logic and corporate logic simultaneously without making an explicit tradeoff. Through maintaining a certain level of ambiguity, MakerHub retained the identities diverse stakeholder groups wanted it to have. 
This study's third contribution relates to how rationalizing past actions and outcomes impact product development decisions, particularly depending on the management's risk averse tendencies. Logics not only prescribe action, but also serve to make sense of what, how, and why outcomes occur. My findings suggest greater nuance in how logics are negotiated, sustained, and replaced even when firm outcomes are internally consistent with the incumbent set of logics' prescriptions. In other words, even when 'what, how, and why' were consistently explained within the startup logic rationalization, that logic was replaced in exchange for a more comfortable known logic. For example, whereas a startup logic was used to rationalize Product 1 and 2's success, a corporate logic formed both the strategy for Product 3 and rationalized its success. Conversely, a professional logic rationalized Product 4's failure, increasing risk aversion tendencies and generating significant rippling effects for future decision making. This suggests a logic may sufficiently explain outcomes yet still be replaced.

Fourth, this study contributes to the growing theoretical interest in makerspaces and further explores one makerspace's practical impact. Recent scholarship (Browder et al., 2019) theorizes "knowledge creation and sharing spaces constitute the central features of the maker movement, creating resource combinations that makers can use for project execution, expansion, and - in some cases—commercialization." MakerHub assumed its location, openness, and advanced fabrication capabilities would attract makers intent on commercial outcomes into its physical environment, generating innovative ideas between employees and individuals. With the exception of students working on class projects or Products Inc. employees, very few makers utilize use MakerHub's technology or tools. 
MakerHub is an open innovation organization. As noted earlier, open innovation is not a silver bullet for companies. Birkinshaw et al. (2011) warn companies are actually much better at internally generating innovative ideas than they are at selecting, developing, or diffusing those ideas. Moreover, they certify, "online tools, open innovation communities and big collaborative forums all have their limitations. None is always right or always wrong. The best approach involves careful judgment and a deep understanding of the particular challenges a company is facing" (Birkinshaw et al., 2011, p. 8). This study provides additional data to the conversation regarding what types of innovations corporate venture makerspaces actually generate. MakerHub's innovative product ideas were generated internally; however, MakerHub had two sources of incremental innovations which were often more similar to the concept of "hacking" (a key element within the maker movement). MakerHub's hacks are derived from two sources: 1) customers hacking addon solutions to products at home (e.g. increased capacity add-on to Product 3, probe incorporated for Product 2), and 2) MakerHub engineers hacking existing appliances, enabling unique applications (e.g. adding a credit card system to a large appliance).

Browder and colleagues (2019) also question the extent to which external labor benefits from engaging with corporations on various projects. MakerHub navigates these potentially challenging waters by often celebrating consumer engagement through social media recognition. As the products being hacked by consumers are generally low tech and inexpensive, recognition appears sufficient as little resistance or objection is raised.

\section{Practical Implications}

There are several practical implications of the present study. First, a corporate venture makerspace offers a new environment in which to study innovation, corporate 
entrepreneurship, and product development. I hope my work offers insights for corporations wanting to develop innovative organizational designs with environments distinct from "corporate culture." The notions of physical environment, cognitive scope, relational access, and cultural norms can be used as a means to create broad categories in which to clearly differentiate how an environment may be created distinct.

A second implication for practitioners is the way in which MakerHub responds as new products flourish or flounder. Both successful and unsuccessful products impact the venture, particularly on firm bureaucracy and organizational outcomes. Successful products necessitate processes to enable the manufacturing, selling, and servicing of products and customers. Such processes can increase bureaucracy, which tends to slow organizations down. Moreover, if products are successful but the firm does not increase human capital, resources may become spread too thinly also decreasing the time and resources necessary to ideate and validate new product ideas. Similarly, unsuccessful products can also increase bureaucracy as management implements new processes to avoid failure in the future. As demonstrated in the case of MakerHub, "management got PTSD" from the failure of Product 4 instead of celebrating having learned something and moving on. Developing such a risk accepting environment may prove challenging, particularly for professional disciplines that emphasize safety and efficiency (e.g. engineering).

As a third practical implication, this study provides an example of a corporate venture navigating between corporate, community, and venture stakeholders. Over time, MakerHub evolved in how it managed each of these relationships to both better serve its own purpose as well as maintain value for its diverse set of stakeholder groups. MakerHub accomplished this goal by emphasizing both the physical environment, bringing interested 
parties into the space, as well as by emphasizing its employees' relational access, enabling engagement with industry experts, makers, enthusiasts, and potential consumers.

\section{Limitations}

In this section, I discuss potential threats to external validity and limitations. First, MakerHub's environment is unique. The location of MakerHub results in human capital, knowledge capital, and other resource constraints that are geographically specific. This study took place in a midsized city in the south-central U.S. It is impossible to determine whether the results of this study would be consistent with a study on either U.S. coast. A second threat to external validity is that MakerHub is situation specific. Indeed, a limitation of case study analysis is lack of generalizability given the small sample size, and in this particular case, the sample size of 1 . However, MakerHub is unique as it is the only corporate venture makerspace I know of, making additional case studies of similar organizational type firms impossible. Moreover, given both the intense national interest in MakerHub (evidenced by publications in the Wall Street Journal, Harvard Business Review and others) and the growing trend in large corporations to adopt innovative strategies, MakerHub's story is potentially relevant to a wide audience of firms and managers. Although MakerHub's environment is distinct from other firms, I contend enough similarities exist to generate relevance to other firms and managers.

There are several limitations to the present study. For example, Products Inc. is in the appliances industry. A corporate venture like MakerHub may not be as effective in a more technologically driven industry or in one significantly less technologically driven. Part of MakerHub's appeal to both community members and customers is MakerHub's involvement in new technology development. However, if Products Inc. was in a 
technology industry (i.e. software), MakerHub might have had greater difficulty in separating identities from the parent (Products Inc.). Conversely, if Products Inc. had no technological component, MakerHub's innovative processes might have been underwhelming, causing stakeholders to dismiss the innovative aspects of MakerHub that generates interest from internal and external stakeholders.

Lastly, a further limitation concerns the interviews conducted. I did not interview current members of Products Inc. as this is not a comparative ethnography and many of the MakerHub employees are former Products Inc. employees.

\section{Future Research}

With a few notable exceptions (Biniari et al., 2015; Pahnke et al., 2015), very little institutional logics research discusses the parent-venture relationship. There are number of potential avenues for further study in this research stream. For example, when a parent spawns a venture with a different logic, understanding the conditions under which the logic remains or fades is significant. What types of hybrids generate the most successful corporate ventures? Under what conditions do geographical distance between parent and venture impact the likelihood of a founding set of logics remain or change? To what extent does hiring non-corporate employees to run the venture impact founding logics? How important are significant successes or significant failures in the likelihood a venture logic stays? Are moderate product successes and moderate failures less causal in logic changes or tensions than significant successes or failures? Such questions are potentially important as firms continue to experiment with various organizational types in an effort to generate sustainable innovation practices. 
A second area for future research concerns the relationship between employee and institutional complexity. Past research highlights the impact changes in logics may have on employee satisfaction (Battilana \& Dorado, 2010). For example, one study discusses the disillusionment that socially focused employees had when a social venture business became more profit focused (Battilana \& Dorado, 2010). In a different study, researchers demonstrate how new hires were frustrated when they realized the firm logics presented to them in interviews were different than the logics emphasized in everyday firm practices. MakerHub provides a unique example. Even when logics shifted dramatically from startup logics to corporate and professional logics, employees remained relatively happy. Although some commercial employees became frustrated as MakerHub returned to a more product development focus away from maximizing profits, even those employees enjoy the overall environment and culture at MakerHub.

\section{Conclusion}

Although several of its founding assumptions were not realized—namely the level of external maker engagement in generating innovative product ideas or the ability to validate innovative products quickly-MakerHub's past successes include several profitable products, national recognition and attention, appreciation by many local stakeholders, and multiple awards for best product in its category at major technology conferences. MakerHub's team is talented and enthusiastic. To date, however, MakerHub's greatest innovation is not one of its products. MakerHub's greatest innovation is MakerHub itself. 


\section{REFERENCES}

Aldrich, H. E. (2014). The democratization of entrepreneurship? Hackers, makerspaces, and crowdfunding. Paper presented at the Annual Meeting of the Academy of Management.

Almandoz, J. (2014). Founding teams as carriers of competing logics: When institutional forces predict banks' risk exposure. Administrative science quarterly, 59(3), 442473.

Anderson, C. (2012). Makers: The New Industrial Revolution (2013) Crown Business. New York.

Ashraf, N., Ahmadsimab, A., \& Pinkse, J. (2017). From Animosity to Affinity: The Interplay of Competing Logics and Interdependence in Cross-Sector Partnerships. Journal of Management Studies, 54(6), 793-822.

Babbie, E. (2015). The practice of social research: Nelson Education.

Baker, T., \& Nelson, R. E. (2005). Creating something from nothing: Resource construction through entrepreneurial bricolage. Administrative science quarterly, 50(3), 329-366.

Barley, S. R., \& Tolbert, P. S. (1997). Institutionalization and structuration: Studying the links between action and institution. Organization Studies, 18(1), 93-117.

Barrett, T., Pizzico, M., Levy, B. D., Nagel, R. L., Linsey, J. S., Talley, K. G., . . . Newstetter, W. C. (2015). A review of university maker spaces.

Battilana, J., \& Dorado, S. (2010). Building sustainable hybrid organizations: The case of commercial microfinance organizations. Academy of management journal, 53(6), 1419-1440.

Bertot, J. C., Real, B., Lee, J., McDermott, A. J., \& Jaeger, P. T. (2015). 2014 Digital Inclusion Survey: Survey Findings and Results: Information Policy \& Access Center, College of Information Studies, University of Maryland.

Bettis, R. A., \& Hitt, M. A. (1995). The new competitive landscape. Strategic Management Journal, 16(S1), 7-19.

Binder, A. (2007). For love and money: Organizations' creative responses to multiple environmental logics. Theory and society, 36(6), 547-571.

Biniari, M. G., Simmons, S. A., Monsen, E. W., \& Moreno, M. P. (2015). The configuration of corporate venturing logics: An integrated resource dependence and institutional perspective. Small Business Economics, 45(2), 351-367.

Birkinshaw, J., Bouquet, C., \& Barsoux, J.-L. (2011). The 5 myths of innovation. MIT Sloan Management Review, 52(2), 43.

Black, L. J., Carlile, P. R., \& Repenning, N. P. (2004). A dynamic theory of expertise and occupational boundaries in new technology implementation: Building on Barley's study of CT scanning. Administrative science quarterly, 49(4), 572-607.

Bowler, L. (2014). Creativity through" maker" experiences and design thinking in the education of librarians. Knowledge Quest, 42(5), 58. 
Brandl, J., \& Bullinger, B. (2017). Individuals' considerations when responding to competing logics: Insights from identity control theory. Journal of Management Inquiry, 26(2), 181-192.

Browder, R. E., Aldrich, H. E., \& Bradley, S. W. (2019). The emergence of the maker movement: Implications for entrepreneurship research. Journal of business venturing.

Brown, B. (2015). Daring greatly: How the courage to be vulnerable transforms the way we live, love, parent, and lead: Penguin.

Brown, S. L., \& Eisenhardt, K. M. (1995). Product development: Past research, present findings, and future directions. Academy of management review, 20(2), 343-378.

Canessa, E., Fonda, C., Zennaro, M., \& Deadline, N. (2013). Low--cost 3D printing for science, education and sustainable development. Low-Cost 3D Printing, 11.

Cavalcanti, G. (2013). Is it a Hackerspace, Makerspace, TechShop, or FabLab. Make, May, 22.

Chesbrough, H. (2003). Open innovation: Boston: Harvard Business School Press.

Chesbrough, H. (2006a). The era of open innovation. Managing innovation and change, 127(3), 34-41.

Chesbrough, H. (2006b). Open innovation: The new imperative for creating and profiting from technology: Harvard Business Press.

Chesbrough, H. (2012). Open innovation: Where we've been and where we're going. Research-Technology Management, 55(4), 20-27.

Christians, C. G., \& Carey, J. W. (1989). The logic and aims of qualitative research. Research methods in mass communication, 354-374.

Colegrove, T. (2013). Editorial board thoughts: libraries as makerspace? Information Technology and Libraries (Online), 32(1), 2.

Covin, J. G., \& Miles, M. P. (2007). Strategic use of corporate venturing. Entrepreneurship Theory and Practice, 31(2), 183-207.

Creswell, J. W., \& Miller, D. L. (2000). Determining validity in qualitative inquiry. Theory into practice, 39(3), 124-130.

Creswell, J. W., \& Poth, C. N. (2017). Qualitative inquiry and research design: Choosing among five approaches: Sage publications.

Cross, A. (2017). Tinkering in k-12: an exploratory mixed methods study of makerspaces in schools as an application of constructivist learning: Pepperdine University.

Currie, G., \& Spyridonidis, D. (2016). Interpretation of multiple institutional logics on the ground: Actors' position, their agency and situational constraints in professionalized contexts. Organization Studies, 37(1), 77-97.

Curry, R. (2017). Makerspaces: a beneficial new service for academic libraries? Library Review, 66(4/5), 201-212.

Dacin, M. T., Munir, K., \& Tracey, P. (2010). Formal dining at Cambridge colleges: Linking ritual performance and institutional maintenance. Academy of management journal, 53(6), 1393-1418.

Dalpiaz, E., Rindova, V., \& Ravasi, D. (2016). Combining logics to transform organizational agency: Blending industry and art at Alessi. Administrative science quarterly, 61(3), 347-392. 
Damanpour, F., \& Wischnevsky, J. D. (2006). Research on innovation in organizations: Distinguishing innovation-generating from innovation-adopting organizations. Journal of engineering and technology management, 23(4), 269-291.

Davidsson, P. (2004). Researching entrepreneurship: Springer.

Davidsson, P. (2016). Researching entrepreneurship: conceptualization and design: Springer.

Davis, D. G. (2017). Novice Behavior in a Makerspace: Pragmatic Pathways to Shaping CS Identity. The University of Texas at San Antonio.

Davis, G. F., \& Marquis, C. (2005). Prospects for organization theory in the early twentyfirst century: Institutional fields and mechanisms. Organization Science, 16(4), $332-343$.

Delbridge, R., \& Edwards, T. (2013). Inhabiting institutions: Critical realist refinements to understanding institutional complexity and change. Organization Studies, 34(7), 927-947.

Demetry, D. A. (2015). Episodic Organizations: Pop-up and Underground Restaurants and the Temporality of Organizational Life. Northwestern University.

DeRosa, M. S. (2016). Let the wild rumpus start!: fostering creative thinking and expression among diverse learners through a makerspace in an international school in China.

DiMaggio, P. J. (1988). Interest and Agency

DiMaggio, P. J. (1991). Constructing an organizational field as a professional project: US art museums, 1920-1940. The new institutionalism in organizational analysis, 267, 292.

DiMaggio, P. J., \& Powell, W. W. (1983). The iron cage revisited: Collective rationality and institutional isomorphism in organizational fields. American Sociological Review, 48(2), 147-160.

Dimov, D. (2007). Beyond the single-person, single-insight attribution in understanding entrepreneurial opportunities. Entrepreneurship Theory and Practice, 31(5), 713731.

Eisenhardt, K. M., \& Schoonhoven, C. B. (1996). Resource-based view of strategic alliance formation: Strategic and social effects in entrepreneurial firms. Organization Science, 7(2), 136-150.

Fiet, J. O. (1996). The informational basis of entrepreneurial discovery. Small Business Economics, 8(6), 419-430.

Fiet, J. O. (2007). A prescriptive analysis of search and discovery. Journal of Management Studies, 44(4), 592-611.

Fjeldstad, Ø. D., Snow, C. C., Miles, R. E., \& Lettl, C. (2012). The architecture of collaboration. Strategic Management Journal, 33(6), 734-750.

Fleming, L. (2015). Worlds of making: Best practices for establishing a makerspace for your school: Corwin Press.

Friedland, R., \& Alford, R. R. (1991). Bringing society back in: Symbols, practices and institutional contradictions.

Geertz, C. (1973). The interpretation of cultures (Vol. 5019): Basic books.

Goodrick, E., \& Salancik, G. R. (1996). Organizational discretion in responding to institutional practices: Hospitals and cesarean births. Administrative science quarterly, 1-28. 
Greenwood, R., Raynard, M., Kodeih, F., Micelotta, E. R., \& Lounsbury, M. (2011). Institutional complexity and organizational responses. Academy of Management annals, 5(1), 317-371.

Gross, N. (2009). A pragmatist theory of social mechanisms. American Sociological Review, 74(3), 358-379.

Guba, E. G. (1990). The paradigm dialog: Sage publications.

Hambrick, D. C., \& Mason, P. A. (1984). Upper echelons: The organization as a reflection of its top managers. Academy of management review, 9(2), 193-206.

Hamilton, A., \& Gioia, D. A. (2009). Fostering sustainability-focused organizational identities. Exploring positive identities and organizations: Building a theoretical and research foundation, 427-451.

Hanushek, E. A. (1996). Measuring investment in education. Journal of Economic Perspectives, 10(4), 9-30.

Hardy, C., \& Maguire, S. (2008). Institutional entrepreneurship. The Sage handbook of organizational institutionalism, 1, 198-217.

Harel, I. E., \& Papert, S. E. (1991). Constructionism: Ablex Publishing.

Hargadon, A. B., \& Douglas, Y. (2001). When innovations meet institutions: Edison and the design of the electric light. Administrative science quarterly, 46(3), 476-501.

Hargadon, A. B., \& Sutton, R. I. (1997). Technology brokering and innovation in a product development firm. Administrative science quarterly, 716-749.

Hatch, M. (2013). The maker movement manifesto: rules for innovation in the new world of crafters, hackers, and tinkerers: McGraw Hill Professional.

Haugen, J. (2015). Stakeholder Voices in Integrating Experiential Education as a Strategic University Initiative. University of Kansas.

Haveman, H. A., \& Rao, H. (1997). Structuring a theory of moral sentiments: Institutional and organizational coevolution in the early thrift industry. American journal of Sociology, 102(6), 1606-1651.

Hedges, L. V., \& Greenwald, R. (1996). Have times changed? The relation between school resources and student performance. Does money matter? The effect of school resources on student achievement and adult success, 74-92.

Hirsch, P. M., \& Lounsbury, M. (1997). Ending the family quarrel: Toward a reconciliation of "old" and "new" institutionalisms. American behavioral scientist, 40(4), 406-418.

Hoskisson, R. E., Hitt, M. A., Johnson, R. A., \& Grossman, W. (2002). Conflicting voices: The effects of institutional ownership heterogeneity and internal governance on corporate innovation strategies. Academy of management journal, 45(4), 697-716.

Ito, J., \& Howe, J. (2016). Whiplash: How to survive our faster future: Hachette UK.

Jain, S., \& Sharma, D. (2013). Institutional logic migration and industry evolution in emerging economies: The case of telephony in India. Strategic Entrepreneurship Journal, 7(3), 252-271.

Karakaya, F., \& Kobu, B. (1994). New product development process: An investigation of success and failure in high-technology and non-high-technology firms. Journal of business venturing, 9(1), 49-66. 
Kiss, A. N., \& Barr, P. S. (2017). New product development strategy implementation duration and new venture performance: A contingency-based perspective. Journal of Management, 43(4), 1185-1210.

Kolb, D. A. (2014). Experiential learning: Experience as the source of learning and development: FT press.

Kraatz, M. S. (1998). Learning by association? Interorganizational networks and adaptation to environmental change. Academy of management journal, 41(6), 621-643.

Kraatz, M. S., \& Block, E. S. (2008). Organizational implications of institutional pluralism. The Sage handbook of organizational institutionalism, 840, 243-275.

Lacy, J. E. (2016). A Case Study of a High School Fab Lab: The University of Wisconsin-Madison.

Lahana, L. I. (2016). The tech café, a social action makerspace: Middle school students as change agents. Teachers College, Columbia University.

Leca, B., \& Naccache, P. (2006). A critical realist approach to institutional entrepreneurship. Organization, 13(5), 627-651.

Lips, D., Watkins, S. J., \& Fleming, J. (2008). Does Spending More on Education Improve Academic Achievement? Backgrounder. No. 2179. Heritage Foundation.

Litts, B. K. (2015). Making learning: Makerspaces as learning environments. The University of Wisconsin-Madison.

Lo, J. Y.-C., \& Kennedy, M. T. (2014). Approval in nanotechnology patents: Micro and macro factors that affect reactions to category blending. Organization Science, 26(1), 119-139.

Lok, J. (2010). Institutional logics as identity projects. Academy of management journal, 53(6), 1305-1335.

Lounsbury, M. (2002). Institutional transformation and status mobility: The professionalization of the field of finance. Academy of management journal, 45(1), 255-266.

Lounsbury, M., \& Beckman, C. M. (2015). Celebrating organization theory. Journal of Management Studies, 52(2), 288-308.

Lucas, K., Kerrick, S. A., Haugen, J., \& Crider, C. J. (2016). Communicating Entrepreneurial Passion: Personal Passion vs. Perceived Passion in Venture Pitches. IEEE Transactions on Professional Communication, 59(4), 363-378.

Mair, J., Mayer, J., \& Lutz, E. (2015). Navigating institutional plurality: Organizational governance in hybrid organizations. Organization Studies, 36(6), 713-739.

March, J. G. (1991). Exploration and exploitation in organizational learning. Organization Science, 2(1), 71-87.

March, J. G., \& Olsen, J. P. (2010). Rediscovering institutions: Simon and Schuster.

Martin, G., Currie, G., Weaver, S., Finn, R., \& McDonald, R. (2017). Institutional complexity and individual responses: delineating the boundaries of partial autonomy. Organization Studies, 38(1), 103-127.

Meyer, J. W., \& Rowan, B. (1977). Institutionalized organizations: Formal structure as myth and ceremony. American journal of Sociology, 83(2), 340-363.

Miles, M. B., Huberman, A. M., \& Saldana, J. (2013). Qualitative Data Analysis: A Methods Sourcebook: Sage. 
Miller, D., Le Breton-Miller, I., Amore, M. D., Minichilli, A., \& Corbetta, G. (2017). Institutional logics, family firm governance and performance. Journal of business venturing, 32(6), 674-693.

Milosevic, I. (2014). Understanding adaptive culture: Exploring the role of symbols in the emergence of innovative solutions in a marketing firm.

Mitchell, R. J., Shepherd, D. A., \& Sharfman, M. P. (2011). Erratic strategic decisions: when and why managers are inconsistent in strategic decision making. Strategic Management Journal, 32(7), 683-704.

Mitchell, R. K., Busenitz, L., Lant, T., McDougall, P. P., Morse, E. A., \& Smith, J. B. (2002). Toward a theory of entrepreneurial cognition: Rethinking the people side of entrepreneurship research. Entrepreneurship Theory and Practice, 27(2), 93104.

O'Reilly, C. A., \& Tushman, M. L. (2013). Organizational ambidexterity: Past, present, and future. The Academy of Management Perspectives, 27(4), 324-338.

Oliver, K. M. (2016). Professional development considerations for makerspace leaders, part one: Addressing "what?" and "why?". TechTrends, 60(2), 160-166.

Özen, Ş., \& Akkemik, K. A. (2012). Does Illegitimate Corporate Behaviour Follow the Forms of Polity? The Turkish Experience. Journal of Management Studies, 49(3), 515-537.

Pache, A.-C., \& Santos, F. (2010). When worlds collide: The internal dynamics of organizational responses to conflicting institutional demands. Academy of management review, 35(3), 455-476.

Pahnke, E. C., Katila, R., \& Eisenhardt, K. M. (2015). Who takes you to the dance? How partners' institutional logics influence innovation in young firms. Administrative science quarterly, 60(4), 596-633.

Pallas, J., Fredriksson, M., \& Wedlin, L. (2016). Translating institutional logics: When the media logic meets professions. Organization Studies, 37(11), 1661-1684.

Peppler, K., Halverson, E., \& Kafai, Y. B. (2016a). Makeology: Makerspaces as learning environments (Vol. 1): Routledge.

Peppler, K., Halverson, E. R., \& Kafai, Y. B. (2016b). Makeology: Makers as learners (Vol. 2): Routledge.

Perlow, L. A., Okhuysen, G. A., \& Repenning, N. P. (2002). The speed trap: Exploring the relationship between decision making and temporal context. Academy of management journal, 45(5), 931-955.

Petrich, M., Wilkinson, K., \& Bevan, B. (2013). It looks like fun, but are they learning. Design, make, play: Growing the next generation of STEM innovators, 50-70.

Porter, M. E. (1979). How competitive forces shape strategy.

Provenzano, N. (2016). Your starter guide to makerspaces: Create Space Independent Publishing.

Rao, H., Monin, P., \& Durand, R. (2003). Institutional change in Toque Ville: Nouvelle cuisine as an identity movement in French gastronomy. American journal of Sociology, 108(4), 795-843.

Reay, T., \& Jones, C. (2016). Qualitatively capturing institutional logics. Strategic Organization, 14(4), 441-454.

Robinson, W. T. (1990). Product innovation and start-up business market share performance. Management science, 36(10), 1279-1289. 
Sarasvathy, S. D. (2001). Causation and effectuation: Toward a theoretical shift from economic inevitability to entrepreneurial contingency. Academy of management review, 26(2), 243-263.

Sauermann, H., \& Stephan, P. (2013). Conflicting logics? A multidimensional view of industrial and academic science. Organization Science, 24(3), 889-909.

Sawyer, R. K. (2011). Explaining creativity: The science of human innovation: Oxford University Press.

Schildt, H., \& Perkmann, M. (2017). Organizational settlements: Theorizing how organizations respond to institutional complexity. Journal of Management Inquiry, 26(2), 139-145.

Selznick, P. (1949). TVA and the Grass Roots.

Selznick, P. (1996). Institutionalism" old" and" new". Administrative science quarterly, 270-277.

Selznick, P. (2011). Leadership in administration: A sociological interpretation: Quid Pro Books.

Shane, S. (2000). Prior knowledge and the discovery of entrepreneurial opportunities. Organization Science, 11(4), 448-469.

Shepherd, D. A., \& DeTienne, D. R. (2005). Prior knowledge, potential financial reward, and opportunity identification. Entrepreneurship Theory and Practice, 29(1), 91112.

Simon, H. A. (2013). Administrative behavior: Simon and Schuster.

Smets, M., Morris, T., \& Greenwood, R. (2012). From practice to field: A multilevel model of practice-driven institutional change. Academy of management journal, 55(4), 877-904.

Smith, L. G., Gillespie, N., Callan, V. J., Fitzsimmons, T. W., \& Paulsen, N. (2017). Injunctive and descriptive logics during newcomer socialization: The impact on organizational identification, trustworthiness, and self-efficacy. Journal of Organizational Behavior, 38(4), 487-511.

Souitaris, V., \& Maestro, B. (2010). Polychronicity in top management teams: The impact on strategic decision processes and performance of new technology ventures. Strategic Management Journal, 31(6), 652-678.

Srivastava, P., \& Hopwood, N. (2009). A practical iterative framework for qualitative data analysis. International journal of qualitative methods, 8(1), 76-84.

Sterman, J. D. (2000). Business dynamics: systems thinking and modeling for a complex world.

Suddaby, R., \& Greenwood, R. (2005). Rhetorical strategies of legitimacy. Administrative science quarterly, 50(1), 35-67.

Thorén, C., Ågerfalk, P. J., \& Rolandsson, B. (2017). Voicing the Puppet: Accommodating Unresolved Institutional Tensions in Digital Open Practices. Organization Studies, 0170840617695358.

Thornton, P. H. (2002). The rise of the corporation in a craft industry: Conflict and conformity in institutional logics. Academy of management journal, 45(1), 81101.

Thornton, P. H. (2004). Markets from culture: Institutional logics and organizational decisions in higher education publishing: Stanford University Press. 
Thornton, P. H., \& Ocasio, W. (1999). Institutional logics and the historical contingency of power in organizations: Executive succession in the higher education publishing industry, 1958-1990. American journal of Sociology, 105(3), 801-843.

Thornton, P. H., Ocasio, W., Greenwood, R., Oliver, C., \& Suddaby, R. (2008). The Sage handbook of organizational institutionalism. Institutional logics.

Thornton, P. H., Ocasio, W., \& Lounsbury, M. (2012). The institutional logics perspective: A new approach to culture, structure, and process: Oxford University Press on Demand.

Tracy, S. J. (2012). Qualitative research methods: Collecting evidence, crafting analysis, communicating impact: John Wiley \& Sons.

Tushman, M. L., \& O'Reilly III, C. A. (1996). Ambidextrous organizations: Managing evolutionary and revolutionary change. California Management Review, 38(4), 829.

van Holm, E. (2014). What are makerspaces, hackerspaces, and fab labs?

Van Maanen, J. (1979). The fact of fiction in organizational ethnography. Administrative science quarterly, 24(4), 539-550.

Vasudeva, G., Zaheer, A., \& Hernandez, E. (2013). The embeddedness of networks: Institutions, structural holes, and innovativeness in the fuel cell industry. Organization Science, 24(3), 645-663.

Villani, E., Greco, L., \& Phillips, N. (2017). Understanding Value Creation in PublicPrivate Partnerships: A Comparative Case Study. Journal of Management Studies, 54(6), 876-905.

Weick, K. E. (1979). The social psychology of organizing (Topics in social psychology series). Columbus, OH: McGraw-Hill Humanities.

Westphal, J. D., Gulati, R., \& Shortell, S. M. (1997). Customization or conformity? An institutional and network perspective on the content and consequences of TQM adoption. Administrative science quarterly, 366-394.

Yang, T., \& Aldrich, H. E. (2017). "The liability of newness" revisited: Theoretical restatement and empirical testing in emergent organizations. Social Science Research, 63, 36-53.

Zhao, E. Y., \& Lounsbury, M. (2016). An institutional logics approach to social entrepreneurship: Market logic, religious diversity, and resource acquisition by microfinance organizations. Journal of business venturing, 31(6), 643-662.

Zucker, L. G. (1977). The role of institutionalization in cultural persistence. American Sociological Review, 726-743. 


\section{APPENDIX}

Warm up/ Generative Questions

1. Why did you come to MakerHub?

2. Tell me about your favorite project at MakerHub.

Fundamental Assumption

3. Before asking my other questions, I would like to confirm your understanding of MakerHub's mission and strategy. I will state my understanding, please correct me if you think I am wrong.

MakerHub was designed to (A) quickly prototype never-seen-before products by (B) engaging with the community through drawing on their ideas and feedback, (C) being separate from Products Inc. so that MakerHub could be more free to prototype innovative product ideas, but (D) to still be a part of Products Inc., so that you could manufacture and develop profitable innovations. Is that correct?

a. If yes, Thank you, I would like to ask you about each element of this mission and strategy. The questions are designed to examine how each element of this strategy interacts with each other element, as thoroughly as possible. Therefore, some parts may seem highly detailed or may seem to overlap with other parts. Thus, if you feel like you have nothing to say in response to a given question that is fine. Please just let me know and we will move on to the next question.

b. If no, ask for clarification and changes. Adapt the subsequent questions accordingly.

Community Engagement

4. In your past experience, what have been some activities you do to engage the community?

5. How do these community activities influence your ability to prototype innovative product ideas?

Please use the following scale to rate the extent to which each of your community related activities help or hinder your ability to prototype innovative product ideas (1) Extremely hindered (2) Somewhat hindered (3) Neutral (4) Somewhat helped (5) Extremely helped

6. How do these community related activities influence MakerHub's or Products Inc.'s ability to manufacture and sell new products? 
Please use the following scale to rate the extent to which each of your community related activities help or hinder MakerHub's or Products Inc.'s ability to manufacture and sell new products.

(1) Extremely hindered (2) Somewhat hindered (3) Neutral (4) Somewhat helped (5) Extremely helped

Internal Activities that Enable/Constrain

7. In your past experience, what have been some activities you have done to prototype innovative product ideas?

8. How do these activities to prototype innovative product ideas influence MakerHub's or Products Inc.'s ability to manufacture and sell new products?

Please use the following scale to rate the extent to which each of your activities to prototype innovative product ideas help or hinder MakerHub's or Products Inc.'s ability to manufacture and sell new products.

(1) Extremely hindered (2) Somewhat hindered (3) Neutral (4) Somewhat helped (5) Extremely helped

9. How do these activities you do to prototype innovative product ideas influence how you interact with the community?

Please use the following scale to rate the extent to which each of your activities to prototype innovative product ideas help or hinder your ability to engage with the community

(1) Extremely hindered (2) Somewhat hindered (3) Neutral (4) Somewhat helped (5) Extremely helped

10. In your past experience, what are some activities you do at MakerHub to manufacture products and make money?

11. How do these activities to manufacture products and make money influence your ability to interact with the community?

Please use the following scale to rate the extent to which each of your activities to manufacture products and make money help or hinder your ability to interact with the community.

(1) Extremely hindered (2) Somewhat hindered (3) Neutral (4) Somewhat helped (5) Extremely helped

12. How do these activities you do to manufacture products and make money influence your ability to prototype innovative product ideas?

Please use the following scale to rate the extent to which each of your activities to manufacture products and make money help or hinder your ability to prototype innovative product ideas 
(1) Extremely hindered (2) Somewhat hindered (3) Neutral (4) Somewhat helped (5) Extremely helped

\section{Triangulation/Validation Question}

13. I will show interviewees the list of activities generated from my field notes, and my ideas about how they would answer the questions above, given the field notes. I will ask interviewees to respond to both the activities listed and then state what they agree with, what they disagree with, and why they agree or disagree.

MakerHub in the Future Questions

14. Where do you think MakerHub will be in 5 years?

15. What do you hope MakerHub looks like in 5 years 


\section{CURRICULUM VITAE}

Cole Crider, MBA, Ph.D.

$\mathrm{CV}$

May 2019

ORCID: 0000-0001-6892-1277

\section{Education}

University of Louisville-College of Business, Louisville, KY

Ph.D., Entrepreneurship

Boyce College, Louisville, KY

Bachelors: Humanities; summa cum laude

2014

\section{Academic Appointments}

University of Louisville-Louisville, KY

\section{Ph.D. Candidate, (August. 2017-May. 2019)}

September 2014-May 2019

- Collected over 600 hours of qualitative data for dissertation, engaging with engineers, product developers, and commercial team.

- Successfully defended dissertation: April 2019

- First author on a manuscript concerning family succession and discontinuous technology adoption. Manuscript submitted to a peer-reviewed journal November, 2018.

- Taught Management and Organizational Behavior, Spring 2018 and Entrepreneurial Creativity and Innovation, Fall 2018 (and Spring, 2019) at the University of Louisville.

- Presented paper at the Academy of Management, August, 2018.

Ph.D. Student/Research Assistant, (August. 2015-May. 2017)

- Co-authored two published, peer-reviewed journal articles.

- Co-supervised undergraduate seniors for capstone projects (Spring, 2017).

- Guest lectured entrepreneurship classes.

- Participated in teaching and learning workshops.

Graduate Research Assistant, Management Department (September 2014-2015)

- Researched, synthesized and wrote on various topics for professors, contributing to an article that was later published.

- Research topics included: (1) Dignity and negative workplace behaviors, (2) Theory of Constraints as applied to Supply Chain, Manufacturing, Inventory Operations and Economic Value Added, and (3) Segregation in corporate America. 


\section{Professional Memberships}

Academy of Management (2016-Present)

Southern Management Association (2018-Present)

\section{Research}

\section{Refereed Research Articles}

- Lucas, K., Kerrick, S. A., Haugen, J., \& Crider, C. J. (in press). Communicating entrepreneurial passion: Personal passion vs. perceived passion in venture pitches. IEEE: Transactions on Professional Communication.

- Lucas, K., Manikas, A. S., Mattingly, E. S., \& Crider, C. J. (in press). Engaging and Misbehaving: How Dignity Affects Employee Work Behaviors. Organization Studies.

\section{Proceedings}

- Lucas, K., Manikas, A. S., Mattingly, E. S., \& Crider, C. J. (2016). Dignity, counterproductive work behavior, and employee engagement. In J. Humphreys (Ed.), Proceedings of the Seventy-sixth Annual Meeting of the Academy of Management. Anaheim, CA.

\section{Conference Papers \& Presentations}

(Papers marked with an * were competitively selected)

- *Crider, C. J. \& Garrett, R. P. (2018) (Author and Presenter). A Review and Comparison of Family Successor Types. Academy of Management Meeting: Entrepreneurship Division. Chicago, Illinois.

- *Lucas, K., Manikas, A. S., Mattingly, E. S., \& Crider, C. J. (2016) (Author). Dignity, counterproductive work behavior, and employee engagement. Academy of Management Meeting: Social Issues in Management Division. Anaheim, California.

- Lucas, K., \& Crider, C. J. (2016, November) (Author and Co-Presenter). Workplace dignity: A qualitative path of discovery. Colloquium presentation. Qualitative Interest Group. University of Louisville.

\section{Drafted Manuscripts}

- Crider, C. J., Kosmidou, V. \& Garrett, R. P. A Review of Family Successor Types and their Adoption of Discontinuous Technologies.

\section{Honors \& Awards}

University of Louisville, Louisville, KY

University Fellowship, School of Interdisciplinary and Graduate Studies (2015-2019)

Graduate Assistantship, Management Department, College of Business (2014-2015)

Academy of Management

Best Paper Award (Finalist), Social Issues in Management Division

\section{Campus Involvement}

Graduate Teaching Academy 
Participated and attended sessions with other $\mathrm{PhD}$ students on how to improve and measure learning outcomes, form collaborative teams, and effectively present information using various learning platforms and knowledge-sharing software.

President, MBA Global Business Club

October 2014-August 2015

Initiated Global Business Club funding and finances, recruited group leadership, and scheduled guest speakers. 